\title{
REDEFINING ATTENTION (AND REVAMPING THE LEGAL PROFESSION?) FOR THE DIGITAL GENERATION
}

\author{
Lauren A. Newell* \\ TABLE OF CONTENTS
}

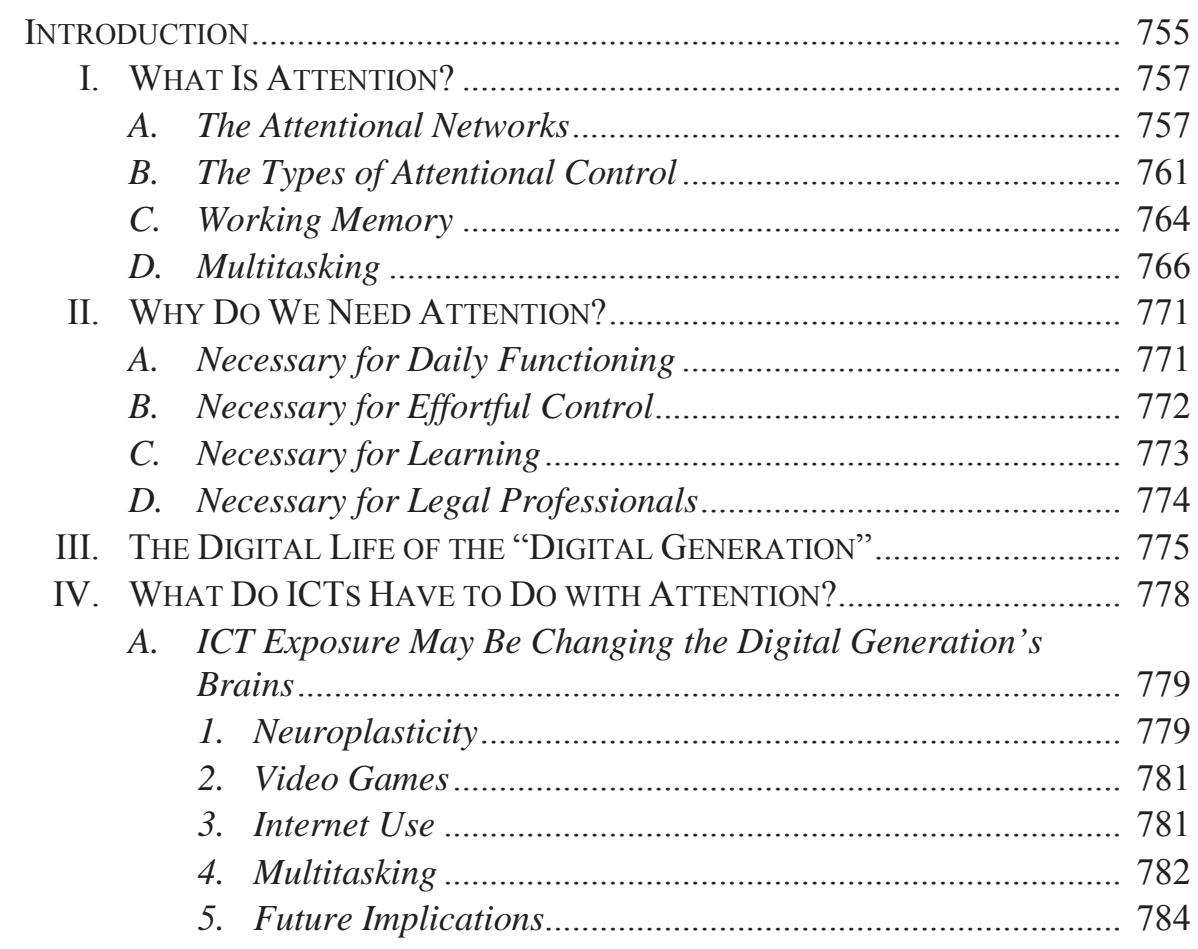

* Copyright (C) 2015, Lauren A. Newell, Assistant Professor of Law, Ohio Northern University, Pettit College of Law; B.A., Georgetown University; J.D., Harvard Law School. Thanks are due to Joanne Brant, James Stark, Lisle Baker, and Brian Anderson, who graciously provided comments on prior drafts of this Article, and to Petra Ehlert and Marissa Lawhun for their research assistance. Thanks also to the participants of the February 2014 Ohio Legal Scholarship Workshop, hosted by the Ohio Northern University Pettit College of Law, and the Conference on Psychology and Lawyering: Coalescing the Field, hosted by the UNLV William S. Boyd School of Law, for their helpful comments. Above all, special thanks to Jim, my Digital Generation muse, without whom this Article would never have come into existence. 
B. ICT Exposure May Be Leading to a Loss of Attentional

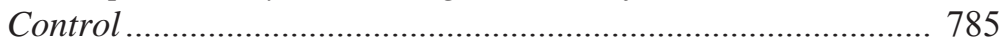

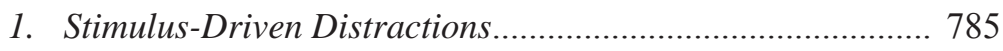

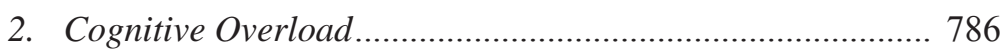

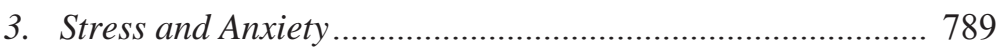

C. ICT Exposure May Be Changing the Definition of "Paying

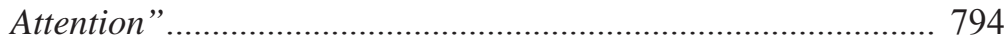

V. What Should LEgAL Professionals Do About IT? .................... 795

A. Shut Off ICTs and Avoid Multitasking ....................................... 796

B. Take Technology Breaks .......................................................... 799

C. Practice Meditation.................................................................... 801

VI. What ChANGES ARE ON THE HoRIZON? ............................................ 806

A. Changes in Law School............................................................ 807

1. Laptops, Laptops Everywhere and Not a Pen in Sight ......... 807

2. Legal Writing, or Just Writing? .......................................... 809

3. Make Room for Meditation .................................................. 810

4. Cutting Back on the Case Method? ...................................... 811

B. Changes in Client Relations................................................... 815

1. Bye-bye, Billable Hour ................................................... 816

2. Why Talk When We Can Text?............................................. 817

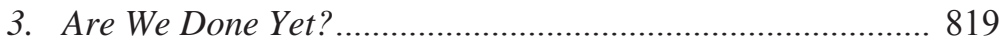

C. Changes in Court …............................................................. 819

1. ICTs Permitted - and Problematic...................................... 820

2. A Multimedia Extravaganza ............................................... 822

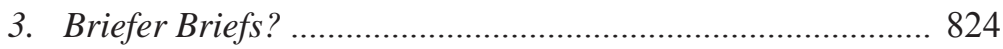

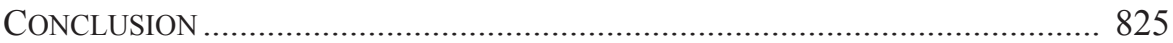

\section{INTRODUCTION}

To pay attention, this is our endless and proper work. ${ }^{1}$

Ask any fidgety five-year-old-paying attention is hard. Our minds like to wander, to meander, to frolic, to detour, to flit from here to there and back again as they please. To focus on just one thing feels like work, particularly if that one thing happens to be work (or school, or anything else that we are not doing purely for the pleasure of it). The only way we can escape the effort and the tedium of paying attention is by finding a means of distraction. Thankfully, these days we have sources of endless distraction, known collectively as information and communication technologies ("ICTs"), and individually as comput-

${ }^{1}$ Mary Oliver, Yes! No!, in Owls and Other Fantasies: Poems and Essays 27, 27 (2003). 
ers, televisions, the Internet, cell phones, smartphones, tablets, email, voicemail, mp 3 and DVD players, ${ }^{2}$ and pretty much any device with a name beginning with a lowercase "i." "We live a life immersed in ICTs - we rely on them at work and in school, at home and on vacation, when we are alone and when we are with others. ${ }^{4}$ Even when we sleep, they are never far from our reach. ${ }^{5}$ Sweet distraction is just a click away. It is a wonderful thing for our restless brains - or is it?

Not everyone is convinced that our love affair with ICTs is an entirely happy story. There is reason to believe that ICT exposure is significantly eroding our ability to pay focused attention, even when we want and try to do so. This effect of ICT exposure may be a special concern for today's young people - a group whom I refer to as the Digital Generation ${ }^{6}$ - because they have never known life without ICTs, so they have always been exposed to them. It is also especially worrisome for members of the legal profession, ${ }^{7}$ who are increasingly embracing $\mathrm{ICTs}^{8}$ and whose work requires that they possess strong powers of attention. ${ }^{9}$ Adding one plus one together, if we are particularly concerned about the effects of ICT exposure on members of the Digital Generation, and we are also particularly concerned about the effects of ICT exposure on the legal profession, then we must be even more concerned about the effects of ICT exposure on members of the Digital Generation who grow up to be legal professionals. But deciding that we should be worried is only half of the equation. The other half is determining what - if anything - we should do about it.

\footnotetext{
2 See Michael P. O'Driscoll et al., Work-Related Technological Change and Psychological Well-Being, in Technology and Psychological Well-Being 106, 106 (Yair AmichaiHamburger ed., 2009). Because new types of ICTs are constantly being developed, an effort to catalog all existing ICTs would be futile. Accordingly, this Article should be understood to refer to ICTs in the broadest, most inclusive sense, including both the devices we use (e.g., tablets, smartphones) and the websites and programs we run on those devices (e.g., email, social media websites).

3 This refers, of course, to the myriad devices made by Apple Inc., including the iPhone, iPad, iPod, and iMac. See generally APPLE STORE, http://store.apple.com/us (last visited Feb. $8,2015)$.

4 Access to ICTs varies greatly worldwide and across different socioeconomic groups. See infra note 168 and accompanying text. The broad generalizations this Article makes about "our lives" and "the legal profession" are intended to reflect the average experience of adults in the United States and the U.S. legal profession, with the caveat that these generalizations are likely not applicable to adults in every country worldwide or even to adults in every socioeconomic group within the United States.

5 See infra note 183.

6 See infra text accompanying notes 166-69.

7 I use the term "legal profession" for convenience to refer both to law school and the practice of law, and "legal professionals" to refer collectively to lawyers and law students, though the terms could certainly also encompass law professors, mediators, arbitrators, and other legal industry professionals and the work that they do.

8 See infra text accompanying notes 384-93, 436, 445, 461-63.

9 See infra text accompanying notes 164-65.
} 
This Article considers both halves of the equation in turn. Part I explores the science of attention and Part II explains why attention is important. Part III introduces the Digital Generation and their relationship with digital technology. Parts IV and V examine the relationship between ICT exposure and attention and review several suggestions that others have made about how legal professionals should respond to the challenges ICTs pose to focused attention. Part VI takes the conversation in a new direction: It predicts the ways in which the legal profession, rather than the legal professionals, will necessarily have to adapt to technology in the future. Finally, the conclusion offers thoughts about how the legal profession should view its relationship with technology going forward.

\section{WhAt Is AtTENTION?}

Prominent nineteenth-century psychologist Williams James famously wrote, "[e]very one knows what attention is." 10 The challenge lies in providing a precise definition. This is difficult because attention "is not a single concept, but an umbrella term for a variety of psychological phenomena." erty of multiple, different perceptual and cognitive operations that are in extensive communication with each other. ${ }^{12}$ Accordingly, the study of attention is a broad field that spans most of perception and cognition research. ${ }^{13}$ Attention has ultimately become "a catch-all term for how the brain controls its own information processing." "14 While recognizing that attention means many things to many people, this Article adopts a narrower, more functional definition. As used herein, attention refers generally to "the ability to attend to desired or necessary stimuli and to exclude unwanted or unnecessary stimuli." $" 15$ This Part describes the anatomical bases of attention, the ways in which we control our attention, the concept of working memory, and the reality of multitasking.

\section{A. The Attentional Networks}

One way of conceptualizing the source of attention is anatomically, by viewing attention as an organ system composed of at least three constituent networks. ${ }^{16}$ Michael I. Posner, a professor emeritus of psychology at the Uni-

101 William James, The Principles of Psychology 403 (Cosimo, Inc. 2007) (1890).

11 Elizabeth A. Styles, The Psychology of Attention 1 (2d ed. 2006).

12 Marvin M. Chun et al., A Taxonomy of External and Internal Attention, AnN. Rev. PsYCHOL., 2011, at 73, 76.

${ }^{13} I d$. at 74 .

${ }^{14} \mathrm{Id}$.

15 M.H. Sam Jacobson, Paying Attention or Fatally Distracted? Concentration, Memory, and Multi-tasking in a Multi-media World, 16 Legal Writing 419, 421 (2010).

16 See generally Michael I. Posner, Attention in a Social World (2012) (analyzing attention as an organ system through the exploration of its physical bases). Posner's view of attentional networks is highly influential, though not universally accepted. See MAGGIE 
versity of Oregon and a leading researcher in the field of attention, refers to these networks as the alerting, orienting, and executive networks. ${ }^{17}$ The first network, the alerting network, is in charge of the process of achieving and maintaining a state of sensitivity to incoming stimuli. ${ }^{18}$ Alertness is akin to our "awareness" or "wakefulness" 19 or "vigilance." ${ }^{20}$ It is the key to sensitivity to our surroundings. ${ }^{21}$ Alertness comes in two general forms, known as "phasic" alertness and "tonic" alertness. Phasic alertness is the rapid change in our alertness triggered in response to a warning signal ${ }^{22}$ - the "get-ready feeling triggered by a teacher's bark or a starting gun. ${ }^{23}$ Phasic alertness likely involves mechanisms in both brain hemispheres, but it relies more strongly on the left hemisphere. ${ }^{24}$ Tonic alertness refers to our sense of overall alertness that fluctuates depending upon the time of day, fatigue, boredom, and other influences. ${ }^{25}$ It is thought to be produced by mechanisms in the brain's right hemisphere. $^{26}$

The second network, the orienting network, helps us to prioritize what our senses take in from the environment by selectively allocating attention to a particular sense or location. ${ }^{27}$ In other words, orienting involves picking what information we absorb from amongst all the information available to our senses. ${ }^{28}$ This means that as we pay attention to one stimulus in the environment, the other stimuli competing for our attention lose their influence-we stop paying attention to them. ${ }^{29}$ For example, as we focus our attention on the sound of a bird chirping, we stop paying attention to the sounds of the wind whistling through the trees and the children kicking a soccer ball nearby.

Functionally, orienting involves aligning our attention with a source of sensory signals, either overtly (our eyes move as our attention moves) or covertly (no eye movements). ${ }^{30}$ The parietal, frontal, and subcortical areas of the

Jackson, Distracted: The Erosion of Attention and the Coming Dark Age 246-47 (2008).

17 Steven E. Petersen \& Michael I. Posner, The Attention System of the Human Brain: 20 Years After, AnN. Rev. NeUROSCIENCE, 2012, at 73, 74.

18 POSNER, supra note 16, at 19.

19 JACKSON, supra note 16, at 23, 247.

${ }^{20}$ Petersen \& Posner, supra note 17 , at 75.

21 JACKSON, supra note 16, at 247.

22 Posner, supra note 16 , at $19,35$.

23 JACKSON, supra note 16 , at 248.

${ }^{24}$ POSNER, supra note 16 , at 35.

$25 I d$. at 20.

${ }^{26} \mathrm{Id}$. at 34.

27 See Diego Fernandez-Duque \& Michael I. Posner, Relating the Mechanisms of Orienting and Alerting, 35 Neuropsychologia 477, 477 (1997); Petersen \& Posner, supra note 17, at 75.

28 POSNER, supra note 16, at 19.

29 Petersen \& Posner, supra note 17 , at 79.

30 Posner, supra note 16, at 20. For instance, using attention to search memory involves a covert shift of attention. Id. at 50. 
brain all participate in the process of orienting. ${ }^{31}$ One brain region interrupts our current focus of attention so that we can shift attention to a new target stimulus. ${ }^{32}$ Another region enables us to shift our attention voluntarily to a new target following a cue. ${ }^{33}$ This second region is part of a broader network that coordinates our alignment of attention (whether covert or overt) with a target. ${ }^{34}$

The third network, the executive network, ${ }^{35}$ monitors and resolves conflict among thoughts, feelings, and responses occurring simultaneously in different brain areas. ${ }^{36}$ Executive attention may also play a role in a number of cognitive tasks underlying intelligence. ${ }^{37}$ When activity occurs in different brain areas and competes for control of our behavior, the executive network permits activity from one area to be expressed in our consciousness and behavior while it represses expression of competing activity in other brain areas. ${ }^{38}$ In this way, the executive network enables us to behave in a goal-directed manner ${ }^{39}$ and also to behave coherently. ${ }^{40}$ Broadly speaking, executive attention is necessary to prevent conflicting behavior in any situation that involves unexpected stimuli, novel responses, planning, making decisions, detecting errors, or overcoming

31 Id. at 64 . The parietal lobe is the area near the crown of the head that is closely connected to eye movements and sensory processing. JACKSON, supra note 16, at 240 . The frontal lobe, toward the front of the brain, is the seat of the brain's higher-order reasoning and is involved in operations commonly associated with intelligence. DANIEL KAHNEMAN, THINKING, FAST AND Slow 37 (2011); Kari Mercer Dalton, Their Brains on Google: How Digital Technologies Are Altering the Millennial Generation's Brain and Impacting Legal Education, 16 SMU SCI. \& TECH. L. REV. 409, 419 (2013). See also infra text accompanying notes 43-50 for more information about the frontal area of the brain. The subcortical areas are those regions below the cerebral cortex. These areas are home to the hippocampus and the amygdala, parts of the limbic system. Denise Feil \& Anand Kumar, The Neuropsychiatry of Subcortical Ischemic Brain Disease, 1 CURRENT PsyChIATRY ReP. 69, 69 (1999). Subcortical regions play an important role in regulation of many behavioral functions, such as affect, mood, impulse control, memory, and motivation. Id.

32 Posner, supra note 16, at 62.

${ }^{33} I d$.

${ }^{34} I d$.

35 There are two prominent theories regarding executive control in the current literature, one of which proposes that there are actually two anatomically separate executive networks. See Petersen \& Posner, supra note 17 , at 80 . Analysis of these competing theories is beyond the scope of this Article, so I refer to a unitary executive network for ease of reference.

${ }^{36}$ Posner, supra note 16, at 10, 19.

37 Id. at 22.

${ }^{38} I d$. at 73 . The classic way of demonstrating this competing brain activity is the Stroop task, which requires subjects to name the color of the ink a word is printed in while ignoring the color word name (e.g., the word "blue" appears in red ink and the subject must say "red" rather than "blue"). Though the name of the word is automatically activated in skilled readers, executive attention enables the subjects to give the desired response (say "red") and to repress the competing response tendency (the impulse to name the word "blue"). Id. at 21.

39 Id. at 21.

40 See infra text accompanying notes $138-40$ for a discussion of executive attention's role in coherent behavior. 
habitual actions because, in all of these situations, multiple brain networks can be activated simultaneously. ${ }^{41}$

Exactly how the executive network functions and its precise anatomical bases are not fully understood. ${ }^{42}$ However, researchers believe that executive attention involves the prefrontal area of the brain. ${ }^{43}$ The medial (middle) prefrontal area is active in the face of conflict between stimuli and responses, and might function as a monitor of conflict. ${ }^{44}$ The lateral (side) prefrontal area appears to be important in holding task-relevant information in mind temporarily while other brain areas retrieve information relevant to the response. ${ }^{45}$ Almost any problem that depends upon the retrieval of stored information relies upon these two prefrontal areas. ${ }^{46}$ Executive attention also seems to involve the anterior cingulate cortex (the "ACC"), ${ }^{47}$ a small region toward the front of the brain that is shaped like a banana. ${ }^{48}$ The ventral (bottom) half of the ACC is involved in regulation of emotion and reward detection. ${ }^{49}$ The dorsal (top) half is strongly connected to certain frontal and parietal areas involved in cognitive processes and plays a role in motor processes and in cognitive functions such as conflict resolution and error detection. ${ }^{50}$

All three of these attentional networks are crucial, and they work together constantly in our everyday lives. ${ }^{51}$ The alerting and orienting networks help us to sense and respond to our environment, while the executive network enables us to make sense of the world. ${ }^{52}$ For instance, imagine Caroline, a baseball fan, sitting in the stands, waiting to see Derek Jeter's ${ }^{53}$ final home regular season atbat. The recorded voice of the late Bob Sheppard ${ }^{54}$ comes over the publicaddress system, announcing, "Now batting for the Yankees, number two, Derek Jeter, number two." The public-address announcement serves as a warning sig-

41 Posner, supra note 16 , at $65,73$.

42 See JACKSON, supra note 16, at 244.

${ }^{43}$ POSNER, supra note 16 , at 82-83.

${ }^{44} I d$. at 83 .

${ }^{45} I d$.

${ }^{46} I d$.

47 Petersen \& Posner, supra note 17, at 76, 80.

48 JACKSON, supra note 16, at 232.

49 Posner, supra note 16 , at 10,81 .

${ }^{50} \mathrm{Id}$.

${ }^{51}$ Id. at 25; JACKSON, supra note 16, at 23.

52 JACKSON, supra note 16 , at 25.

53 Derek Jeter, the former captain of the New York Yankees baseball team, made his major league debut in 1995 after being drafted by the Yankees in 1992. Harvey Araton, Of All His Numbers, the One on His Back Matters the Most, N.Y. Times, Sept. 26, 2014, at B11; Richard Goldstein, Bob Sheppard, Mellifluous Voice of Yankees, Dies at 99, N.Y. TIMES, Jul. 12, 2010, at D8. Jeter retired at the end of the 2014 baseball season. Araton, supra.

54 Bob Sheppard was the Yankees' public-address announcer from 1951 until his death in 2010 at age 99. Goldstein, supra note 53. Out of respect for Yankee history, Jeter asked to be introduced by a recording of Sheppard's voice for all of his home at-bats after Sheppard's death. Id.; see also Tyler Kepner, Yankee Who Lived a Dream Says It's Near End, N.Y. Times, Feb. 13, 2014, at A1. 
nal that triggers Caroline's alerting network, making her watchful for Jeter's plate appearance. Caroline's eyes overtly orient to Jeter and follow him as Jeter walks from the on-deck circle to stand at home plate, poised for the first pitch. Caroline's orienting network works to focus her attention on Jeter and to filter out the thousands of camera flashes as fans snap photos of Jeter. Her alerting network maintains her vigilance as she waits for the first pitch, and her orienting system overtly aligns her attention with the ball as her eyes watch it leave the pitcher's hand and make contact with Jeter's bat. When Jeter hits the ball high and deep and quite close to where Caroline is sitting, her executive network resolves the conflict between the part of the brain urging her to keep a hold of her nearly full, six-dollar cup of beer ${ }^{55}$ and the part urging her to drop it on the ground so she can try to catch the ball—and she goes for the ball, of course.

\section{B. The Types of Attentional Control}

Posner's attentional networks model explains the anatomical mechanisms involved in paying attention, but it does not fully explain how it is determined what we pay attention to - for example, how does the orienting system know to what it should orient? An early answer to this question was inspired by research on spatial orienting by Posner and others in the 1970s and early 1980s, which found that subjects responded faster to targets that appeared in locations they were attending to as compared to unattended locations. ${ }^{56}$ Intrigued by these studies, University of Michigan psychologist John Jonides conducted research that highlighted the distinction between voluntary and automatic orienting of attention. ${ }^{57}$ Jonides hypothesized that certain salient stimuli cause us to shift attention reflexively and automatically, but that we also have internal control over attention allocation, meaning we can voluntarily shift attention from one location to another when motivated to do so. ${ }^{58}$ This dichotomy between automatic and voluntary attentional control remains the predominant theory of attentional control. ${ }^{59}$ Jonides's automatic and voluntary forms of attentional control are widely referred to as "bottom-up" or "stimulus-driven" or "exogenous"

55 The average cost for a twelve-ounce beer at Yankee Stadium was \$6 in 2014. Cork Gaines, Here's What a Beer Will Cost You at Every Major League Baseball Stadium, Bus. INSIDER (Apr. 21, 2014, 2:52 PM), http://www.businessinsider.com/beer-prices-ma jor-league-baseball-stadium-2014-4. Though Jeter did not actually hit a home run in his final game at Yankee Stadium, he did hit a characteristic opposite-field single in the bottom of the ninth inning that drove in the winning run against the Baltimore Orioles. Araton, supra note 53.

${ }^{56}$ Edward Awh et al., Top-Down Versus Bottom-Up Attentional Control: A Failed Theoretical Dichotomy, 16 Trends Cognitive SCI. 437, 438 (2012).

${ }^{57}$ Id.; POSNER, supra note 16, at xvi-xvii.

58 John Jonides, Voluntary Versus Automatic Control over the Mind's Eye's Movement, in Attention And Performance IX 187, 188 (John Long \& Alan Baddeley eds., 1981).

59 Awh et al., supra note 56, at 438. But see id. at 438-40 (describing the dichotomy's limitations). 
attentional control, and "top-down" or "goal-directed" or "endogenous" attentional control. ${ }^{60}$

When psychologists refer to bottom-up attentional control, they are speaking of the mechanisms by which external events capture our attention involuntarily. ${ }^{61}$ Factors external to us, such as the salience of stimuli (e.g., the brightness of a sudden flash of light), determine to what we attend. ${ }^{62}$ Bottom-up control is largely instinctual and automatic, ${ }^{63}$ our brains constantly review the environment for disturbances and we are pre-programmed to attend to novel or sudden changes. ${ }^{64}$ Fast-paced, reflexive shifts in focus were once crucial to human survival because they decreased the chances that a predator would take us by surprise or that we would overlook a potential food source. ${ }^{65}$ Though our circumstances may have changed, our brains have not. Modern brains react to novel stimuli just as the brains of Cro-Magnon man did forty thousand years ago. ${ }^{66}$ While the information we perceive through our bottom-up processes can sometimes be lifesaving (e.g., the child who suddenly chases a ball into the road), it is often nonessential and merely distracting (e.g., our cubicle mate's sudden coughing fit). ${ }^{67}$

In contrast, top-down attentional control refers to the voluntary attention we pay to processing information and regulating our internal mental lives. ${ }^{68}$ This control is goal-directed and driven by internal factors (e.g., we voluntarily allocate attention toward the goal of finding our friend's red jacket in a crowd). ${ }^{69}$ Top-down attentional control involves conscious awareness and cognitive effort to focus on the task at hand..$^{70}$ It draws upon the executive attention mechanisms to select between alternatives competing for attention ${ }^{71}$ and allocates attention to the effortful mental activities that require it, including the ac-

60 See Chun et al., supra note 12, at 77; see also R. Lisle Baker \& Daniel P. Brown, On Engagement: Learning to Pay Attention, 36 U. ARK. LitTLE Rock L. Rev. 337, 348-49 (2014); Jacobson, supra note 15, at 429; Claudia Roda \& Julie Thomas, Attention Aware Systems: Theories, Applications, and Research Agenda, 22 Computers Hum. Behav. 557, 560 (2006).

${ }^{61}$ Roda \& Thomas, supra note 60 , at 560.

62 Awh et al., supra note 56, at 437.

63 See Jacobson, supra note 15, at 429; Roda \& Thomas, supra note 60, at 560 (noting that research on visual attention indicates that bottom-up mechanisms may have different degrees of power, such that certain stimuli become almost impossible to ignore, while others are more controlled by volition).

${ }^{64}$ See Baker \& Brown, supra note 60, at 349; Jacobson, supra note 15, at 429-30.

${ }^{65}$ Nicholas Carr, The Shallows: What the Internet Is Doing to Our Brains 64 (2010).

66 Jacobson, supra note 15 , at 430.

67 See Baker \& Brown, supra note 60, at 349; Jacobson, supra note 15, at 429-30 (examples mine).

${ }^{68}$ Chun et al., supra note 12 , at 77,82 .

69 Awh et al., supra note 56, at 437; Roda \& Thomas, supra note 60, at 560.

70 Jacobson, supra note 15 , at 429.

71 See Chun et al., supra note 12, at 82. 
tivities involved in our experience of agency, choice, and concentration. ${ }^{72} \mathrm{Un}$ like bottom-up attentional control, top-down control results in conscious, highlevel concentration. ${ }^{73}$

The reason it is hard to pay attention without getting distracted is because our top-down, goal-oriented attentional processes are in a constant battle with our more powerful bottom-up attentional processes. ${ }^{74}$ While the top-down system fights to keep our attentional resources directed toward a particular activity, the bottom-up system continually determines whether other sensory information in the environment deserves our attention at any given moment. ${ }^{75}$ It takes significant cognitive effort for the top-down system to maintain focus without interruption or interference from the bottom-up system. ${ }^{76}$ This ability to sustain attention over extended periods of time is the ability to sustain vigilance - to maintain focused alertness. ${ }^{77}$

Sustained vigilance is challenging. The brain's natural state is distractedness, ${ }^{78}$ so it is not surprising that top-down attentional control often succumbs to bottom-up control and results in distraction. "We are born to be interruptdriven ... and we must painstakingly learn and keep striving to retain the everdifficult art of focus. ${ }^{, 79}$ But because our success in performing tasks that involve reasoning and other higher-order cognitive operations is determined by our ability to control attention and avoid distractions, our natural distractedness is problematic. ${ }^{80}$

To understand the battle between our top-down and bottom-up mechanisms, consider John, a lawyer, who sits in his office late in the evening and works on drafting a contract. John endeavors to remain focused on his drafting, but he instinctively looks up from his work when a colleague knocks on his door and asks if he wants to place a food order. Though John's top-down processes strive to maintain vigilance and keep him focused on his goal (completing the contract), his bottom-up processes automatically react to a sudden change in his environment (the knock on the door). Unless John's top-down mechanisms can overcome the instinctual pull of his bottom-up mechanisms more often than not, he will never finish drafting his contract (but, then again, he may get to eat dinner).

72 See Kahneman, supra note 31, at 21.

73 Jack Fuller, What Is Happening to News: The Information Explosion and the CRISIS IN JOURNALISM 60 (2010).

74 JACKSON, supra note 16, at 79.

75 See Baker \& Brown, supra note 60, at 350.

76 Jacobson, supra note 15 , at 429.

77 Chun et al., supra note 12, at 76; Petersen \& Posner, supra note 17, at 75.

${ }^{78}$ CARR, supra note 65 , at 63.

79 JACKSON, supra note 16 , at 79.

80 Jacobson, supra note 15 , at 430. 


\section{Working Memory}

Higher-order cognitive processes require more than just attentional control. They also rely upon an aspect of memory known as working memory. To explain working memory, it is first helpful to understand how our brains make memories.

Our brains are made up of brain cells called neurons. When first formed, neurons contain just the cell body, which as it matures grows dendrites (like branches of a tree) and an axon (like a long wire). ${ }^{81}$ Memories are created when messages are sent across the gaps between the neurons, known as synapses, from the axon on one neuron to the dendrites on another. ${ }^{82}$ Memories are held in the connections made by this network of synapses and are established either temporarily (for short-term memories) or permanently (for long-term memories) when the network is strengthened. ${ }^{83}$ Working memory is crucial for establishing these long-term memories (and thus for learning anything ${ }^{84}$ ).

Working memory is "a system, or ... a set of processes, that serves to process and maintain temporary information for use in other cognitive tasks." ${ }^{\circ 5}$ This definition implies that working memory involves both passive, temporary maintenance of information as well as active mental manipulation of that information. ${ }^{86}$ Working memory is complex, and researchers do not agree whether working memory is a distinct structural entity with its own specific processes, or whether it combines processes shared by other psychological functions. ${ }^{87}$ The former view envisions working memory as a multicomponent system with three subsystems: an "articulatory loop" responsible for maintaining and processing verbal material, a "visuospatial sketchpad" responsible for maintaining and processing visuospatial information, and a "Central Executive" system responsible for coordination and planning. ${ }^{88}$ The latter view envisions working memory as simply an activated subset of long-term memory that uses the same

81 Gary Small \& Gigi Vorgan, iBrain: Surviving the Technological Alteration of THE MODERN Mind 7 (2008).

82 Judith Horstman, The Scientific American Brave New Brain 39 (2010).

${ }^{83} \mathrm{Id}$. The more times the incoming data are repeated to the brain and the more intense or emotional the message is, the stronger and longer lasting the memory will be. Id. at 46; see also infra note 196 and accompanying text.

84 Jacobson, supra note 15, at 423; see also infra text accompanying notes 157-62.

85 Anik de Ribaupierre, Working Memory and Attentional Processes Across the Lifespan, in Lifespan Development of Human Memory 59, 59 (Peter Graf \& Nobuo Ohta eds., 2002). Though the precise definition of working memory varies according to different researchers, there is consensus regarding working memory's function. $I d$.

${ }^{86} I d$. Insofar as the constructs of working memory and short-term memory both involve temporary maintenance of information, the two notions overlap. However, the active manipulation component of working memory makes working memory broader in scope than shortterm memory. Id.; Cornelius J. König et al., Working Memory, Fluid Intelligence, and Attention Are Predictors of Multitasking Performance, but Polychronicity and Extraversion Are Not, 18 Hum. Performance 243, 245 (2005).

87 de Ribaupierre, supra note 85 , at 59.

${ }^{88} \mathrm{Id}$. 
processes that are also used for other cognitive tasks. ${ }^{89}$ Under either view, working memory is assumed to be responsible for such cognitive operations as transforming information that has already been stored in long-term memory, building new relations between elements of information, activating certain cognitive representations and procedures, and monitoring ongoing cognitive processes. ${ }^{90}$ Working memory is also related to our conception of consciousness: Whatever we are currently conscious of is in our working memory; if something is not in our working memory, we are not conscious of it. ${ }^{91}$

Though working memory is critically important to various cognitive operations, it is also severely limited in capacity. ${ }^{92}$ Researchers believe working memory can only handle between three and seven bits of information at a time, depending on the complexity and type of the information and the degree of grouping, or "chunking," of bits of associated information. ${ }^{93}$ A significant bottleneck forms as information is passed from working memory into long-term memory because of this capacity limitation. ${ }^{94}$ The limitation is problematic because bits of information held in working memory vanish quickly unless they are rehearsed. ${ }^{95}$

Memory and attention are closely linked, as the information that we remember seems to be the information that we have attended to. ${ }^{96}$ Our brains weigh our minute-to-minute experiences and pick some experiences to keep for reference (which become memories) and others to discard. ${ }^{97}$ Working memory relies upon attention ${ }^{98}$ in four ways: First, attention is necessary to ensure that the right bits of information get absorbed into working memory, while others get ignored. ${ }^{99}$ Second, attention is necessary to hold bits of information in working memory so they can be processed and stored in long-term memory. ${ }^{100}$

${ }^{89} I d$.

${ }^{90}$ König et al., supra note 86 , at 245.

91 CARR, supra note 65, at 123.

92 Id. at 124.

93 Jacobson, supra note 15, at 423-24; see also JACKSON, supra note 16, at 90. Chunking means grouping separate but associated bits of information into one larger chunk of information, such as grouping the nine digits of a Social Security number into three chunks of digits. Jacobson, supra note 15 , at 424.

94 CARR, supra note 65, at 124.

95 Id. Chunking helps prevent information loss because it allows more information to be held until it is processed into long-term memory. Jacobson, supra note 15 , at 424 . Long-term memory appears to have limitless capacity, though because information stored there is retrieved into working memory, retrieval of information from long-term memory is limited by the limits of working memory. Id. at 427.

96 STYles, supra note 11, at 8; see also Jacobson, supra note 15, at 422-23 ("Only those tasks attended to will be remembered ....").

97 HORSTMAN, supra note 82, at 40.

98 The reverse is also true: We need to remember what we are concentrating on, so ability to maintain attention also depends upon working memory. CARR, supra note 65, at 125.

99 Jacobson, supra note 15, at 422-23, 425.

${ }^{100} I d$. at 425. 
Third, attention is necessary to encode and store information into long-term memory, through repetition or chunking, so it is available for future retrieval. ${ }^{101}$ Fourth, attention is necessary to retrieve information from memory. ${ }^{102}$

To illustrate this relationship, consider two college roommates, Owen and Dominic, sitting in their dorm room one evening. Owen is talking on his cell phone with Carissa, his new girlfriend, while Dominic is watching The Godfather ${ }^{103}$ on his computer. Owen exercises attention to focus on what Carissa is saying and to block out the movie's dialogue, so that Carissa's offhand comment that her birthday is coming up soon is absorbed into his working memory instead of Don Corleone's conversation with his consigliere. After Carissa tells Owen when her birthday is, attention helps him to hold the date in his working memory long enough to write it on a nearby scrap of paper. As Owen repeats the date to himself several times, attention assists in encoding and storing it in his long-term memory. And next year, when that scrap of paper is long gone, Owen will need attention to pull the date from his long-term memory so he can remember to buy Carissa's birthday present. This relationship between memory and attention makes working memory's limitations and their consequences especially relevant to the impact of ICT exposure on attention, as Part IV explains. ${ }^{104}$

\section{Multitasking}

In part because of the interplay between capacity-limited working memory and attention, one of attention's hallmarks is its limited capacity for information processing. ${ }^{105}$ At any given time, we face severe limits in the number of choices that we can select, the number of tasks that we can execute, and the number of responses that we can generate, ${ }^{106}$ along with the limits in the number of items that can be maintained in working memory. As psychologist and Nobel Prize winner Daniel Kahneman puts it:

The often-used phrase "pay attention" is apt: you dispose of a limited budget of attention that you can allocate to activities, and if you try to go beyond your budget, you will fail. It is the mark of effortful activities that they interfere with

101 Id. at $425 \&$ n.29. Chunking information is easiest when the new information can be associated with information already existing in long-term memory. Id. at 426 . It requires greater attention when the new information cannot associate with any existing information because entirely new memory structures must be built. $I d$.

102 Id. at 421, 428 n. 43.

103 The Godfather (Paramount Pictures 1972). This classic film based on a novel by Mario Puzo depicts the transfer of control of a New York Mafia family from aging patriarch Vito Corleone (played by Marlon Brando) to his youngest son, Michael (played by Al Pacino). See generally id.

104 See infra notes 252-81 and accompanying text.

105 STYLES, supra note 11, at 1.

106 Chun et al., supra note 12 , at 82. 
each other, which is why it is difficult or impossible to conduct several at once. $^{107}$

This implies that when we believe we are multitasking-doing two or more things simultaneously, while paying full attention to both-we are most likely instead dividing our attention between the different tasks. ${ }^{108}$ As Posner writes, "it is simply not possible for people to carry out multiple tasks that require executive attention at exactly the same time." 109 The explanations for why we must divide attention between tasks vary according to different theories, ${ }^{110}$ but researchers generally agree that, rather than doing multiple tasks simultaneously, we are rapidly shifting our attention back and forth between the different tasks. ${ }^{111}$

Whether we are merely task switching or truly multitasking, we are doing it frequently throughout the day. Forty-six percent of us eat while driving, according to a 2011 National Highway Transportation Safety Administration sur-

107 KAHNEMAN, supra note 31, at 23.

108 While this is generally the case, it may be possible to do more than one automatic or highly practiced task at a time. Jacobson, supra note 15 , at 437 . Automatic tasks are ones that do not require conscious control, such as breathing or walking. Id. at 421-22. Highly practiced tasks are ones that initially required attention but became more automatic with practice, such as typing on a keyboard. Id. at 422. Also, experiments suggest that the limits on our attentional processing come into play when we try to do multiple tasks that require the same type of cognitive resources, but that there may not be a limit on our ability to do multiple non-competing tasks. STYLES, supra note 11, at 161 (experiments found no limit on a subject's ability to perform simultaneously a visual task (matching letters) and an auditory task (saying "bip" when the subject heard a tone)).

109 POSNER, supra note 16, at 139.

110 Bottleneck theories propose the existence of a central processing bottleneck that limits how much processing can be done at one time, the result of which is that the brain must finish processing the first task before it can start processing the second one. See LARRY D. Rosen, Rewired 79 (2010) [hereinafter Rosen, Rewired]; Styles, supra note 11, at 15, 154. Capacity theories suggest that the brain has a limited pool of processing resources, and tasks share that limited resource from moment to moment in a graded fashion. See RosEN, REWIRED, supra; STYLES, supra note 11, at 155-56. Crosstalk theories propose that processing two tasks may result in an "outcome conflict" between two streams of processing that would otherwise be independent of each other, meaning processing one task produces outputs or side effects that interfere with processing the second task. See Harold Pashler, Dual-Task Interference in Simple Tasks: Data and Theory, 116 Psychol. Bull. 220, 221, 240-41 (1994).

111 E.g., LARRY D. Rosen, IDisorder: Understanding Our OBSESSION With TECHNOLOGY AND OverComing Its Hold ON Us 106 (2012) [hereinafter Rosen, IDisorder] (“[P]eople lack the ability to pay full attention to two tasks at a time."); Jacobson, supra note 15, at 438 (studies almost universally agree that attention shifts back and forth between the tasks); Reynol Junco, In-Class Multitasking and Academic Performance, 28 COMPUTERS Hum. BEHAV. 2236, 2236 (2012) (finding that research on multitasking has provided clear evidence that human information processing is insufficient for performing simultaneous tasks); see also Dario D. Salvucci et al., Toward a Unified Theory of the Multitasking Continuum: From Concurrent Performance to Task Switching, Interruption, and Resumption, in CHI 2009: Digital LifE New World 1819, 1819-20 (describing a continuum of multitasking, from concurrent multitasking (tasks are performed almost simultaneously) to sequential multitasking (a period of minutes to hours is spent on one task before switching to another)). 
vey. ${ }^{112}$ While we are at work, we spend an average of just eleven minutes on a single project before turning to another, according to one study, and while we are engaged in a project, we typically change tasks every three minutes. ${ }^{113}$ The working parents amongst us spend a full quarter of their waking hours engaged in multitasking. ${ }^{114}$ It is not only the adults who multitask; as discussed in Part III, ${ }^{115}$ young people have caught the multitasking bug as well.

All of our attempts to perform multiple tasks simultaneously come with efficiency costs, in three primary forms. First, each shift in attention from one task to another takes time, known as a "switch cost," as our brains take time to change their goals, remember the rules needed for the new task, and block interference from the prior task. ${ }^{116}$ Switch costs make shifting between tasks both time-consuming - generally taking about 20 percent longer than completing tasks sequentially ${ }^{117}$ - as well as inefficient. ${ }^{118}$ The more complex, cognitively similar, or time-pressured the tasks are, the greater the switch costs. ${ }^{119}$ Second, when we get interrupted in the middle of something and switch tasks, there is some lag time (known as a "resumption lag")—-sometimes up to several minutes - between when we finish the interrupting task and when we go back to the original task. ${ }^{120}$ Third, even if we do not switch tasks after an interruption, our performance slows down, exacting a "restart cost" when we resume

112 Julie Tison et al., Nat'l Highway Traffic Safety Admin., National Phone SuRVEY ON Distracted DRIVING ATtITUdES AND BEHAVIORS 14 (2011), available at http://www.distraction.gov/downloads/pdfs/national-phone-survey-on-distracted-driving-attitudes-and-behaviors.pdf. Another survey puts this figure at closer to 70 percent. Jamie Locher \& Owen Moritz, Eat-\&-Drive Sure Recipe for a Crash, Daily News (N.Y.), Jul. 19,2009 , at 14 .

113 JACKSON, supra note 16 , at 84-85.

114 Id. at 74.

115 See infra text accompanying notes $178-80$.

116 JACKSON, supra note 16 , at 79.

117 Jacobson, supra note 15 , at 438.

118 SMALl \& VORGAN, supra note 81 , at 68 . One study by University of Michigan psychologists found that switching tasks (e.g., answering an email while trying to write a memo) may decrease brain efficiency by up to 50 percent in comparison to completing the tasks sequentially. Id.

119 Jacobson, supra note 15, at 438 (describing greater switch costs when "the work gets more complex, when the work moves from familiar to unfamiliar, when the tasks must be done quickly, and when the tasks compete for the same cognitive resource" (footnotes omitted)); Darryl W. Schneider \& John R. Anderson, Asymmetric Switch Costs as Sequential Difficulty Effects, 63 Q.J. EXPERIMENTAL PsYCHOL. 1873, 1873 (2010) (noting greater switch cost when moving from an easier task to a harder one than vice versa).

${ }^{120}$ Erik M. Altmann \& J. Gregory Trafton, Task Interruption: Resumption Lag and the Role of Cues, in Proceedings of the Twenty-Sixth Annual Conference of the Cognitive SCIENCE Society 43, 43 (Kenneth Forbus et al. eds., 2005); see also Rosen, IDisORDER, supra note 111, at 109 (citing a study of computer programmers that found that resumption lags were frequently more than five minutes); Larry D. Rosen et al., An Empirical Examination of the Educational Impact of Text Message-Induced Task Switching in the Classroom: Educational Implications and Strategies to Enhance Learning, 17 Psicología EduCATIVA 163, 166 (2011) (defining resumption lag as the time between completing the interrupting task and returning to the primary task). 
what we were doing before the interruption. ${ }^{121}$ As with switch costs, restart costs may be higher when we are interrupted from a more demanding task. ${ }^{122}$ These switch costs, resumption lags, and restart costs combine to make multitasking significantly less efficient than completing tasks sequentially. Various factors - such as the comfort of our surroundings, our degree of sleep deprivation, and the complexity and familiarity of the tasks involved - make it more or less difficult for us to try to combine tasks, and thus more or less likely that the multitasking costs will be significant. ${ }^{123}$

To illustrate what our brains experience when we try to multitask, imagine Avery, an emergency room doctor in a busy hospital. Avery is stitching up a gash on a patient's forehead when a nurse approaches her with an urgent test request that Avery needs to sign. Avery steps away from her patient, removes her gloves, signs the request form, and hands it to the nurse. She then washes her hands, dons new gloves, turns back to her patient, and resumes stitching up the wound. A few minutes later, a second nurse comes to the door. Avery pauses her suturing momentarily and glances toward the nurse, who tells Avery that her next patient is ready. After thanking the nurse, Avery turns back to her patient and finishes the sutures.

The way that the nurses' interruptions delay Avery's completion of her primary physical task (i.e., sewing stitches) is like the way that trying to multitask delays our brains' completion of their primary cognitive task. The seconds it takes Avery to step away from her patient, take off her gloves, and sign the form after the first nurse's request is similar to the switch cost exacted as our brains prepare for the new task and block interference from the old one. The minute it takes Avery to wash her hands, put on new gloves, and take up her needle is similar to the resumption lag between the time it takes for our brains to finish the interrupting task and turn back to the original one. The moment it takes Avery to acknowledge and thank the second nurse is similar to the restart cost that slows our brains' performance after an interruption. The costs of Avery's physical task switching in this example are minor-a minute here and a few seconds there, with no perceptible harm done to her patient. But now imagine that Avery is a trauma surgeon operating on a gunshot victim's heart-in this scenario, even brief delays could have grievous consequences.

In the same way, the switch costs, resumption lags, and restart costs our brains experience when we try to combine tasks may be inconsequential. No one gets hurt if we chat with a friend while filling out a crossword puzzle, for example. But when the task is more complex - such as driving a racecar-a

121 Schneider \& Anderson, supra note 119, at 1874.

122 See Florian Waszak et al., Task-Switching and Long-Term Priming: Role of Episodic Stimulus-Task Bindings in Task-Shift Costs, 46 Cognitive Psychol. 361, 380, 400 (2003) (finding a substantial restart cost following interruption from a word-reading task, as compared to subsequent trials involving switching between word-reading and picture-naming tasks).

123 See STYLES, supra note 11, at 155; Jacobson, supra note 15, at 438. 
performance cost of even half a second could make a life-or-death difference. And the more times we switch between tasks while trying to multitask, the greater the impact of these switch costs, resumption lags, and restart costs is on our performance.

Multitasking imposes other performance costs as well. Multitasking can decrease our awareness of stimuli, disrupt our decision making, and impair our behavior on one or more of the tasks. ${ }^{124}$ In addition, recent studies suggest that the increased time it takes to accomplish a task while multitasking can lead to more errors in completing the task. ${ }^{125}$ Decreases in accuracy from 20 to 40 percent can result, and the greatest decreases are likely when we try to multitask while doing intellectually demanding work. ${ }^{126}$ Multitasking can also impair our memory because it discourages paying full attention to what we need to learn and recall later, ${ }^{127}$ as well as because bits of information are lost from our working memory with each task switch. ${ }^{128}$ Even becoming a more successful multitasker might be harmful: Some have argued that improving our ability to multitask actually hurts our ability to think deeply and creatively by making us more likely to rely on conventional ideas and solutions. ${ }^{129}$ Compounding these performance problems are the psychological tolls multitasking can take on us. As previously explained, multitasking involves interrupting one task to perform another. Such interruptions tend to produce feelings of stress and anxiety, as discussed in Part IV. ${ }^{130}$ Multitasking may also make work feel more effortful, time pressured, and frustrating. ${ }^{131}$ Though there are some caveats to these findings ${ }^{132}$ and some ways to minimize multitasking's various costs, ${ }^{133}$ it seems that

124 Junco, supra note 111, at 2237.

125 See Rosen et al., supra note 120, at 166.

126 Jacobson, supra note 15 , at 440.

127 SMALl \& Vorgan, supra note 81, at 137.

128 Jacobson, supra note 15 , at 441.

129 CARR, supra note 65, at 140. In the words of psychologist David Meyer of the University of Michigan, when we multitask, we are "learning to be skillful at a superficial level." Sharon Begley \& Jeneen Interlandi, The Dumbest Generation? Don't Be Dumb, Newsweek, June 2, 2008, at 42, 42 (quoting David Meyer).

130 See George Mandler, Mind and Body 239 (1984); Small \& Vorgan, supra note 81, at 32; Rosen et al., supra note 120; see also infra notes 282-308 and accompanying text.

131 See KAHNEMAN, supra note 31, at 37 (switching between tasks is effortful, especially under time pressure); ROSEN, IDISORDER, supra note 111, at 114 (describing a study that found workers who were interrupted while performing a task seemed to compensate for the interruption by working faster, with more stress, higher levels of frustration, greater feelings of time pressure, and more effort).

132 For example, combining certain tasks that activate different parts of the brain-such as performing manual tasks while listening to music-may actually improve performance. SMALl \& VORGAN, supra note 81, at 68-69 (noting that some surgeons perform stressful non-surgical tasks more quickly and accurately when they listen to their preferred music, suggesting that music may enhance the efficiency of those who work with their hands). Also, some environmental "distractions" may not be as distracting as expected. ROSEN, REWIRED, supra note 110, at 84 (describing a study in which college students learning new material received the same score on a subsequent test if they studied with a distracting video playing in the background as when studying in silence, though performance suffered when they were 
multitasking is more effortful and counterproductive than it is effortless and efficient.

Moreover, we do not become better at combining activities (i.e., multitasking) simply because one of the activities involves an ICT. If anything, ICTinduced multitasking is more insidious because we may not realize the frequency or extent to which we are trying to do it. While we might recognize that we are having trouble concentrating on the book we are reading while our spouse is standing in the room talking to us, we might not feel as though we are equally distracted ${ }^{134}$ when we have the same conversation via text message. The act of reading a text message feels similar to the act of reading a book, so it is possible that we do not consciously recognize we are actually trying to do two things at once.

\section{Why Do We NeEd AtTEnTION?}

With the foregoing background on what attention is and how it works, this Part outlines why attention is so important for our daily functioning, our ability to exercise effortful control, and our ability to learn. It then explains why attention is particularly crucial for legal professionals.

\section{A. Necessary for Daily Functioning}

Attention is crucial for our basic daily functioning. Our ability to perform simple motor movements, such as reaching and grasping, depends upon attention. ${ }^{135}$ So does our capacity for higher-order cognitive operations, such as

required to memorize both the video and the material (i.e., they could ignore background noise but were unable to split attention)). Finally, a few studies have suggested that interruptions may not have the same negative performance effects in a real-world setting, with less stringent time constraints, as in a laboratory. See Rosen et al., supra note 120, at 166-67 (noting that the study's reading comprehension task took longer when it was interrupted, but ultimate comprehension was unaffected); see also ROSEN, REWIRED, supra note 110, at 7677.

133 See Small \& Vorgan, supra note 81, at 138-39 (finding that varying tasks throughout the day reduces multitasking stress; slowing pace may increase accuracy and efficiency); Jacobson, supra note 15, at 439-40 (switch costs can be reduced by self-cuing and practice of tasks to make them more automatic). But see JACKSON, supra note 16, at 79-80 (" "Training can help overcome some of the inefficiencies by giving you more optimal strategies for multitasking,' ... . 'but except in rare circumstances, you can train until you're blue in the face and you'd never be as good as if you just focused on one thing at a time. Period.'”) (quoting David Meyer of the University of Michigan).

${ }^{134}$ Alternatively, we may actually be less distracted by ICT interruptions than by live ones because we may be able to determine when it is necessary to ignore technological distractions and focus in a way that we cannot with live ones. See Don TAPSCOTt, Grown Up Digital: How the Net Generation Is Changing Your World 116 (2009) (arguing that the Digital Generation are better at handling pervasive distractions than Baby Boomers are, because the Digital Generation know when they have to focus and think deeply and are able to block out distractions to help them do so).

135 STYLES, supra note 11, at 251. 
planning and remembering things. ${ }^{136}$ Because our environment provides us with far more perceptual information than we can effectively process, ${ }^{137}$ we rely upon our attentional mechanisms to focus our limited processing capacity efficiently on the most important information relevant to our ongoing goals and behavior. ${ }^{138}$ In essence, we need attention to help us focus on the right inputs so that we can produce the right outputs.

The brain is known to be a massively parallel computational device in which many varieties of information are concurrently available from different parts of the system. In order to maintain coherent behaviour, some of this information needs to be combined for response while other subsets need to be "ignored" to allow selection for action. ${ }^{139}$

This selection ability is essential for us to function coherently — and thus for our survival. ${ }^{140}$

\section{B. Necessary for Effortful Control}

Also crucial for our coherent functioning is our ability to exercise effortful control, which in turn depends upon our executive attention mechanisms. Effortful control is "the ability to inhibit a dominant response to perform a subdominant response, to detect errors, and to engage in planning." ${ }^{, 141}$ It is the source of our ability to focus and shift our attention and to regulate our impulses. ${ }^{142}$ For example, when our entrée is the first to arrive at the table, it takes effortful control to wait until everyone has been served before we start to eat. Effortful control is a major form of self-control (or self-regulation), ${ }^{143}$ and is important for controlling our emotions as well as our cognition. ${ }^{144}$ Research has linked children's effortful control to their development of empathy and conscience and to lower levels of maladjustment and psychopathology. ${ }^{145}$ Devel-

${ }^{136} I d$.

137 Chun et al., supra note 12 , at 75 .

138 Id.

139 STYLES, supra note 11, at 251.

140 Posner, supra note 16, at 73; see also STYLES, supra note 11, at 252 ("In order to interact with the environment in a goal-directed manner, we have to be able to select which response is appropriate at any given moment. . . For goals to be achieved other potential actions have to be inhibited.").

${ }^{141}$ Mary K. Rothbart \& M. Rosario Rueda, The Development of Effortful Control, in Developing Individuality In THE Human BRAin 167, 169 (Ulrich Mayr et al. eds., 2005).

142 Posner, supra note 16, at 91; Mary K. Rothbart et al., Developing Mechanisms of Temperamental Effortful Control, 71 J. PERSONALITY 1113, 1114 (2003).

143 Rothbart \& Rueda, supra note 141, at 169. The term "self-control" is more frequently used in studies of adults, while the term "self-regulation" is more often used in studies of children. POSNER, supra note 16, at 73. They both refer to the suppression of brain activity that conflicts with our current goals so that we can control our thoughts, behaviors, feelings, and reactions to stress, maintain focused attention, and interpret our and others' mental states. Id. at 73, 87; Rothbart \& Rueda, supra note 141, at 169.

144 POSNER, supra note 16, at 91.

145 Rothbart et al., supra note 142, at 1115. 
opmental psychologists have identified lack of control as a risk factor for a number of undesirable behaviors in adolescents, such as aggressiveness, delinquency, substance use, and antisocial behaviors. ${ }^{146}$

Researchers believe that effortful control and executive attention are linked. ${ }^{147}$ They both reflect our ability to regulate our emotions, thoughts, and behavior. ${ }^{148}$ It seems that executive attention mechanisms provide the basis for effortful control. ${ }^{149}$ In fact, some developmental psychologists view our development of effortful control as a product of our having developed executive attention mechanisms, which happens during our toddler and preschool years. ${ }^{150}$ This connection between executive attention and effortful control makes sense because our executive attention processes enable us to deploy our attention voluntarily. ${ }^{151}$ If we were unable to direct our attention voluntarily, we would similarly be unable to do things associated with effortful control, such as rein in our negative emotions, prevent ourselves from overreacting, or overcome our habitual responses. ${ }^{152}$ We need executive attention whenever a situation calls for careful control of our actions. ${ }^{153}$ It follows that, without this attention, we would be unable to exercise effortful control.

\section{Necessary for Learning}

Attention and learning are closely connected ${ }^{154}$ — so much so that attention is necessary for each step in the learning process. ${ }^{155}$ First, we need attention to absorb from the environment the information relevant to our current goal and to ignore all the irrelevant stimuli. ${ }^{156}$ Studies show that the likelihood of our recalling information later (i.e., having learned it) is greatly increased when we paid close attention to the information at the time we first encountered it. ${ }^{157}$ Second, we need attention to process the stimuli we attended to. ${ }^{158}$ Not only must we attend consciously to the task we are doing while we are processing it, but we must also utilize our top-down attentional mechanisms to prevent interruptions and distractions from taking us off-task. ${ }^{159}$ Third, we need attention to

${ }^{146} I d$.

147 POSNER, supra note 16, at 91-92.

148 Id. at 92; Rothbart \& Rueda, supra note 141, at 173.

149 Rothbart \& Rueda, supra note 141, at 184.

${ }^{150}$ Rothbart et al., supra note 142, at 1114-15.

151 Rothbart \& Rueda, supra note 141, at 173.

152 See id.

153 Id. at 184.

${ }^{154}$ Posner, supra note 16, at 152.

155 Jacobson, supra note 15 , at 428 .

156 See id. at 421.

157 POSNER, supra note 16, at 152.

158 Jacobson, supra note 15 , at 421 . Although automatic or highly practiced tasks can be processed without attention, processing other tasks requires attention. Id. at 421-22; see supra note 108 .

159 Jacobson, supra note 15, at 422. 
remember the relevant information - to hold bits of information in working memory and then to transfer them to long-term memory. ${ }^{160}$ It is not entirely clear how attention facilitates the process of storing information long-term, but it appears that attention is a precondition for its happening. ${ }^{161}$ Fourth, once information is stored in our long-term memory, we need attention to retrieve it and to bring the learned information into our conscious minds so we can use it. ${ }^{162}$ Because attention is involved in every step of the process, without attention there could be no learning.

\section{Necessary for Legal Professionals}

Neither could there be lawyering without attention. "The ability to sustain attention and focus over time is essential for practical domains ... as well as for daily functioning in work, school, and social settings." 163 The nature of legal work imposes particularly strong demands upon attention. To begin with, law school is an intense cognitive endeavor. ${ }^{164}$ In everything from reading and understanding cases, to listening to and processing lectures, to drafting appellate briefs and writing seminar papers, law students must exercise their powers of attention. And attention is no less necessary when students graduate and become practicing attorneys; the practice of law is, in many ways, the practice of learning. Lawyering skills — such as researching precedent cases and statutory authority, drafting contracts and court documents, interviewing clients, and making coherent arguments - all depend upon higher-order cognitive functions. Lawyers need sustained focus (to slog through the thousands of pages of discovery), impulse control (lest the lawyer tell the judge what she really thinks of that ruling), a sharp memory (to realize the witness just contradicted his affidavit), an eagle eye for errors (to spot the internal inconsistencies in the draft LLC agreement), top-notch planning (to anticipate problems the client never consid-

\footnotetext{
${ }^{160} I d$. at 425 . Working memory's role in performing various cognitive operations makes it crucial for learning. Id. at 423; see also supra text accompanying notes 85-96.

161 Posner, supra note 16, at 152-53. This is the case for explicit learning - the type of learning that involves specific, conscious effort to learn something. See id. at 153. For example, students who take a class to learn a second language are engaged in explicit learning. Explicit learning relies upon the hippocampus, which helps to distribute and integrate information that is ultimately stored in the brain long-term. $I d$. at 152 . However, there is evidence of so-called implicit learning - a form of learning without conscious awareness that does not require the involvement of the hippocampus or specific efforts to store the information being learned long-term. Id. at 153 . For instance, the way a young child learns to string together grammatical sentences in his native language is through implicit learning.

162 Jacobson, supra note 15 , at 421, 425-27.

163 Chun et al., supra note 12, at 76.

164 See Jacobson, supra note 15, at 419-20 (noting that law school involves an "intense and sustained cognitive effort" in every aspect and requires students to pay attention and concentrate).
} 
ered), and countless other traits born out of attention. A lawyer who cannot pay attention effectively is unlikely to be an effective lawyer. ${ }^{165}$

\section{The Digital Life OF THE “Digital GENERATION”}

Today there is a new generation of young people who have never known a world in which computers, the Internet, and cell phones did not exist. There is no consensus on what these youth should be called, ${ }^{166}$ exactly what birth year separates them from earlier generations, ${ }^{167}$ or even whether it is appropriate to refer to them as a generation at all. ${ }^{168}$ What probably can be agreed upon is that what makes this generation unlike any other generation before them is their lifelong exposure to ICTs. These young people are the Digital Generation. ${ }^{169}$

It is hardly astonishing that digital technology plays a big part in the Digital Generation's lives. According to a 2012 survey of technology use by American ${ }^{170}$ teens, 95 percent of teens are on the Internet. ${ }^{171}$ Almost three-quarters of

165 Lawyers and law students who are able to focus on their work are likely to be more efficient and may make fewer errors. Baker \& Brown, supra note 60, at 340 . The converse may also be true, as suggested by Baker and Brown's observation that "a number of Bar discipline cases involving lack of diligence or related ethical issues also involved a claim of mitigation because of problems of attention deficit or lack of concentration." Id. at 340 n.10.

${ }^{166}$ For different examples of how scholars refer to this generation, see, e.g., RosEN, IDISORDER, supra note 111, at 7 (the "Net Generation" and the "iGeneration," depending upon their age); TAPSCOTT, supra note 134, at 16 (noting that the "Net Generation" are also known as the "Millennials" and "Generation Y," while "Generation Next" are also known as "Generation Z"); Marc Prensky, Digital Natives, Digital Immigrants Part 1, ON THE HorizON, Sept./Oct. 2001, at 1, 1 ("Digital Natives").

167 See, e.g., Horstman, supra note 82, at 56 (those born after 1980 are "digital natives"); Rosen, REWIRED, supra note 110, at 12-13 (the "Net Generation" were born in the 1980s, while the "iGeneration" were born in the 1990s and the 2000s); TAPSCOTT, supra note 134, at 16 (the "Net Generation" were born between January 1977 and December 1997 while "Generation Next" were born between January 1998 and the present).

168 See John PALFrey \& Urs Gasser, Born Digital: Understanding the First Generation of Digital Natives 14 (2008). Palfrey and Gasser note that access to ICTs varies across countries and populations, so it cannot be assumed that everyone born after a certain year will have the same exposure to ICTs. Therefore, they argue, it is more useful to think of young people with ICT exposure as a population, rather than a generation. Id.

169 The eldest of the Digital Generation are currently in their early thirties, while the youngest are just being born. This is, admittedly, a broad span of years. Others have divided this group into at least two different generations (see supra notes 166-67), but the dividing lines seem rather arbitrary. I consider the entire group to be the Digital Generation. However, for the sake of consistency with much of the research cited herein, this Article uses "Digital Generation" primarily in reference to today's "tweens," teens, and college-age youth-i.e., young people roughly ages eleven to twenty-two.

${ }_{170}$ All of the statistics cited in this Part refer to technology use by young people in the United States. As with the generalizations about adults in this Article, generalizations about the Digital Generation are not intended - and are unlikely-to represent technology habits of young people worldwide, given the variance in access to ICTs in different countries and different populations. Cf. supra note 4.

171 Mary Madden et al., Pew Research Ctr., Teens and Technology 2013 2, 3 (2013), available at http://www.pewinternet.org/Reports/2013/Teens-and-Tech.aspx. This report, 
teens at least occasionally use their cell phones, tablets, and other mobile devices to access the Internet. ${ }^{172}$ Ninety-three percent of teens either own their own computer or have access to one at home. ${ }^{173}$ More than three-quarters of teens now own a cell phone, and almost half of these are smartphones. ${ }^{174}$ The Digital Generation struggle to go even fifteen minutes without checking their ICTs for new messages, ${ }^{175}$ which is perhaps not surprising considering they are more likely to communicate with other people in their lives via text message than by talking to them on the phone or in person. ${ }^{176}$

In fact, most of the time that young people are awake and not attending school, they are using some form of digital technology. A recent survey on media use among American youth found that children between eight and eighteen years old spend on average more than seven and one-half hours per day doing things such as watching TV and movies, playing video games, listening to music, using computers, and - for just a small part of this time - reading print me-

part of a series of reports issued by the Pew Research Center in collaboration with Harvard's Berkman Center for Internet \& Society, is based on a 2012 nationally representative telephone survey of 802 parents and their 802 teens, ranging in age from twelve to seventeen years old, with a plus or minus 4.5 percent margin of error. $I d$. at 2 .

${ }^{172}$ See id. at 4 . Seventy-four percent of teens aged twelve to seventeen at least occasionally use mobile devices to access the Internet. Id. Older teens, those aged fourteen to seventeen, are slightly more likely than twelve- and thirteen-year-olds to access the Internet via mobile devices ( 76 percent versus 71 percent, without distinguishing between genders). Id.

${ }^{173} \mathrm{Id}$. at 5 . The survey found that 80 percent of teens own a desktop or laptop, and twothirds of the remaining 20 percent can access one at home, for a combined 93 percent of teens who own or have access to a computer. $I d$. On average, white teens are more likely to own a computer than black teens are ( 81 percent vs. 64 percent), older teens are more likely to own one than younger teens are (83 percent for fourteen- to seventeen-year-olds vs. 72 percent for twelve- to thirteen-year-olds), and teens living in suburban areas are more likely to own a computer than urban teens are ( 84 percent vs. 75 percent). Id.

174 See id. at 6-7. Seventy-eight percent of teens own a cell phone, and 47 percent of those have smartphones, for a combined 37 percent of all teens with smartphones. Id. For purposes of comparison, 45 percent of adults have a smartphone. Id. at 7.

175 See RosEN, IDISORDER, supra note 111, at 7, 13. A study of message checking habits among different generations found that 64 percent of "Net Generation" respondents (born in the 1980s) check every fifteen minutes or less for text messages, while 42 percent check for cell phone calls, and 36 percent check Facebook. $I d$. at 13 . Of those respondents from the "iGeneration" (born in the 1990s), 62 percent check texts, 34 percent check calls, and 32 percent check Facebook every fifteen minutes or less. Id. at 7, 13. In contrast, of the Baby Boomers surveyed, 18 percent check texts, 20 percent check calls, and 8 percent check Facebook with the same frequency. Id. at 13.

176 See Amanda Lenhart, Pew Research Ctr.'s Internet \& Amer. Life Project, Teens, SMARTPHONES \& TEXTING 16-17 (2012), available at http://www.pewinternet.org/2012 /03/19/teens-smartphones-texting/. This 2011 nationally representative telephone survey of 799 teens aged twelve to seventeen years old and their parents found (with a plus or minus 4.8 percent margin of error) that 63 percent of teens communicate with others every day by text, compared to 39 percent who talk on a cell phone, 35 percent who socialize face-to-face outside of school, 29 percent who exchange messages through social networking sites, 22 percent who use instant messaging, 19 percent who talk on landlines, and a mere 6 percent who exchange emails. Id. at 16-17, 19. 
dia. ${ }^{177}$ Almost a third of the time that these youngsters are using digital media, they are multitasking, using multiple media at once. ${ }^{178}$ This combined media use adds up to more than ten and one-half hours of media exposure per day, ${ }^{179}$ not even counting the time they spend talking on a cell phone, texting, or using media for school-related purposes. ${ }^{180}$

177 Victoria J. Rideout et AL., Henry J. Kaiser Family Found., Generation M²: Media IN THE LIVES OF 8- TO 18-YEAR-OLDS 6, 11 (2010), available at http://kff.org/other/event /generation-m2-media-in-the-lives-of/. This finding comes from a nationally representative survey conducted in 2008 and 2009 of 2,002 third through twelfth grade public, private, and parochial school students aged eight to eighteen, including 702 volunteers who completed seven-day media use diaries, with a plus or minus 3.9 percent margin of error. $I d$. at 6 . Media use refers to the amount of time that young people spend using media in a given day, taking into account the proportion of time they are using multiple media at the same time (e.g., if a teenager listens to music for the entire hour he spends using a computer, the report accounts for one hour of media use). See id. Print media use (time spent reading print versions of books, magazines, or newspapers for pleasure) accounted for thirty-eight minutes of the average seven hours and thirty-eight minutes the survey respondents reported using media in a typical day. Id. at 2, 11. See also id. at 6-7 (describing what was or was not included in each type of media use).

${ }^{178} I d$. at 33 (reporting that young people use two or more media concurrently 29 percent of the time they are using media). Multitasking varies in frequency depending upon the type of medium being used, with 48 percent of young people reporting multitasking "some of the time" or "most of the time" while playing video games, as compared to 53 percent while reading, 68 percent while watching TV, 66 percent while using a computer, and 73 percent while listening to music. Id. (quotation marks omitted). This variance likely has to do with the different mental resources required to engage with different media. Rosen attributes the greater likelihood of multitasking while listening to music than while playing video games to the fact that playing video games requires greater mental resources (vision, hearing, and manual skills, along with logic and problem solving), making it more difficult to multitask while playing. ROSEN, REWIRED, supra note 110 , at 81 .

179 See RiDEOUT ET AL., supra note 177, at 11. This survey found that young people on average are exposed to a total of ten hours and forty-five minutes of media content per day because of the frequency with which they use two or more media concurrently. Id. Media exposure refers to the amount of media content young people consume in a day, without taking multitasking into account (e.g., if a teenager listens to music for the entire hour she spends using a computer, the report accounts for two hours of media use). See id. at 6 . The amount of media exposure varies substantially by age, ethnicity, and gender, with older youth (fifteen- to eighteen-year-olds) exposed to more media on average than younger children (eightto ten-year-olds) (eleven hours and twenty-three minutes vs. seven hours and fifty-one minutes), black or Hispanic youth exposed to more than white youth (twelve hours and fiftynine minutes and thirteen hours vs. eight hours and thirty-six minutes), and boys exposed to more than girls (eleven hours and twelve minutes vs. ten hours and seventeen minutes). Id. at 11.

180 See id. at 18. This report excludes the time spent texting or talking on the phone from the media use calculation, but includes time spent listening to music, playing games, and watching videos on a phone. $I d$. at 6 . Moreover, the findings reflect only recreational (non-schoolrelated) media use. $I d$. When the excluded media use is included, the total media exposure figure is likely to be significantly greater. For example, Rosen's studies estimate the figure to be more than twenty hours per day. ROSEN, REWIRED, supra note 110, at 12. 
The Digital Generation interact with their ICTs right up until the moment they close their eyes. ${ }^{181}$ Even sleep cannot part them from their ICTs and the thousands of messages ${ }^{182}$ they send and receive every month. Many of them wake up in the middle of the night to check their messages and send a text or an email, or are awakened by an incoming call or message. ${ }^{183}$ Clearly, ICTs are a big part of the Digital Generation's lives. Their generation is defined by the facts that they have grown up with technology, that they spend a lot of time every day using it, and that they tend to use more than one form at a time.

\section{What Do ICTS Have To Do WITH AtTENTION?}

The great deal of exposure the Digital Generation have to ICTs may be affecting their attention in three significant ways. ${ }^{184}$ First, ICT exposure may be causing neurological changes that in turn change how-and how well- the Digital Generation pay attention. Second, ICT exposure may be altering the Digital Generation's attentional control, decreasing their ability to pay attention. And third, ICT exposure may be redefining what it means to the Digital Generation to be "paying attention." This Part explores all of these potential changes in turn.

181 See Press Release, Nat'l Sleep Found., Annual Sleep in America Poll Exploring Connections with Communications Technology Use and Sleep (Mar. 7, 2011), available at http://sleepfoundation.org/media-center/press-release/annual-sleep-america-poll-ex ploring-connections-communications-technology-use-. A poll of 1,508 Americans between ages thirteen and sixty-four reports (with a plus or minus 2.5 percent margin of error) that 55 percent of thirteen- to eighteen-year-olds surf the Internet within the hour before sleep, and 56 percent send, read, or receive text messages. $I d$.

182 See Nielsen, State of the Media 2010: U.S. Audiences \& Devices 3 (2011), available at http://www.nielsen.com/content/dam/corporate/us/en/newswire/uploads/2011/01/niel sen-media-fact-sheet-jan-11.pdf. An analysis of over sixty thousand phone bills from the third quarter of 2010 found that the number of text messages sent and received in a month was 1,178 for children twelve and under, 1,707 for eighteen- to twenty-four-year-olds, and a staggering 3,705 for thirteen- to seventeen-year-olds. Id. at 3-4.

${ }^{183}$ See Press Release, Nat'1 Sleep Found., supra note 181. In this poll, 18 percent of thirteen- to eighteen-year-olds reported being awakened by a phone call, text message, or email at least a few nights a week. Id. Additionally, in a 2013 nationally representative survey of 1,103 parents and caregivers of children age six to seventeen years old, parents reported that 43 percent (plus or minus 4 percent) of their fifteen- to seventeen-year-olds sent or read text messages, emails, or other electronic communications after initially going to sleep. NAT'L Sleep Found., 2014 SLEEP IN AMERICA® Poll: Sleep in the Modern FAmily: Summary OF FINDINGS 5, 36 (2014), available at http://sleepfoundation.org/sites/default/files /2014-NSF-Sleep-in-America-poll-summary-of-findings---FINAL-Updated-3-26-14-.pdf.

Further, a 2011 study of 3,500 people from 1,100 corporations worldwide found that 77 percent of "Net Generation" employees (born in the 1980s) keep their cell phone in their bedroom and 60 percent keep it within arm's reach. ROSEN, IDISORDER, supra note 111, at 7, 9 . Those who keep it within reach are 60 percent more likely than average to awaken and check it for new messages. $I d$. at 9.

184 This Article's focus is the impact of ICT exposure on the Digital Generation, and so the neurological and attentional changes outlined in this Part are described as if applicable solely to the Digital Generation. This choice of language notwithstanding, many of the described changes are likely experienced by all ICT users, regardless of their generation. 


\section{A. ICT Exposure May Be Changing the Digital Generation's Brains}

Bestselling author of books on technology Nicholas Carr has called the Internet "the single most powerful mind-altering technology that has ever come into general use." ${ }^{, 185}$ Indeed, ICT exposure may be physically altering the Digital Generation's brains. Such neurological change is possible because the brain is not an entirely static organ; it does change over time in the face of different influences and experiences. This Section explores the brain's capacity to change and the various types of changes different ICTs may be causing to the Digital Generation's brains.

\section{Neuroplasticity}

Prior to the late twentieth century, it was commonly believed that the brain was hardwired and unchanging and that brain cell creation ended at or shortly after birth. ${ }^{186}$ Scientists thought that once the brain developed in a certain way, it remained fixed except for a degree of decay with age. ${ }^{187}$ More recently, scientists have determined that the brain is an inherently changeable - or plasticorgan. ${ }^{188}$ This quality is generally referred to as "neuroplasticity." ${ }^{189}$ Changes in the brain result mainly from the growth of new networks of, and connections between, our neurons. ${ }^{190}$

Mature human brains create new neurons throughout life, a process known as neurogenesis. ${ }^{191}$ Newly created neurons die within a few weeks unless they are activated, ${ }^{192}$ which happens whenever we perform a new task or experience a new sensation. ${ }^{193}$ If the neurons are near each other, they join together by exchanging synaptic neurotransmitters - the chemicals that transmit signals between neurons across a synapse. ${ }^{194}$ This communication between neurons is what gives us the ability to think, feel, and move. ${ }^{195}$ If we repeat the experience, the synaptic links between our neurons strengthen and become more plentiful, which makes our brains perform that task faster and more efficiently. ${ }^{196}$

185 CARR, supra note 65, at 116.

186 HORSTMAN, supra note 82, at 8; TAPSCOTT, supra note 134 , at 99.

187 TAPSCOTT, supra note 134, at 99.

188 Dalton, supra note 31, at 413-14.

189 HORSTMAN, supra note 82, at 8.

190 Id. at 11.

191 Id. at 8. This is not unique to humans; all mammalian brains experience neurogenesis. See id.

192 Id. at 15 . The more effortful the experience is, the more likely it is that new neurons will survive. Merely repeating skills that have already been learned does not seem to promote survival. Id. at 15-17.

193 CARR, supra note 65 , at 27.

${ }^{194} I d$.

195 SMALl \& VORGAN, supra note 81.

196 CARR, supra note 65 , at 27,34 . In other words, "[c]ells that fire together wire together." Id. at 27 (quotation marks omitted). 
Neural network pathways can become permanent (so to speak) as we repeat tasks or experiences. ${ }^{197}$ The unused pathways are pruned away, ${ }^{198}$ giving truth to the old maxim: "Use it or lose it."199

Our number of existing synapses peaks by the time we are two years old and is reduced by about 60 percent by the time we reach adulthood. ${ }^{200}$ This pruning process prevents our brains from creating so many neural connections that they cannot operate efficiently. ${ }^{201}$ As a result of this deterioration, our brains devote a greater portion of their neural area to the more frequently used connections. ${ }^{202}$ These brain changes can be desirable, such as when the neural connections in blind people devoted to sight are pruned back, while the connections devoted to the other senses are strengthened. ${ }^{203}$ They can also be undesirable, such as when the neural pathways for a bad habit are strengthened. ${ }^{204}$

Given the fact that the Digital Generation's brains are plastic and change in response to new experiences, it seems likely that ICT exposure is changing their brains. What is less well understood is exactly how their brains are changing: "Research has been showing for decades that how we use mind and body changes our brain and brain activity. Hours spent with today's digital technology and on the Internet are bound to result in a shift in neural processing. So far, though, no one knows exactly how. ${ }^{205}$ Difficulty finding nonusers of digital technologies makes it challenging to conduct studies that compare the brains of users and nonusers. ${ }^{206}$ But because interaction with ICTs is stimulating and often repeating, it seems very likely that ICT exposure is strengthening the neural connections related to the use of ICTs ${ }^{207}$ and altering the Digital Generation's brain function in some way. ${ }^{208}$

197 SMALL \& VORGAN, supra note 81, at 5.

198 CARR, supra note 65, at 34.

199 Illustrating this concept, children who speak another language at home before entering school may lose the capacity to speak that language without retraining once they have redirected all of their language skills to learning English in school. TAPSCOTT, supra note 134, at $100-01$.

200 SMALl \& VORGAN, supra note 81 , at 7.

201 Id.

202 Dalton, supra note 31, at 416.

203 Id.

204 CARR, supra note 65, at 34 ("[N] othing says the new state has to be a desirable one. Bad habits can be ingrained in our neurons as easily as good ones.").

205 HORSTMAN, supra note 82 , at 57.

206 Id. at 60.

207 Dalton, supra note 31, at 417-18.

208 SMALl \& Vorgan, supra note 81, at 1-2 ("Daily exposure to high technologycomputers, smart phones, video games, search engines like Google and Yahoo-stimulates brain cell alteration and neurotransmitter release, gradually strengthening new neural pathways in our brains while weakening old ones. .. . Although we are unaware of these changes in our neural circuitry or brain wiring, these alterations can become permanent with repetition."). 


\section{Video Games}

One digital technology that has received significant attention in this regard is video games. Research indicates that playing video games can improve the player's mental dexterity, pattern recognition, hand-eye coordination, information processing skills, and perhaps even attention span. ${ }^{209}$ Video game play seems to improve peripheral vision and shorten reaction time to visual stimu1i. ${ }^{210}$ Moderate video game play may even lead to more systematic thinking and enhanced executive skills. ${ }^{211}$ These improvements may particularly benefit professionals such as architects, engineers, and surgeons. ${ }^{212}$

Yet not all of the studies of video game play suggest that it leads to positive developments. There are indications that video game play stimulates brain areas that control lower-order brain functions - such as movement and visionbut neglects the frontal lobe. ${ }^{213}$ Studies by researchers at Tokyo's Nihon University found that the more time adolescents spent playing video games, the less time they used key areas of the brain associated with executive functions. Players who typically played between two and seven hours per day sometimes developed a condition in which their frontal lobes essentially shut off, even when they were not playing. ${ }^{214}$ Although moderate game play may have some cognitive benefits, excessive play may actually stunt the Digital Generation's frontal lobe development and lead to a decrease in their working memory. ${ }^{215}$

\section{Internet Use}

Adding to the effects video game play may be having on the Digital Generation's brains, evidence suggests that Internet use may also be producing neurological changes. Internet searching and browsing appear to strengthen lowerorder cognitive skills - such as hand-eye coordination, reflexes, and processing of visual cues - similarly to video games. ${ }^{216}$ This may be because the Internet makes users repeatedly evaluate headlines, snippets of text, hyperlinks, and images, making them better at distinguishing quickly between bits of competing information, analyzing the information's features, and determining whether it is

\footnotetext{
209 HorSTMAN, supra note 82, at 30. There is a caveat to this research, in that video game play may cause greater activity in males' brains than in females'. Id. Presumably, then, males may reap more of these benefits than females.

210 Id. at 58; TAPSCOTT, supra note 134, at 98.

211 SMALl \& VORGAN, supra note 81, at 39. Along the same lines, a study of laparoscopic surgeons at Beth Israel Medical Center in New York City found that those who played three or more hours of video games per week made approximately 40 percent fewer errors during surgical procedures as compared to non-gaming surgeons. Id. at 38-39.

212 TAPSCOTT, supra note 134, at 98.

213 Dalton, supra note 31, at 419.

214 SMALL \& VORGAN, supra note 81, at 36.

215 See Dalton, supra note 31, at 419.

${ }^{216}$ CARR, supra note 65, at 139.
} 
relevant to their current goals. ${ }^{217}$ Using the Internet may also expand working memory capacity ${ }^{218}$ and may generally increase users' mental activity. ${ }^{219}$

Moreover, these changes may be rapid. A small study of newcomers to computer technology and their computer-savvy peers by UCLA professor of psychiatry Dr. Gary Small used fMRI scans to map the volunteers' brain activity while they searched for information using Google. In the initial test, the computer-savvy group showed significant activity when searching in the dorsolateral prefrontal cortex, a brain region involved in decision making and complex reasoning, ${ }^{220}$ while the newcomers had minimal or no activation there. But after only five days' practice searching Google for just one hour per day, the newcomers' brain activity during the searching task was virtually identical to that of the computer-savvy group. ${ }^{221}$ The fact that the brain apparently can rewire itself so fast is both astounding and somewhat unsettling. ${ }^{222}$ That said, it remains to be seen what - if any - effect on cognitive performance these neural changes from Internet use may bring about. ${ }^{223}$

\section{Multitasking}

A frequent question in the context of neuroplasticity and the Digital Generation is whether their constant multitasking with $\mathrm{ICTs}^{224}$ is changing their brains in a way that makes them better at multitasking than their elders. It has been argued that the Digital Generation are learning "to juggle multiple activities, use time efficiently and use existing technologies in creative ways" because of their proclivity for multitasking, and that with extensive practice in multitasking, their brains may adapt to be proficient both at multitasking and at

${ }^{217} I d$.

218 Id.

219 Horstman, supra note 82, at 30.

${ }^{220} I d$. at 60 . There was no difference in the two groups' brain activity in the initial test during the control task of reading pages of a book. SMALL \& VORGAN, supra note 81, at 16.

221 SMALl \& VORGAN, supra note 81, at 15-16.

${ }^{222}$ It also raises the question of how quickly this rewiring might be reversed, a subject that Posner grapples with:

[W] hen it comes to discussions of negative influence [from ICTs], they [those who say brain plasticity makes ICT use a cause for concern] often consider the brain to be hard-wired and suggest that we are raising a generation that is changed for all time. However, if the brain is plastic, it is as likely that any change induced by the use of media could be changed back by a vacation in the woods with a long intense novel.

POSNER, supra note 16, at 139. Yet Posner believes it is unlikely that such brain changes will be undone, given our current social environment. "[I]t seems clear that the desire to carry out many tasks at the same time [using ICTs] will remain a constant feature of human life." Id.

223 See Horstman, supra note 82, at 60-61 (describing a 2009 Dutch study of the cognitive performance of people aged sixty-four to seventy-five that found no differences in standard tests of cognitive functions between a group of computer nonusers and a group given a year of computer training).

${ }^{224}$ See supra notes $178-80$ and accompanying text. 
tasks requiring extended concentration. ${ }^{225}$ It has also been suggested that the Digital Generation may have greater cognitive resources for multitasking than their elders do and may be able to handle a larger amount of information at one time. ${ }^{226}$

A recent study of multitasking across three generations calls these assertions into question. The research team found that the Net Generation (those born after 1978) were more likely to multitask than were Baby Boomers or Generation X, but also that there were strong similarities in the nature of the three generations' multitasking. ${ }^{227}$ For instance, all of the age groups agreed on what types of activities were good candidates for multitasking (e.g., eating and listening to music) and what were not (e.g., reading and playing video games). ${ }^{228}$ This suggests that the Digital Generation may not be able to combine challenging activities more successfully than their elders can. Moreover, the generations agreed about which activities were relatively hard to combine and which were relatively easy. ${ }^{229}$ Although the Digital Generation rated multitasking to be easier on the whole than the other generations did, the researchers found no evidence that the Digital Generation's multitasking differed qualitatively; their self-report of multitasking ease might be attributable to the Digital Generation's having "younger" brains, or it might simply have been a matter of perception and not necessarily indicative of greater skill. ${ }^{230}$ Given the current understanding of the brain's limitations with respect to multitasking, ${ }^{231}$ it may be the case that the Digital Generation's propensity for multitasking more reflects differences in generational preferences than in capabilities. Even if the Digital Generation are adapting to be more proficient multitaskers, the question

${ }^{225}$ Ulla G. Foehr, Henry J. Kaiser Family Found., Media Multitasking Among American Youth: Prevalence, Predictors and Pairings 5, 24 (2006), available at http://files.eric.ed.gov/fulltext/ED527858.pdf.

${ }^{226}$ L. Mark Carrier, Nancy A. Cheever, Larry D. Rosen, Sandra Benitez \& Jennifer Chang, Multitasking Across Generations: Multitasking Choices and Difficulty Ratings in Three Generations of Americans, 25 COMPUTERs HuM. BEHAV. 483, 488 (2009).

${ }^{227} I d$. at 487 . These findings are based on a survey of 1,319 people in Los Angeles, California, including 312 Baby Boomers (born between 1946 and 1964), 182 "Gen Xers" (born between 1965 and 1978), and 825 "Net Geners." Id. at 484.

228 Id. at $483,487-88$.

229 Id. at 488 .

${ }^{230}$ See id. (quotation marks omitted) ("Essentially, although the younger generations found task combinations easier to combine, this ease could possibly be attributed to their young ages and not to their generation. ... [I]t is possible that the responses reflect the respondents' perceptions of their own multitasking experiences, rather than their real multitasking behaviors.").

231 See id. at 489 (describing their findings as "consistent with the idea that all generations share mental limitations affecting which tasks can be combined with other tasks" and noting that "some basic human limitations in multitasking ability appear to be shared by all generations"). 
remains whether greater multitasking ability necessarily means greater overall cognitive functioning. ${ }^{232}$

\section{Future Implications}

The same question is being asked generally about neurological changes from ICT exposure. If the Digital Generation's brains are changing because of their ICT use, what are the implications? One camp views ICT exposure as having largely negative implications for the Digital Generation. ICTs have been blamed for creating a generation with a short attention $\operatorname{span}^{233}$ a craving for instant gratification, ${ }^{234}$ impaired social skills, ${ }^{235}$ increased narcissism, ${ }^{236}$ and a reduced ability to empathize. ${ }^{237}$ At the other end of the spectrum, the Digital Generation have been credited with enhanced ability to process, categorize, and absorb information quickly, ${ }^{238}$ superior capacity for some forms of attention, ${ }^{239}$ and increased intelligence. ${ }^{240}$ They have been called both "The Dumbest Generation" 241 and "the smartest generation ever." draw from this? Probably the most we can say with any degree of confidence is that ICT exposure is likely changing the Digital Generation's brains, though we cannot be sure whether this is a positive or negative development, or even whether it will be a long-lasting one. Their brains may reflect undesirable tradeoffs in cognitive functioning, ${ }^{243}$ or they may be better adapted to function

${ }^{232}$ As Jordan Grafman, the head of the National Institute of Neurological Disorders and Stroke's cognitive neuroscience section, frames it:

"If you're multitasking a lot as a kid, the likelihood is that your brain will develop around your adaptive behavior." ... "Would it change the brain to optimize multitasking? The answer might be yes." ... "Does optimizing for multitasking result in better functioning - that is, creativity, inventiveness, productiveness? The answer is, in more cases than not, no."

TAPSCOTT, supra note 134, at 108 (quoting Jordan Grafman).

233 SMALL \& VORGAN, supra note 81 , at 32.

${ }^{234} I d$. at 24.

${ }^{235} I d$. at 2, 21, 116.

${ }^{236}$ ROSEN, IDISORDER, supra note 111, at 18-19.

237 Id. at 126; SMALL \& VORGAN, supra note 81, at 30, 32.

${ }^{238}$ SMALl \& VORGAN, supra note 81, at 21; TAPSCOTT, supra note 134 , at 30.

239 SMALl \& Vorgan, supra note 81 , at 20-21.

240 TAPSCOTT, supra note 134, at 30.

241 Mark Bauerlein, The Dumbest Generation: How the Digital Age Stupefies Young Americans AND Jeopardizes Our Future [OR, Don't Trust ANyone Under 30] 26 (2008) (citing Philip Roth, The Human Stain (2000) as the source of the appellation, "The Dumbest Generation") (describing the Digital Generation as "a portrait of vigorous, indiscriminate ignorance").

242 TAPSCOTT, supra note 134 , at 30.

243 As Patricia Greenfield, a psychologist who teaches at UCLA, writes:

Every medium has its strengths and weaknesses; every medium develops some cognitive skills at the expense of others. Although the visual capabilities of television, video games, and the Internet may develop impressive visual intelligence, the cost seems to be deep processing: mindful knowledge acquisition, inductive analysis, critical thinking, imagination, and reflection. 
in today's ICT-saturated society, or they may simply be different- - neither better nor worse than those that have come before them. ${ }^{244}$

\section{B. ICT Exposure May Be Leading to a Loss of Attentional Control}

Though the long-term neurological effects of ICT exposure on the Digital Generation is still a matter for debate, research suggests that this exposure is currently contributing to the erosion of their attentional control. In professor and research psychologist Dr. Larry Rosen's blunt terms, "using our technological devices . . . may be permanently ruining our focused attention." ${ }^{245}$ Loss of attentional control is worrisome because of how crucial focused attention is to the ability to function coherently ${ }^{246}$ and to engage in higher-order cognitive operations. ${ }^{247}$ Three significant factors linking ICT exposure to this erosion are (1) stimulus-driven distractions, (2) cognitive overload, and (3) stress and anxiety.

\section{Stimulus-Driven Distractions}

ICTs are distracting - purposefully so. The Digital Generation program their devices to interrupt them and let them know when something potentially of interest is happening - to ding or ring or flash or buzz or pop up (or sometimes all of these) when a new call or message comes in, or when it is time for an appointment, or when a friend has just posted new pictures on Facebook. These message indicators undermine the Digital Generation's top-down attentional control mechanisms because they are designed to trigger their bottom-up processes. The flashes and dings and pop-up messages are novel or sudden changes in the Digital Generation's environment - the very things that their bottom-up attentional control systems are primed to be alert to. When the Digital Generation are engaged in a task and their ICTs produce an auditory or visual notification, the battle between their top-down and bottom-up control systems ensues. This is not to say that the bottom-up systems always win, ${ }^{248}$ but they frequently do.

Patricia M. Greenfield, Technology and Informal Education: What Is Taught, What Is Learned, SCIENCE, Jan. 2, 2009, at 69, 71 (2009) (endnote omitted).

244 See Andrew E. Taslitz, Information Overload, Multi-Tasking, and the Socially Networked Jury: Why Prosecutors Should Approach the Media Gingerly, 37 J. LEGAL PROF. 89, 113 (2012) ("[T] he new net-brain is neither better nor worse than its predecessors . . ..").

245 ROSEN, IDISORDER, supra note 111, at 106.

246 See supra text accompanying notes 135-40.

247 See supra text accompanying notes 141-62.

248 The likelihood that their bottom-up systems will prevail varies based on the types of interruptions and the nature of the people confronted with the disruptions. See Jacobson, supra note 15 , at $448-50$. Auditory distractions and distractions that are frequent or complex are more likely to be interruptive. Id. at 448-49. That said, certain noises or types of music might distract some people more than others. Id. at 449-50. For instance, a Manhattanite may not even notice the sounds of sirens and delivery trucks outside her window while she is 
As a result, the Digital Generation shift focus from their original task to the interrupting stimulus as they consult their devices to determine the reason for the notification. Inevitably, this interrupts their ongoing cognitive activity ${ }^{249}$ and impairs their memory and information processing. ${ }^{250}$ The more complex the interrupted mental activity is, the more impairment the distraction causes. ${ }^{251}$ One might argue that the gravity of this situation is overblown, that hearing an innocuous little text message ding is hardly comparable to being surprised by a fire alarm, that the extent to which ICTs engage the Digital Generation's bottom-up attentional control processes is simply "not a big deal." And while it is surely true that there are different degrees of distractors, it is also true that anything that engages the Digital Generation's bottom-up mechanisms imposes an extra burden on their top-down mechanisms and makes it harder for them to exercise top-down attentional control.

\section{Cognitive Overload}

The second way that ICTs diminish the Digital Generation's attentional control is by contributing to their cognitive overload. The information entering our working memory at any given time is called cognitive load. ${ }^{252}$ Cognitive overload occurs when our brains are "receiving too much information" 253 and our working memory is unable to handle the amount of information being taken $\mathrm{in}^{254}$-in other words, when the amount of processing required for a task exceeds our cognitive capacity available for processing. ${ }^{255}$ When our working memory is overloaded, there is no room left in it to retain information about what we are trying to concentrate on, so we are more likely to become distracted and lose focus. ${ }^{256}$ Our working memory becomes unable to transfer new information into our long-term memory or to make connections between the new information and what is already in our long-term memory. ${ }^{257}$ It also becomes more difficult for us to determine what is relevant and to filter out irrelevant information. ${ }^{258}$ We become restless and our attention span is reduced. ${ }^{259}$ Our

studying, whereas her mother visiting from suburban Florida might be jolted from her book by every such noise.

${ }^{249}$ Maurizio Corbetta \& Gordon L. Shulman, Control of Goal-Directed and StimulusDriven Attention in the Brain, 3 NATURE Revs. NeUROsCIENCE 201, 208 (2002).

250 Jacobson, supra note 15, at 432-33.

251 CARR, supra note 65, at 132.

252 Id. at 125 (quotation marks omitted).

253 PALFREY \& GASSER, supra note 168, at 190 (quotation marks omitted).

254 CARR, supra note 65, at 125.

255 Richard E. Mayer \& Roxana Moreno, Nine Ways to Reduce Cognitive Load in Multimedia Learning, 38 Educ. Psychologist 43, 45 (2003).

${ }^{256}$ CARR, supra note 65, at 125.

257 Id.

258 Id.

${ }^{259}$ PALFREY \& GASSER, supra note 168, at 190. 
reading skills and ability to learn suffer. ${ }^{260}$ In addition to its impact on our attentional control, cognitive overload can also have primary and secondary physical effects, including increased heart rate and blood cholesterol, migraines, decreased appetite, insomnia, and suppressed immune function. ${ }^{261}$

ICTs - particularly those involving the Internet - increase the possibility of this overload, ${ }^{262}$ and the Digital Generation's heavy usage of ICTs and the Internet greatly improves the chances that they will experience it. ICT usage contributes to cognitive overload primarily because it involves "extraneous problem-solving" and "divided attention." "263 A task that involves extraneous problem-solving is one that is both mentally demanding and superfluous to the primary cognitive task, such as trying to complete a crossword puzzle while reading a book. ${ }^{264}$ One significant way in which ICTs add extraneous problemsolving tasks to what the Digital Generation are doing is by making frequent use of hypertext - text containing hyperlinks - on a screen. ${ }^{265}$ Hypertext permits ICT users to move rapidly from information on the screen to other, related information located elsewhere. In the 1980s, many educators believed that hypertext would significantly enhance learning and strengthen students' critical thinking skills by allowing them to explore multiple viewpoints easily and to make intellectual connections between otherwise unrelated texts. ${ }^{266}$ But the process of evaluating hyperlinks and navigating through them is itself a mental problem-solving task, one that is extraneous to the act of reading. ${ }^{267}$ Figuring out which links are worth clicking on and which should be ignored increases the users' cognitive load and decreases their ability to understand and retain what they are reading. ${ }^{268}$ Several studies show that even experienced computer users are distracted when they try to read documents that are online or that contain hypertext. ${ }^{269}$ Though experimental results are not uniform, the preponderance of research evidence suggests that people understand more, remember more, and learn more when they read linear text rather than hypertext. ${ }^{270}$ Rather

260 CARR, supra note 65, at 125; PALFREY \& GASSER, supra note 168, at 190.

261 PALFREY \& GASSER, supra note 168, at 190.

${ }^{262} I d$.

263 CARR, supra note 65, at 125 (internal quotation omitted).

264 See id. at 126.

265 See id.

${ }^{266}$ Id.

267 Id.

${ }^{268} I d$.

269 ROSEN, IDISORDER, supra note 111, at 106. Interestingly, research also demonstrates that if ICT users know they will be able to access information on the Internet or on their computer later, they will not remember the information as well as if they are told it will not be available in the future. Id. at 202.

270 See CARR, supra note 65, at 127-29 (summarizing experiments suggesting hypertext interferes with learning). Part of this may be due to the manner in which readers of online material read. A 2006 eye tracking study by the Nielsen Norman Group recorded how 232 users looked at thousands of web pages and found the dominant reading pattern resembled the letter "F": Readers read horizontally all the way across the first few lines, then their eyes 
than enhance learning, combining a primary reading task with extraneous ICT usage can impede learning. In this way, the Digital Generation's tendency to read on screens instead of in print ${ }^{271}$ may be contributing to their cognitive overload.

ICTs also contribute to the Digital Generation's cognitive overload by dividing their attention. ICTs put them in a state of "continuous partial attention," in which they are "continually staying busy - keeping tabs on everything while never truly focusing on anything.,"272 In this way, ICTs "seize[] [their] attention only to scatter it." ${ }^{273}$ ICTs divide the Digital Generation's attention not only by distracting them with message indicators, but also by delivering information through "hypermedia" - the Internet's combination of hypertext and multimedia. ${ }^{274}$ Many educators initially thought that hypermedia would deepen comprehension and strengthen learning because it presents information in multiple forms (audio, video, text, etc.). ${ }^{275}$ Instead, hypermedia seems to divide attention in a way that strains cognitive abilities, decreases learning, and weakens understanding. ${ }^{276}$

To understand how hypermedia divides attention and contributes to cognitive overload, consider Rodney, a teenage aspiring chef. Rodney props up his tablet on the kitchen counter and pulls up a recipe for traditional lasagne Bolognese on an online recipe site, intending to follow the recipe on his tablet like he would a recipe from a printed cookbook. The first sentence of the recipe's preamble tells Rodney that this is a traditional Italian recipe from Bologna. The word "Bologna" is hypertext-he taps the hyperlink and finds himself reading a web encyclopedia page about the city of Bologna. He turns back to the recipe

dropped down the page and read about halfway across a few lines, and then finally scanned down the page's left side in a vertical movement. Jakob Nielsen, F-Shaped Pattern for Reading Web Content, Nielsen Norman Group (Apr. 17, 2006), http://www.nngroup.com/articles/f-shaped-pattern-reading-web-content/.

271 See supra note 177 and accompanying text.

272 SMall \& Vorgan, supra note 81, at 18. Carr agrees: "The Net's cacophony of stimuli short-circuits both conscious and unconscious thought, preventing our minds from thinking either deeply or creatively. Our brains turn into simple signal-processing units, quickly shepherding information into consciousness and then back out again." CARR, supra note 65, at 119.

273 CARR, supra note 65, at 118. Carr argues that the Internet "returns us to our native state of bottom-up distractedness, while presenting us with far more distractions than our ancestors ever had to contend with." Id.

${ }^{274} I d$. at 129 (quotation marks omitted). Hypermedia is also referred to as "rich media." Id. (quotation marks omitted).

${ }^{275} I d$.

276 Id. Presenting information in more than one form does not always reduce understanding. It is possible for carefully designed presentations to combine audio and visual instructions or explanations in a way that actually enhances learning. Id. at 131. This process of presenting information in different processing channels is known as "off-loading." Mayer \& Moreno, supra note 255, at 46 . But because the Internet was not built to optimize learning, it is rare to find information presented in these optimal circumstances. See CARR, supra note 65, at 131. Instead, it presents information in a "concentration-fragmenting mishmash." Id. 
page and reads the next sentence of the preamble, which says lasagne Bolognese combines alternating layers of pasta, long-cooked ragú Bolognese, Parmigiano Reggiano, and besciamella. Rodney clicks on besciamella and learns from the newly opened web encyclopedia page that it is a white sauce made with a roux of butter and flour cooked in milk, known more commonly by its French name, béchamel. Now he turns back to the recipe page, where a video featuring a famous television chef preparing lasagne Bolognese has automatically started playing. Rodney shifts his attention back and forth from the stove to the text of the recipe while cooking, all the while half-listening to the TV chef talk about the ideal ratio of ragú to besciamella, and occasionally glancing at the video to see the chef demonstrate how to tell whether the roux has achieved proper thickness and what the finished lasagne should look like. Would it be any surprise if Rodney missed a step in the recipe or left out an ingredient or two in the face of the processing demands from the flood of information spewing forth from the tablet?

Both message indicators ${ }^{277}$ and hypermedia ${ }^{278}$ also divide the Digital Generation's attention by interrupting what they are doing, thereby encouraging them to multitask. Each time the Digital Generation shift attention to check a message (or, in Rodney's case, to watch the video accompanying the recipe he is making), their brains are forced to reorient themselves. ${ }^{279}$ This process adds substantially to their cognitive load and further taxes their limited mental resources ${ }^{280}$ potentially leading to cognitive overload. Like all forms of multitasking, this comes with costs - including for the Digital Generation's attentional control. ${ }^{281}$

\section{Stress and Anxiety}

The third way that ICTs diminish the Digital Generation's attentional control is by contributing to their stress ${ }^{282}$ and anxiety, which have adverse effects

277 See supra text accompanying notes 248-51.

278 See CARR, supra note 65, at 131.

$279 I d$. at 133 .

$280 \mathrm{Id}$.

281 See id.

282 Stress is rarely defined in scientific literature; the term tends to be used in vague and inconsistent ways. Margaret E. Kemeny, The Psychobiology of Stress, 12 CURRENT DiRECTIONS PSYCHOL. SCI. 124, 124 (2003). It is used both in the sense of circumstances that threaten our physical or psychological wellbeing (i.e., stressors) and in the sense of our negative psychological response to such circumstances (i.e., distress). Id. While stress is often discussed in negative terms, it enables us to cope in circumstances that call for vigilance, action, or heightened arousal, and is therefore both useful and adaptive. Kenneth J. Thiel \& Michael N. Dretsch, The Basics of the Stress Response: A Historical Context and Introduction, in The Handbook of Stress: Neuropsychological EfFects on the Brain 3, 4 (Cheryl D. Conrad ed., 2011). The body's response to stress serves a protective function because it is designed to restore balance. Id. Though the experience of excessive stress over time can have negative health and behavioral consequences, an utter lack of stress would leave us unable to respond adequately to internal and external demands. $I d$. 
on their attention and their capacity to control it. ${ }^{283}$ ICT exposure is connected with stress and anxiety in three primary ways. First, ICTs' visual and auditory message indicators are stressful because they are interruptive. Second, the state of continuous partial attention that ICTs put the Digital Generation in is a form of inherently stressful hyper-alertness. Third, ICTs create a stressful and anxiety-inducing culture in which instantaneous communication is both possible and expected.

Before exploring the role ICT exposure plays in contributing to the Digital Generation's stress and anxiety, it is helpful first to understand what happens to us when we encounter stress. Short-term stress is associated with high levels of autonomic arousal. ${ }^{284}$ The autonomic nervous system (the "ANS") controls our bodies' visceral functions, such as the beating of our hearts, the smooth muscles of our digestive organs, and the activation of certain glands. ${ }^{285}$ ANS arousal sends the signal throughout our bodies that "[s]omething is going on, something needs to be done." 286 A subsystem of the ANS, the sympathetic nervous system (the "SNS"), then mobilizes the functions that help our bodies react to threats and danger, producing what is known as the flight-or-fight response. ${ }^{287}$

The flight-or-fight response is an innate, involuntary physiological response that we and other animals display in the face of acute or chronic stressful situations. ${ }^{288}$ It heightens our alertness and prepares us to react quickly by increasing the blood supply to our muscles and brain, increasing our heart rate, decreasing our digestive activity, widening our pupils, increasing our metabolism, and raising our blood sugar content. ${ }^{289}$ These responses are aimed at achieving physiological equilibrium, or homeostasis, meaning that they attempt to restore our bodies' internal environment to "normal" levels in response to external events. $^{290}$

283 See Jacobson, supra note 15, at 442-44.

${ }^{284}$ MANDLER, supra note 130, at 249-50.

$285 I d$. at 134.

286 Id. at 137 (quotation marks omitted).

287 Id. at 134.

288 Herbert Benson with Miriam Z. Klipper, The Relaxation Response 54 (updated \& expanded ed. 2000). While this is generally the case, our bodies' physiological response to stress may vary depending upon factors such as the type and duration of the stressor. See Thiel \& Dretsch, supra note 282, at 5. Also, both sexes experience similar hormonal reactions to stress, but it has been suggested that human females may have developed a stress reaction better suited to protecting their offspring than the flight-or-fight response is, known as the "tend-and-befriend" response. See Shelley E. Taylor et al., Biobehavioral Responses to Stress in Females: Tend-and-Befriend, Not Fight-or-Flight, 107 PsychOL. ReV. 411, 412 13, 421-22 (2000) (describing the tend-and-befriend response).

289 MANDLER, supra note 130, at 134-35.

290 MANDLER, supra note 130, at 118, 139 (quotation marks omitted); Thiel \& Dretsch, supra note 282, at 7. Mandler suggests that we both adjust our internal environments in response to external events, and that we also adjust the external environment so that our internal environments are restored to their normal resting points. MANDLER, supra note 130, at 139. 
ANS arousal also sends signals to our attentional networks that they need to take in more information, either about the cause of the arousal or about our present condition and the present state of our environment. ${ }^{291}$ In this way, any events that trigger ANS activity also trigger attentional activity. ${ }^{292}$ However, intense arousal diminishes the amount of information from the environment or from memory that we can use effectively because this intense arousal floods our attentional mechanisms. ${ }^{293}$ The number of stimuli that can share our conscious attention becomes more limited as the arousal increases. ${ }^{294}$ Our attentional resources are allocated to detecting and processing the stressor, while information nonessential to that task is blocked out. ${ }^{295}$ If ANS arousal continues for the long term, it can lead to numerous undesirable consequences, such as decreases in our cognitive efficiency, negative effects on our heart and visceral functions, and suppression of our immune system. ${ }^{296}$

Interruptions appear to cause autonomic arousal ${ }^{297}$ and are an important type of stressor. ${ }^{298}$ Research shows that frequent interruptions make us tense and anxious. ${ }^{299}$ When we are interrupted and ANS activity is triggered, our cognitive resources are diverted from whatever we are doing and are redirected to seeking out information about the interruption. ${ }^{300}$ It requires conscious effort for us to try to cope with the interruption, and this effort demands our attentional resources. ${ }^{301}$ If the interruption produces a high level of autonomic activity, our attention narrows and our capacity for pursuing cognitive activities and thought processes unrelated to the interruption is reduced. ${ }^{302}$ Our other cognitive functions suffer. ${ }^{303}$ This redirection of cognitive resources can be beneficial if the interruption is very important and our current task less so, but

291 MANDLER, supra note 130, at 118. This information-seeking behavior may help us to identify and evaluate threats. Id. at 141; Thiel \& Dretsch, supra note 282, at 8.

292 MANDLER, supra note 130, at 139.

293 Id. at 141.

294 Id. at 254.

295 Thiel \& Dretsch, supra note 282, at 14; Phillip R. Zoladz et al., Neurobiological Basis of the Complex Effects of Stress on Memory and Synaptic Plasticity, in THE HANDBOOK OF STRESS, supra note 282, at 157, 158.

296 MANDLER, supra note 130, at 264.

${ }^{297} I d$. at 171. This makes sense from an evolutionary perspective because if the interruption is something dangerous, engagement of the flight-or-fight functions and an increase in information-seeking behavior could have survival value. Id. at 172 .

298 Id. at 252-53; see also BENSON WITH KLIPPER, supra note 288, at 86 (circumstances that involve "uncertainty in the immediate environment" are stressful); S.J. Lupien et al., The Effects of Stress and Stress Hormones on Human Cognition: Implications for the Field of Brain and Cognition, 65 Brain \& Cognition 209, 210 (2007) (a situation will induce a stress response if it is "novel, and/or unpredictable, and/or the individual [has] the feeling that he/she does not have control over the situation" (emphasis omitted)).

299 CARR, supra note 65, at 132.

${ }^{300}$ MANDLER, supra note 130, at 251-53.

$301 \mathrm{Id}$. at 253.

${ }^{302}$ See id. at 251, 254-55.

303 Id. at 251. 
more problematic if the interruption is trivial and it diverts our cognitive resources from a more important task. ${ }^{304}$

To illustrate, imagine co-workers carpooling to work. As they are chatting, a truck swerves into their car's lane. The driver stops talking mid-sentence and devotes her cognitive resources to avoiding the truck. In this case, the primary task (holding a conversation) is less important than the interrupting stressor (the swerving truck), and the diversion of attentional resources is beneficial. Now imagine it is snowing and the driver is focused intently on steering the car through the snow. One of the backseat passengers suddenly sneezes loudly, scaring the driver, who then swerves into the neighboring lane. In that case, the primary task (navigating the slippery roads) is more important than the interrupting stressor (the loud sneeze), and the diversion of attention to the sneeze is harmful.

With this background, it is easy to see how ICTs contribute to the Digital Generation's stress and anxiety by producing auditory and visual alerts that trigger autonomic arousal and the related stress responses. ICTs produce these alerts (i.e., interruptions) at an alarming rate-at least twelve alerts per hour, according to one estimate. ${ }^{305}$ In reaction to the stress of these alerts, the Digital Generation's brains go into "survival mode" and begin to panic. ${ }^{306}$ As their bottom-up attentional control processes start to overwhelm their top-down processes and their stress and anxiety build, their attention is diverted and redirected to the interruptions. ${ }^{307}$ When the brain enters this panicked state, "the frontal lobes lose their sophistication, intelligence dims, and the brain is unable to think clearly." 308 The Digital Generation lose cognitive efficiency and effectiveness as they lose their attentional control.

For instance, imagine Marilyn, a Digital Generation intern sitting at her desk in front of her computer, reading a company memo on the screen. A popup window appears on the screen, notifying her of a new email from her supervisor. Marilyn's pulse quickens and her breath grows slightly more rapid as she experiences autonomic arousal. Her attention turns toward the pop-up and she momentarily forgets about the memo and the paragraph she just read as she wonders, Why is a window popping up? Who is emailing me? It's my supervisor-am I in trouble? Once she clicks on the pop-up, reads the email, and determines it is non-threatening (just providing the location for the upcoming "welcome interns" party), Marilyn's autonomic arousal decreases; her heart rate and breathing slow. She regains attentional control and can refocus on the memo. Now imagine how this arousal and response could intensify if instead of one email disrupting her, Marilyn received multiple emails from different ac-

304 See id. at 256.

305 See CARR, supra note 65, at 132 (estimating that the Internet interrupts an average person with at least twelve alerts per hour, and possibly many more).

306 See Jacobson, supra note 15 , at 433.

307 Id. at $442-43$.

$308 I d$. at 433. 
counts at the same time that her fellow intern called her office line and her boyfriend sent a flurry of text messages about their weekend plans with his parents. Intense arousal - and the accompanying stress responses - would surely ensue. Loss of attentional control and cognitive impairments would be the price.

Another way that ICT exposure contributes to the Digital Generation's stress and anxiety is by putting them in the state of continuous partial attention, ${ }^{309}$ which is a state of inherently stressful hyper-alertness. In this condition of constantly divided attention, the Digital Generation are on alert for new information and new contact at all times. ${ }^{310}$ They have no time for thoughtful decision making or deep reflection. ${ }^{311}$ As they become used to being constantly on alert, the heightened state of stress begins to feel normal, even desirable. ${ }^{312}$ This condition can be acculturating and potentially even addictive. ${ }^{313}$ But because their brains were not meant to maintain this heightened monitoring state for extended time periods, trying to do so can cause a type of stress that Small labels "techno-brain burnout." 314 In the face of this stress, the Digital Generation's brains signal their adrenal glands to secrete the hormones cortisol and adrenaline, which in the short term boost their energy levels and memory, but in the long term can impair their cognition, lead to depression, and alter their neural circuitry in the brain regions responsible for controlling mood and thought. ${ }^{315}$ Feelings of fatigue, irritability, and distraction may ensue. ${ }^{316}$ When the Digital Generation's brains remain in this state of divided attention and hyper-alertness for too long, they "gradually lose[] [their] capacity to attend fully and thoroughly to anything."

Finally, ICT exposure contributes to the Digital Generation's stress and anxiety by creating a culture in which instantaneous communication and con-

309 See supra text accompanying note 272.

310 SMALL \& VORGAN, supra note 81, at 18.

311 Id.

312 Id.

313 PALFREY \& GASSER, supra note 168, at 187 (discussing Internet addiction as an extreme form of overload); ROSEN, IDISORDER, supra note 111, at 62-71 (discussing risk factors for and characteristics of Internet addiction and addictive behaviors associated with ICT use); Jacobson, supra note 15, at 433-34 (stating that overstimulation "is certainly acculturating" and "may even be addictive"); see SMALl \& VORGAN, supra note 81, at 48-62 (describing technology addiction, including neurochemical and other causes, and proposed diagnostic criteria). Though many authors refer to Internet "addiction," the most recent version of the Diagnostic and Statistical Manual of Mental Disorders (DSM-5) published by the American Psychiatric Association does not include Internet usage as a disorder. DSM-5 lists "Internet Gaming Disorder" as a condition warranting more research, though "the criteria for this condition are limited to Internet gaming and do not include general use of the Internet, online gambling, or social media." Internet Gaming Disorder, AM. PSYCHIATRIC Ass'N (May 2013), http://www.dsm5.org/Documents/Internet\%20Gaming\%20Disorder\%20Fact\%20Sheet.pdf.

314 SMALL \& VORGAN, supra note 81, at 19.

${ }^{315} I d$.

316 Id.

317 Edward M. Hallowell, Overloaded Circuits: Why Smart People Underperform, HARV. Bus. ReV., Jan. 2005, at 3. 
stant connectivity are possible - and expected. In the days before the telephone, people might write their friends a letter and not expect a reply for days or even weeks. Today, ICTs make it possible to communicate with people at a distance as rapidly as with those in the same room. While this is wonderful progress from a communications standpoint, this technological capability is also problematic insofar as it has led to societal expectations of instant responses. ${ }^{318}$ Modern message senders expect that the recipients will answer immediately and may grow anxious, frustrated, or angry in the face of unresponsiveness. ${ }^{319}$ In turn, message receivers feel the pressure of these expectations and may feel overwhelmed by the demands of keeping up with their digital lives:

The pressure of living in an instantaneous environment can overwhelm some Net Geners. They know others are expecting an immediate response from them, and many experience feelings of saturation, craziness, and never having a moment of peace. Some wish they could disconnect by turning off their cell phones and logging off their computer, but they're reluctant to do this because they fear missing an important message and don't want to feel detached from their social environment. $^{320}$

As a result, those on both sides of the screen may experience heightened arousal, feelings of stress and anxiety, and the associated cognitive and attentional decrements.

\section{ICT Exposure May Be Changing the Definition of "Paying Attention"}

Along with its neurological effects and impact on the Digital Generation's attentional control, ICT exposure is also causing significant societal changes, insofar as it is changing the Digital Generation's definition of what it means to be "paying attention." Elder generations might consider multitasking with a device in the midst of a face-to-face conversation to be rude, but the Digital Generation are starting to find it to be de rigeuer. ${ }^{321}$ Digital distraction is the new normal. ${ }^{322}$ Real-life examples of this are rampant. Movie theaters are aglow

318 Alina Tugend, What to Think About Before You Hit 'Send', N.Y. TimES, Apr. 21, 2012, at B5 (stating that most people expect to get a response to electronic communication "almost instantaneously"); Alina Tugend, The Anxiety of the Unanswered E-Mail, N.Y. TIMES, Apr. 20, 2013, at B5 [hereinafter Tugend, Unanswered E-Mail] (describing feelings of frustration, anger, and discomfort with unanswered messages).

319 See Tugend, Unanswered E-Mail, supra note 318.

320 TAPSCOTT, supra note 134, at 94.

321 In the study by Rosen's team cited supra note 226, members of the "Net Generation" (born after 1978) "were more likely than ... other generations to multitask while talking face-to-face with other people," particularly by listening to music, "despite the apparent rudeness of the act." ROSEN, REWIRED, supra note 110 , at 81 ; see Carrier et al., supra note 226, at 484, 485-87 (defining study participants with birth years after 1978 as "Net Geners" or the "Net Generation" and discussing study results).

322 To the extent that behavioral norms are shaped by observing peers' behaviors, the Digital Generation are learning about the acceptability of ICT use from observing their peers. For instance, as one law professor notes, using laptops in class for non-class purposes is contagious. If students see a room full of their peers surfing the Internet during class, they learn 
with the light of smartphone screens as teens text throughout the film. Bars and restaurants are abuzz with pictures being taken (and uploaded to Facebook and Instagram) as Digital Generation diners share their dining experience with absent friends. Earbuds and screens block family conversations during car rides as children listen to music and send messages to friends throughout the trip. For members of the older generations, this can be maddening. ${ }^{323}$ Why are the Digital Generation living their lives through a screen? Why aren't they paying attention to what is going on around them? But members of the Digital Generation know that they are paying attention - they are simply operating under a different definition of what that means. For them, divided attention is both expected and acceptable.

Perhaps one of the primary drivers of this changing definition is that the Digital Generation find digital technology unremarkable - simply part of the landscape, no more otherworldly than an airplane and no more magical than a microwave. ${ }^{324}$ They are not amazed when they see a two-year-old playing Angry Birds ${ }^{325}$ on her dad's tablet. They do not see why they should not surf the Internet on their iPads while they watch TV. And they do not expect that their friends will ignore their incoming text messages while they are talking to them. The Digital Generation are acculturated to digital technology, and as a result of this acculturation, the concept of paying attention means something different to them.

\section{What Should Legal Professionals Do AbOUt IT?}

Scholars and researchers in many different fields have noted the attentional challenges that ICT users face and have proposed a number of possible tactics for coping with these challenges. This Part examines three tactics that have

that it is acceptable to surf the Internet during class. Jeff Sovern, Law Student Laptop Use During Class for Non-Class Purposes: Temptation v. Incentives, 51 U. LouIsvilLe L. Rev. 483, 488 (2013). The converse is also true: If students see that most of their peers are focused on the class material, they may conclude that it is unacceptable to let their attention wander to non-class topics. $I d$.

323 It can also be acculturating. Looking around those movie theaters, bars, and restaurants, it is clear that elder generations are taking lessons from the Digital Generation about the acceptability of using ICTs in public.

324 Tapscott puts it well:

Technology has been completely transparent to the Net Gen. ...

Net Gen kids growing up looked at computers in the same way boomers look at TV. Boomers don't marvel at the technology or wonder how television transfers video and audio through thin air, we simply watch the screen. TV is a fact of life. So it has been with Net Geners and computers. And as technology relentlessly advances each month, young people just breathe it in, like improvements in the atmosphere.

TAPSCOTT, supra note 134, at 19.

325 Angry Birds is a video game franchise created by Finnish video game developer Rovio Entertainment, with games available to play on the iPhone, iPad, Android, Windows Phone, and Kindle, among other platforms. See generally ANGRY BIRDS, http://www.angrybirds.com/ (last visited Mar. 7, 2015). 
been suggested for improving attention in legal professionals, namely (1) shutting off the ICTs entirely, (2) taking "technology breaks," and (3) learning to meditate. After describing each suggestion, this Part analyzes its strengths and weaknesses, both for current legal professionals and for the Digital Generation lawyers and law students of the future.

\section{A. Shut Off ICTs and Avoid Multitasking}

The most basic of these suggestions is simply to turn off the ICTs or otherwise arrange their settings so as to minimize their ability to distract-i.e., silence ringers, set the email program not to send a visible or audible notification each time a message comes in, and generally put ICTs out of view so they are not a visible distraction. ${ }^{326}$ This advice's goal is to prevent multitasking altogether. ${ }^{327}$ The concept is simple: Legal professionals are incapable of resisting the temptation of ICTs' distractions, so they must eliminate ICTs to give themselves a fighting chance to focus. This suggestion provides the foundation for retreats such as Camp Grounded, an adults-only summer camp that forbids the use of ICTs. ${ }^{328}$

The advice to turn off ICTs and avoid multitasking altogether makes intuitive sense - if legal professionals are powerless to resist ICTs' allure when they are on, their only hope is to turn them off. And since legal professionals are presumably poor multitaskers, ${ }^{329}$ they should avoid multitasking altogether. This suggestion resonates from a brain science perspective as well: Legal professionals' top-down attentional control mechanisms are less likely to lose out to their bottom-up mechanisms if they eliminate some of the stimuli that are likely to appeal to their bottom-up mechanisms. Much like advice to avoid fatand sugar-laden desserts will probably aid in a quest to shave off a few pounds, the suggestion to put aside technology for a few hours or days or weeks at a time - if followed - will probably be effective in improving legal professionals' attention by reducing bottom-up distractions and the stress and anxiety associated with multitasking.

The trouble with this suggestion, of course, lies largely in that "if." Like passing up a slice of cake at an office birthday party, turning off ICTs and disa-

326 See SMALl \& Vorgan, supra note 81, at 141 (minimize distractions by keeping ICTs out of view and by closing email); Karen Erger, Mono-Mania: The Case Against "Multitasking”, 94 ILL. B.J. 206, 207 (2006) ("Turn off the phone, stop checking email, close your door."); Jacobson, supra note 15, at 452 (eliminate auditory and visual announcements of new email and turn off auditory and visual prompts on the phone).

327 See, e.g., Erger, supra note 326, at 206 (advocating "'monotasking' rather than multitasking").

328 See Leslie Gordon, Technology-Free Zone: Summer Camp Offers Adults a Detox from Their Devices, A.B.A. J., Oct. 2013, at 9, 9. Camp Grounded is organized by Digital Detox, a group that runs ICT-free meet-ups for those wishing to take a break from technology. Id. Camp Grounded targets lawyers and other professionals who are constantly on call, such as doctors, accountants, and CEOs. See id. at 10.

329 See supra text accompanying notes 108-11, 116-28. 
bling their notifications requires discipline and willpower. And, like dieters trying to eliminate sweets, legal professionals are unlikely to succeed with this advice, for four primary reasons. First, they will have to overcome their own message-checking habits and the temptation of the ICTs, which anyone who has ever received a "phantom vibration" "330 knows is no easy task. As Rosen puts it: "All of this is fine, but impossible for most people. Face it: We are connected and we have created a cyber world that requires us to be connected." $" 331$ Second, studies show that it is difficult to do tasks well when we are tempted by something. ${ }^{332}$ This suggests that legal professionals who are trying to resist interacting with their ICTs may have trouble completing their work efficiently and accurately. Third, attorneys who turn off their message indicators will likely also encounter client-relations issues, as clients have come to expect that their lawyers will be nearly instantly available. Clients may view a delay of several hours as a sign of overall unresponsiveness, and they may seek out a new lawyer who is more attached to his ICTs. And fourth, shutting off ICTs is not a panacea that guarantees perfect attention. An absence of message indicators does not ensure a similar absence of daydreaming, trips to the vending machines, and other forms of self-interruptions. ${ }^{333}$

These obstacles will only be exacerbated for Digital Generation lawyers and law students. As discussed above, ICTs are ubiquitous in the Digital Generation's lives. ${ }^{334}$ Moreover, multitasking may be more ingrained in them than in their elders. ${ }^{335}$ It stands to reason that breaking the ICT habit will be even

330 See RoSEN, IDISORDER, supra note 111, at 54. In conversations with hospital medical staff, researchers at Baystate Medical Center in Massachusetts found that approximately 70 percent of the staff had experienced phantom vibrations from a pager or cell phone. Id. at 55. More frequent phone users were more prone to reporting experiencing phantom rings. $I d$.; see also Gordon, supra note 328, at 10 ("She [a San Francisco-based business lawyer] caught herself reaching for her phone for moments of mindless entertainment, felt phantom vibrations in her pocket and heard ringtones that weren't there.").

331 ROSEN, IDISORDER, supra note 111, at 207.

332 See id. at 209. This phenomenon has been demonstrated in a number of different contexts. When a group of six- to thirteen-year-olds were told not to eat any of the prominently displayed marshmallows, they performed a paper folding task more slowly than if they ate the tempting sweets first and then folded the paper. Id. Similar results were found when dieting adults were told to ignore a nearby snack. Id. And when a group of adults were asked to complete a counting task before they were allowed to watch a funny video that was getting guffaws from another group who were watching it, they made more counting mistakes than if they were allowed to watch the video before the task, "as their brains were undoubtedly distracted by the thought that they were missing out." Id.

333 Similarly, Baker and Brown suggest that there is a difference between simply reducing distractions and actually learning to pay attention. See Baker \& Brown, supra note 60, at 346 (commenting that although some sources offer "useful ideas," such as the "advice to try to minimize distractions," they still provide only "limited guidance on how to learn how to pay attention more successfully").

334 See supra text accompanying notes 171-83.

335 See, e.g., Carrier et al., supra note 226, at 486-87. Rosen's team found significantly more multitasking among the "Net Generation" than the older generations, with each generation multitasking more than the one before it. Id. 
more challenging for Digital Generation legal professionals. Furthermore, research suggests that the Digital Generation do not view their habitual checking of messages as particularly problematic ${ }^{336}$ and that they believe themselves to be proficient multitaskers. ${ }^{337}$ With this in mind, it seems unlikely that the Digital Generation would think it worthwhile to divorce themselves from their ICTs, even if they were able to. It also seems unlikely that Digital Generation clients would be willing to accept their lawyers' digital hiatus. What may be forgivable today in that regard may be a client-relations disaster in the future.

In addition, turning off the ICTs may do more harm than good for the Digital Generation; research tells us that the Digital Generation quickly become anxious when separated from their communication devices. ${ }^{338}$ Rather than reduce the stress born from multitasking, turning off ICTs may result in true anxiety for the Digital Generation. ${ }^{339}$ Even if Digital Generation lawyers and law students can handle shutting off their ICTs, this may not be effective in ending their distractions. Thinking about a text message is just as disruptive from their brains' perspective as actually interrupting what they are doing to check it. ${ }^{340}$ Thus, while disabling the ICTs may prevent external distractions, it may do lit-

336 See Antti Oulasvirta et al., Habits Make Smartphone Use More Pervasive, 16 PERS. \& UbiQuitous COMPUTING 105, 112 (2012). In this small study of high school students who were asked to keep a diary for two weeks after receiving a new smartphone, the participants described their repetitive message checking as "annoying at times" and "distracting from regular activities," though "the majority of the participants did not consider habitual use negatively, even if it was very frequent." $I d$.

337 See Carrier et al., supra note 226, at 487-88. For example, in the study by Rosen's team, 87 percent of "Net Generation" adults reported being able to do two or more typical daily activities - such as being online, playing video games, listening to music, watching TV, eating, reading books, and talking face-to-face-concurrently. ROSEN, IDISORDER, supra note 111, at 106-07. These "Net Generation" adults reported finding 65 percent of the various task combinations "very easy." Id. at 107. In comparison, 67 percent of Baby Boomers reported being able to do more than one task at the same time, and they labeled 23 percent of the task combinations "very easy." Id.

338 See TAPSCOTT, supra note 134, at 46-47 (noting that teens begin to feel real anxiety and a sense of deprivation when they are separated from their phones for more than twenty-four hours).

339 The converse may be true as well— being able to multitask often makes the Digital Generation feel more productive and less stressed. PALFREY \& GASSER, supra note 168, at 205. In light of the research regarding ICTs and stress (see supra notes 305-20 and accompanying text), it would be interesting to know whether the Digital Generation's perceived stress levels while multitasking actually coincide with their degree of autonomic arousal while doing so.

340 See RosEn, IDISORDER, supra note 111, at 209 ("[M] any technological actions are firmly ensconced in the brain and are stealing valuable resources needed for actual attention. In fact, these 'internal' interruptions are just as brain activating as external interruptions, such as responding to a phone call or text message."); see also Rosen et al., supra note 120, at 174 (finding shift in neural activity from the hippocampus (the brain region associated with thought and memory) to the striatum (the brain region associated with habitual learning) during task switching may happen as a result of internally driven task switching, such as thinking about a message, as well as externally driven task switching, such as responding to a message notification). 
tle to stop internal interruptions in Digital Generation legal professionals who wonder what messages they may be missing. ${ }^{341}$

\section{B. Take Technology Breaks}

The second frequently made suggestion of how to improve attention in a world filled with ICTs is to take "technology breaks"- designated times during the day that are reserved for checking messages and otherwise interacting with ICTs. The form of this advice varies. A more restrictive version counsels checking messages once daily, or perhaps a couple of times throughout the day. ${ }^{342}$ A more expansive version recommends taking one- to two-minute technology breaks as frequently as every fifteen minutes, with intense periods of focus in between each break. ${ }^{343}$ This Section focuses on the latter formulation because the anxiety the Digital Generation experience when separated from their ICTs probably makes it a better fit for them.

The technology break suggestion neatly balances the benefits of minimizing distractions and the challenges posed by turning off ICTs altogether. For current legal professionals, limiting ICT usage to specified break times should reduce external distractions similarly to turning off their ICTs altogether. In addition, technology breaks may help to minimize their internal distractions. Knowing that a break is coming makes it easier to focus on the current task for the specified amount of time, so their attention should improve during the time in between breaks. ${ }^{344}$ Even Digital Generation lawyers and law students will probably be able to focus for fifteen minutes, knowing that a technology break awaits them at the end of that time period. ${ }^{345}$

341 This concern about missing out on what others are doing has a name: FOMO, an abbreviation for "fear of missing out," which was added to the Oxford English Dictionary in 2013. See Buzzworthy Words Added to Oxford Dictionaries Online-Squee!, OxFORD DictionARIES ONLINE (Aug. 28, 2013), http://blog.oxforddictionaries.com/2013/08 /new-words-august-2013/; Definition of FOMO in English, OXFORD DiCTIONARIES ONLINE, http://www.oxforddictionaries.com/definition/english/FOMO (last visited Mar. 7, 2015). Oxford defines FOMO as "[a]nxiety that an exciting or interesting event may currently be happening elsewhere, often aroused by posts seen on a social media website." Id. FOMO is not merely a Digital Generation affliction. See Kristi Hedges, Do You Have FOMO: Fear of Missing Out?, ForBes (Mar. 27, 2014, 2:36 PM), http://www.forbes.com/sites /work-in-progress/2014/03/27/do-you-have-fomo-fear-of-missing-out/.

342 E.g., Jacobson, supra note 15 , at 451.

343 Rosen et al., supra note 120, at 174.

344 See SMall \& Vorgan, supra note 81, at 141.

345 Research on the Digital Generation's undergraduate and law school classroom habits casts some doubt on this assertion. One study of student attention involving 186 college chemistry students reported lapses in student attention during class as early as the first thirty seconds of the lecture, with a peak in attention lapses between four and one-half and five and one-half minutes into the lecture. Diane M. Bunce et al., How Long Can Students Pay Attention in Class? A Study of Student Attention Decline Using Clickers, 87 J. CHEMICAL EduC. $1438,1441-42$ (2010). Another study, this one of law student laptop use in class, found that 58 percent of the 387 upper level students observed were distracted (i.e., using laptops for non-class purposes) for at least half of the class period. Sovern, supra note 322, at 492. 
The trouble with the technology break advice is twofold. The first problem is that taking frequent technology breaks would require breaking some of the legal profession's current rules. For instance, it is not yet the norm for professors to permit technology breaks; in fact, many professors - such as myselfaffirmatively ban the use of ICTs during class time. A law student seeking to improve her attention in my class by taking technology breaks every fifteen minutes would be forced to break the rules laid out in the syllabus. Even more problematic, a bar exam taker could find his score nullified and himself being disqualified and reported to his state's character and fitness committee if he tried to use his phone to take a technology break during the exam. ${ }^{346}$ Perhaps no test taker would realistically believe this use of technology breaks to be permissible, and perhaps it should be assumed that law students would only take technology breaks when the rules allow. Both groups certainly could take technology breaks without violating current rules by waiting until scheduled break times (i.e., in between classes or test sessions). But as with anything else, practice makes permanent. If students are trained to take technology breaks every fifteen minutes in order to help them concentrate, it is not unreasonable to think that they would want to make use of this strategy whenever they need aid in concentrating, and that they would have trouble waiting the hour or more between sanctioned breaks.

Lawyers face similar obstacles under current rules. Many courts ban the use of ICTs within the courthouse by persons other than court officials, or similarly restrict the use and/or possession of ICTs. ${ }^{347}$

An attorney in Maryland state court who wished to improve her attention by browsing Pinterest periodically during a trial would be prohibited from doing so by rules requiring that ICTs remain turned off inside the courtroom. ${ }^{348}$

Though this study had some methodological limitations (see id. at 487-91), its findings are nonetheless troubling from the standpoint of student attention. However, it is important to note that neither of these studies involved scheduled technology breaks. Whether scheduling technology breaks would have a positive impact upon law student attention is an area for future research.

346 See, e.g., Misconduct Statement, N.Y. ST. BoARD L. Examiners, http://www.nybarexam.org/Misconduct/Misconduct.htm (last visited Mar. 7, 2015) (penalties for misconduct violations (e.g., using a cell phone in the exam room) include nullification of exam results and report to the Committee on Character \& Fitness, among others).

347 For instance, U.S. courthouses in the Eastern District of Virginia ban all electronic devices, other than those used by attorneys for their trial presentations. See, e.g., Alexandria Courthouse, U.S. District CT. E. District VA., http://www.vaed.uscourts.gov/loca tions/ale.htm\#security (last visited Mar. 7, 2015) (attorneys must receive prior approval from the judge to use laptops for courtroom presentations); Local Rules and Standing Orders: Clerk's Office Helpful Hints Richmond Division, U.S. District CT. E. District VA., http://www.vaed.uscourts.gov/localrules/richmondhints.htm (last visited Mar. 7, 2015) (electronic devices not permitted in courthouse).

348 See MD. R. P. 16-110, available at http://mdcourts.gov/reference/rule16-110.pdf (last visited Mar. 7, 2015) (stating that all electronic devices shall remain off in the courtroom, other than during reasonable and lawful use by attorneys and their agents in connection with the proceeding). 
Violation of these court rules could lead to confiscation of her phone, being held in contempt of court, and possible sanctions. ${ }^{349}$ Again, this attorney could wait until the court calls a break, but again, she may have difficulty waitingand concentrating in the interim - if she has trained herself to take breaks more frequently. While it is likely that more classrooms and courtrooms will permit periodic ICT use in the future, ${ }^{350}$ the current rules present obstacles to frequent technology breaks.

The second problem is that technology breaks are inherently disruptive. On the one hand, having periodic scheduled breaks may generally improve a class's or other group's attention, assuming students or group members use ICTs only during the scheduled breaks and not continually throughout the class session or group meeting. On the other hand, it will surely take time to bring the class or group back to attention after a scheduled technology break. A professor teaching a ninety-minute class who provides a two-minute technology break every fifteen minutes will lose a minimum of ten minutes of class time, and probably more, since it will likely take another two to three minutes in total to regain his students' attention after the breaks. ${ }^{351}$ This may be worthwhile if there is a marked improvement in student focus and improvement during the remaining seventy-seven minutes; if, instead, students remain distracted throughout the class by their ICTs, this is simply thirteen wasted minutes.

\section{Practice Meditation}

The third prominent suggestion for how legal professionals can combat technology's negative effects on attention is to practice a form of meditation, such as mindfulness meditation or concentration meditation. Practitioners of mindfulness meditation seek to develop mindfulness, "a deliberate, present-

349 Id.

350 Perhaps predictive of things to come, the Southern District of New York recently reversed its prior ban on personal electronic devices in the courtroom. See Court Notice to the Bar, U.S. Dist. Court S. Dist. N.Y., SDNY Board of Judges Revises Its Electronic Devices Policy (Mar. 19, 2014), available at http://www.nysba.org/WorkArea/DownloadAsset.aspx? $\mathrm{id}=47593$. The SDNY now allows attorneys to obtain prior permission to bring cell phones, laptops, tablets, and other comparable devices into the SDNY's courthouses for personal use, subject to certain restrictions. S.D.N.Y. Standing Order M10-468 (Revised) (Feb. 27, 2014), available at http://www.nysba.org/WorkArea/DownloadAsset.aspx?id=47593. Other courts are more permissive. For example, the U.S. Court of Appeals for the Ninth District permits anyone to bring "electronic devices" (smartphones, laptops, etc.) into the courthouse and to use such devices in the courtrooms to "take notes, transmit and receive data communications, and access the Internet," including media members who are transmitting written accounts of the proceedings. U.S. Court of Appeals for the Ninth Circuit Electronic Device Policy, U.S. COURTS (Jun. 23, 2010), available at http:/cdn.ca9.uscourts.gov/datastore /uploads/calendar/elec_policy6_23_10.pdf.

351 Mathematically, this assumes the professor calls a technology break in the last ten minutes of class, for a total of five technology breaks. If he chose to forego the fifth break, then he would lose a minimum of eight class minutes, plus another two to three minutes to regain the students' attention. 
moment non-judgmental awareness of whatever passes through the five conventional senses and the mind - to simplify: emotions, thoughts, and body sensations. ${ }^{352}$ In other words, mindfulness is a way of paying attention intentionally but calmly, without becoming attached to any particular thought or sensation. ${ }^{353}$ The ability to be mindful can be cultivated through formal meditative practices, in which practitioners systematically learn to pay attention to their breath, body sensations, thoughts, and emotions, first one at a time, and then simultaneously. ${ }^{354}$ Followers of Buddhist philosophy and psychology developed and popularized these practices starting nearly 2,500 years ago. ${ }^{355}$ Mindfulness can also be cultivated through informal practice, using techniques that produce present-moment, non-judgmental awareness in daily life. ${ }^{356}$ Though mindful awareness is more a "state" than a "trait," practitioners can become more adept at sustaining it with sufficient and continued practice. ${ }^{357}$

Concentration meditation refers to a distinct set of meditation practices that are expressly intended to enhance practitioners' ability to pay attention by developing the capacity to concentrate. ${ }^{358}$ Like mindfulness meditation, concentration meditation is based on practices developed in the eastern contemplative traditions, but the two are separate forms of meditative practice. ${ }^{359}$ The goals of concentration meditation are twofold: first, to stay focused continuously and completely on a single concentration object without becoming distracted; and second, to minimize the distractions of background noises and thoughts to help produce a sense of calm. ${ }^{360}$

Meditative practices have many proven benefits related to attention. Meditation physically changes the brain in ways that produce enhanced clarity of

352 Leonard L. Riskin, Awareness and the Legal Profession: An Introduction to the Mindful Lawyer Symposium, 61 J. Legal EduC. 634, 635 (2012) [hereinafter Riskin, Mindful Lawyer Symposium]. Mindfulness is also called "mindful awareness." Leonard L. Riskin, Annual Saltman Lecture: Further Beyond Reason: Emotions, the Core Concerns, and Mindfulness in Negotiation, 10 NEV. L.J. 289, 308 (2010) [hereinafter Riskin, Saltman Lecture]. See generally id. at 308-15 for a deeper discussion of mindful awareness and mindfulness practices.

${ }^{353}$ Riskin, Saltman Lecture, supra note 352, at 308.

354 Id. at 314.

355 Id. at 293; Riskin, Mindful Lawyer Symposium, supra note 352, at 635.

356 Riskin, Saltman Lecture, supra note 352, at 314-15 (e.g., deciding to be mindful while brushing one's teeth).

357 Id. at 315 (quotation marks omitted).

358 Baker \& Brown, supra note 60, at 359.

359 See id. at 360, 362-63. Traditionally, there is a distinction between concentration meditation and awareness meditation, the latter of which is intended to train continuous awareness of whatever occurs in consciousness. $I d$. at 360. At least one type of mindfulness meditation may be considered a "hybrid" system that combines pure concentration and pure awareness practices by training some degree of concentration on the breath to stabilize concentration before training the continuous awareness characteristic of mindfulness. Id. at 362-63. Though concentration meditation and mindfulness meditation may overlap in some ways, they are treated here as two distinct practices.

${ }^{360} I d$. at 359-60. For a detailed explanation of concentration meditation practice and training, see generally id. at 365-72. 
thought and focus. ${ }^{361}$ Researchers have found that long-time meditators tend to have a thicker prefrontal cortex and right anterior insula (an area of the brain related to sensory data processing) than do non-meditators. ${ }^{362}$ Observable changes in the high-frequency brain waves associated with attention and perception can be achieved with as little as two weeks of meditation practice. ${ }^{363}$ Meditation can also produce the "relaxation response," a term coined by Dr. Herbert Benson, cardiologist and founder of the Mind/Body Medical Institute at Harvard Medical School, to describe "an inducible, physiologic state of quietude" characterized by decreased heart rate, metabolic rate, breathing rate, and blood pressure. ${ }^{364}$ The relaxation response counteracts the autonomic arousal evoked in connection with the flight-or-fight response. ${ }^{365}$ In producing the relaxation response and in helping to reduce and relieve stress, ${ }^{366}$ meditation may help lawyers and law students learn more, focus better, and improve their performance. $^{367}$

In addition to the general benefits of various forms of meditation, specific attentional benefits have been observed as a result of mindfulness and concentration meditation practices. Mindfulness training appears to improve practitioners' alerting network operations by improving their readied awareness, as well as their orienting network functions by improving their ability to concentrate on a specific object. ${ }^{368}$ Similarly, an exercise done with law students by Professor R. Lisle Baker of Suffolk University Law School and Dr. Daniel P. Brown of the Department of Psychiatry at Harvard Medical School suggests that concentration meditation training might help to increase meditators' ability to focus their thoughts and to listen attentively without having their minds

361 HORSTMAN, supra note 82 , at 31 .

362 Id.

363 Id. at 34. Though changes can be observed after such limited practice, meditation triggers these brain waves to a much greater extent in experienced meditators than in novices. Id.; see also SMALL \& VORGAN, supra note 81, at 142 (observing significant brain wave changes during and after meditation in systematic electroencephalographic brain studies).

364 BENSON WITH KLIPPER, supra note 288, at 9.

365 See id. at 99; see also supra notes 287-89 and accompanying text.

366 See HoRSTMAN, supra note 82, at 20.

367 See Riskin, Mindful Lawyer Symposium, supra note 352, at 639 (explaining that mindfulness practices can improve concentration and stress management, resulting in benefits for legal professionals and law students in terms of increased learning, more efficient studying, and better performance in class, clinics, and law practice settings).

368 See Amishi P. Jha et al., Mindfulness Training Modifies Subsystems of Attention, 7 Cognitive, Affective \& Behav. Neuroscience 109, 109-16 (2007). In this study, participants in an intensive, one-month, residential mindfulness retreat demonstrated improved orienting and alerting performance following mindfulness training as compared to participants in a weekly mindfulness-based stress reduction course and a control group. See id. at 11116. These types of enhancements in practitioners' ability to concentrate and in turn enhance everything they do. Riskin, Saltman Lecture, supra note 352, at 323. 
wander, as well as lead to increased feelings of alertness, relaxation, and calm. $^{369}$

Legal education has begun to embrace the teaching of meditative practices. Many law schools offer for-credit or non-credit courses on mindfulness or other topics that introduce or integrate mindfulness practices, such as negotiation, mediation, professional responsibility, trial practice, and clinics. ${ }^{370}$ Special programs on mindfulness can be found at the University of Miami School of $\mathrm{Law}^{371}$ and the UC Berkeley School of Law, ${ }^{372}$ among others. Law students and practicing lawyers can attend workshops and continuing legal education programs involving mindfulness, which have been sponsored by law schools, the American Association of Law Schools, the American Bar Association (the "ABA") and other bar associations, law firms, courts, government agencies, and other sponsors in the United States and internationally. ${ }^{373}$ While less broadly taught than mindfulness meditation, concentration meditation has been introduced in at least one law school: Professor Baker and Dr. Brown have partnered to train Professor Baker's students in concentration meditation practices for purposes of improving their attentional skills. ${ }^{374}$

The availability of courses that teach meditative practices enhances the practicality of this advice for improving attention. Moreover, there are informal avenues available to legal professionals for learning about mindfulness or concentration meditation practices. These include meditation groups for lawyers, ${ }^{375}$ books and audio programs available from bookstores and libraries, ${ }^{376}$ and even apps available for smartphones and tablets, many of which are free. ${ }^{377}$

369 See Baker \& Brown, supra note 60, at 372-75. Although Baker and Brown's work focused exclusively upon law students, it is reasonable to think that concentration meditation could yield similar benefits for other practitioners as well.

370 Riskin, Mindful Lawyer Symposium, supra note 352, at 637 (for-credit and non-credit courses offered at law schools at the University of Miami, the University of Missouri, the University of Florida, Northwestern, Georgetown, and Vanderbilt, among others).

371 See generally MiAMI LAW Mindfulness IN LAW PROGRAM, http://www.miami mindfulness.org/ (last visited Mar. 7, 2015).

372 See generally Berkeley Initiative for Mindfulness in Law, BERKELEY LAW U. CAL., http://www.law.berkeley.edu/mindfulness.htm (last visited Mar. 7, 2015).

373 Riskin, Mindful Lawyer Symposium, supra note 352, at 638 (noting that programs have taken place in the U.S., Australia, Austria, Canada, Denmark, Israel, and Greece).

374 See generally Baker \& Brown, supra note 60, at 372-75, 378-82.

375 Riskin, Mindful Lawyer Symposium, supra note 352, at 638 (functioning groups located in Northern California, Denver, New York City, and Portland, Oregon).

376 A search of the public library catalog in my suburban Ohio town for "concentration meditation" yielded titles such as The Beginner's Guide to Meditation, an audiobook lecture by clinical psychologist Dr. Joan Z. Borysenko, designed to teach the listener about three forms of meditation, including concentration and mindfulness. Catalog, MARYsviLle PuB. LiBR., http://catalog.clcohio.org/polaris/ (search performed Oct. 17, 2014).

377 For example, a search for "mindfulness" on the iTunes App Store turns up too many apps to count, such as Mindfully Me, a free app for the iPhone that promises to "enhance your mindfulness, leading to increased self-awareness, authenticity, and self-care" based on an approach designed by a "passionate team" of "psychologists, engineers, and meditation teachers." "Mindfully Me," iTunes App Store, ITUNES (search performed Jan. 6, 2015). 
However, the suggestion to improve attention by practicing meditation is not a perfect solution, either now or in the foreseeable future. The two primary obstacles are access and effort. Though the number of legal education programs that incorporate meditation training is laudable, these programs may not be reasonably available to all legal professionals. Cost is one factor. Attending a workshop or CLE event may include registration fees as well as travel and accommodation costs that could be prohibitive for attorneys, educators, and students on tight budgets. ${ }^{378}$ Another factor potentially limiting access to meditation training is limited availability in student schedules for elective courses that are not tested on the bar exam. Conscious of the importance of bar exam passage rates for attracting new students, law schools may steer students toward doctrinal courses that are tested on the state exams, rather than "nonessential" courses that focus on meditation practices. ${ }^{379}$ In addition, as law schools reduce their number of faculty members in an attempt to cut costs in line with declining enrollment, ${ }^{380}$ there may be less room in the curriculum to teach nonmainstream courses. Furthermore, there may be value for legal professionals in courses that specifically tie meditation training to law practice, such that the availability of meditation books and free apps may not provide the same degree of benefit as meditation training in a legal context. But given the ability to incorporate meditation training into well-established classes - such as alternative dispute resolution and trial practice - as well as the availability of free or lowcost resources available to lawyers - such as attorney meditation groups-the access obstacle does not seriously undermine the suggestion of developing meditation skills to improve attention.

The second obstacle, effort, is perhaps a greater (though not insurmountable) impediment to the success of implementing this advice. Simply put, reap-

378 To illustrate, a law teacher who attended the Workshop on Mindfulness in Legal Education hosted by the Berkeley Initiative for Mindfulness in Law on June 6-9, 2013, may have spent $\$ 450$ for the regular registration fee and $\$ 129$ per night at one of the recommended hotels, plus the cost of the flight to California and of those meals that were not included in the Workshop. See Workshop on Mindfulness in Legal Education: Berkeley Initiative for Mindfulness in Law, BERKELEY LAW U. CAL., http://www.law.berkeley.edu/14864.htm (last visited Mar. 7, 2015). The Workshop organizers were clearly cognizant of the cost issue and offered $\$ 50$ student registrations and a limited number of $\$ 250$ reduced-cost registrations for those for whom cost was an obstacle, but registrants who had to travel to the Workshop may still have incurred significant expenses. See id.

379 Presumably, this practice would be more likely to occur at law schools that tend to have lower bar passage rates and more of a regional employment focus than at schools with higher passage rates and more of a national focus. Many schools have found room in their curricula to teach "nonessential" courses, such as Wine Law (taught at UC Berkeley) and Law, Psychology, and Morality: An Exploration through Film (taught at Harvard Law School). See Courses@Boalt, BERKELEY LAw U. CAL., http://www.law.berkeley.edu/php-programs /courses/coursePage.php?cID=10697 (last visited Mar. 7, 2015); Harvard Law School Course Catalog: 2014-2015 Academic Year, HARVARD L. SCH. (Jan. 6, 2015, 2:04 AM), https:/helios.law.harvard.edu/CourseCatalogs/hls-course-catalog-2014-2015.pdf.

380 See Ashby Jones \& Jennifer Smith, In Rare Step, Law Schools Shrink Faculty, Wall ST. J., Jul. 16, 2013, at B1. 
ing the benefits of meditation involves an up-front investment of time and effort to learn how to meditate, and an ongoing investment of time and effort to practice. Changing the brain with meditation requires at least twenty minutes of regular practice, preferably daily. ${ }^{381}$ Legal professionals may be initially resistant to the idea of carving out a block of time most days to practice meditation, particularly if they are unaware of meditation's numerous benefits or do not view themselves as suffering from attentional problems. ${ }^{382}$ Even those lawyers and law students who genuinely believe in the benefits of meditation and actively desire to practice may find their busy schedules too demanding to make meditative practice a priority. Presumably, this will be most true of those who are relatively new to meditation and have experienced the difficulties of learning to practice ${ }^{383}$ but not the significant benefits of doing so.

\section{What ChANGES ARE ON THE HoRIZON?}

All of the foregoing suggestions for how legal professionals should cope with the attentional challenges presented by ICTs have their own strengths and weaknesses. But more significantly, all of these suggestions share something in common: They focus upon how lawyers and law students need to change to overcome the problems the legal profession has, and will continue to have, with ICTs. Perhaps this misses the point. In some form or another, ICTs are here to stay. Even if we could undo the last century of technological advances and get rid of ICTs, we surely would not want to. More importantly, the Digital Generation would not let us. So perhaps the question is not, How do we change legal professionals so that they overcome what technology is doing to them?, but rather, How is the legal profession going to adapt to the new technological environment when the Digital Generation are in charge? This question is not so much about what new technologies will be introduced to the profession as it is about how legal professionals will interact with technology in the future. Keeping this inquiry in mind, this Part contains a number of predictions about what changes might be in store for law schools, client relations, and the courtroom when the Digital Generation take over the legal profession.

381 HORSTMAN, supra note 82 , at 31 .

382 See supra note 336 and accompanying text.

383 See Baker \& Brown, supra note 60, at 359 n.96, 368. Baker and Brown suggest that concentration meditative practices may be especially difficult for legal professionals, for several reasons. First, they note that law teachers and students often pride themselves on how busy they are, such that when they "find the rare opportunity to be alone with [their] thoughts, [they] tend to get fascinated by them rather than staying focused on the concentration object, in turn requiring special effort." $I d$. at 359 n.96. Second, they refer to a natural pride among law students and lawyers in having developed a "capacity for reasoned analysis," which may make it "specifically challenging ... to turn aside from often intriguing problems or trains of thought to focus on something seemingly as relatively uninteresting as one's breathing." $I d$. at 368. But, as Baker and Brown demonstrate in their work with law students, these difficulties - though real - may be overcome with sufficient motivation. See id. at 372-75, 378-82. 


\section{A. Changes in Law School}

Changes to the law school experience will necessarily be part of overarching changes to the legal profession because of ICTs, either as an impetus for broader change to legal practice or as a result thereof. Bearing this in mind, this Section predicts four ways in which the Digital Generation and new technology will bring about future changes in law schools, including (1) widespread permission for students to use laptops in class, (2) a revised focus for legal writing courses, (3) broader incorporation of meditation practice in the law school curriculum, and (4) decreased reliance on the case method as the primary method of legal instruction.

\section{Laptops, Laptops Everywhere and Not a Pen in Sight}

In all likelihood, when the Digital Generation dominate the legal profession, The Great Laptop Debate ${ }^{384}$ will be resolved in favor of those who allow laptops in class, and laptops (along with tablets and smartphones) will be permitted in every law school classroom. Several factors will contribute to this resolution. First, law school is more and more becoming a service industry and the "clients" are demanding - and will continue to demand-to use their electronic devices in class. Whether students' use of ICTs in class ultimately improves or hurts their academic outcomes is a question being studied, ${ }^{385}$ and not one that has been definitively answered either way. ${ }^{386}$ Without strong evidence that allowing laptops in class is affirmatively detrimental to students' academic performance, law schools will likely provide what students are asking for. ${ }^{387}$

384 The debate whether to permit students to use laptops in class has been raging throughout legal academia for several years. See Jana R. McCreary, The Laptop-Free Zone, 43 VAL. U. L. REV. 989, 993-1005 (2009) (describing the debate and competing viewpoints).

385 See generally, e.g., Carrie B. Fried, In-Class Laptop Use and Its Effects on Student Learning, 50 COMPUTERS \& EDUC. 906 (2008) (discussing the negative correlation between in-class laptop use and understanding of course material and overall course performance); Reynol Junco \& Shelia R. Cotten, No A 4 U: The Relationship Between Multitasking and Academic Performance, 59 COMPUTERS \& EDUC. 505 (2012) (conducting study to "examine how college students multitask with ICTs and to determine the impacts of this multitasking on their college grade point average"); Junco, supra note 111 (examining the frequency with which students multitask in class and how that correlates with students' overall semester grade point averages). The bulk of the empirical work is being done at the undergraduate level, though some law professors have also undertaken more informal studies on laptop use in their classes. See generally, e.g., Sovern, supra note 322 (describing a law professor's study conducted by stationing observers in the back of law classes to determine students' use of ICTs for non-class purposes).

${ }^{386}$ See Junco, supra note 111, at 2237 (describing studies that suggest there may be some cases in which technology use during class may not be detrimental to academic performance, and other studies that found laptop use was negatively related to various learning outcomes).

387 The recent law school "crisis" stemming from a decline in law school applications and declining student enrollment will no doubt contribute to law schools' willingness to accommodate student demands such as this one. See James B. Stewart, A Bold Bid to Combat a Crisis in Legal Education, N.Y. TIMES, Apr. 5, 2014, at B1 (describing a "crisis in legal edu- 
Second, there is a growing sense that in-class ICT use is inevitable because it is an ever-increasing part of students' elementary and secondary education, ${ }^{388}$ and because - speaking practically — it is very difficult for professors to prevent it. Attempts at shutting off in-class Internet access have proved to be in vain, as students remain one step (or several) ahead of their professors. ${ }^{389}$ Why turn professors into the laptop police when students can just as easily surf the Internet on their smartphones under their desks? Rather than continue to lose daily battles, professors will likely surrender and end the war.

Third, there is a growing number of legal educators who are embracing electronic course materials in lieu of traditional printed books. ${ }^{390}$ It would seem unfair, perhaps hypocritical, to assign students to access materials electronically out of class and then to prohibit them from accessing the materials electronically in class. This would leave students with a choice either to forgo bringing their materials to class or to incur significant printing costs (both in monetary and in environmental terms) and would surely generate student complaints.

Fourth, as time passes and older generations of professors retire, more professors will be of the Digital Generation themselves. These Digital Generation

cation" and noting that law school applications nationwide fell to fifty-four thousand in 2013, down from one hundred thousand in 2004).

388 The use of ICTs in schooling starts early. The National Center for Education Statistics reported that as of 2008 the average U.S. public school had 189 computers, 98 percent of which had Internet access, for a ratio of 3.1 students per instructional computer with Internet access. Thomas D. Snyder \& Sally A. Dillow, U.S. Dept. Educ., Digest of Education StATistics 2012, at 187 (2013), available at http://nces.ed.gov/pubs2014/2014015.pdf. Throughout grade school education, teachers are incorporating ICTs in the classroom and students are encouraged to utilize ICTs in completing their assignments. See, e.g., KRISTEN Purcell et al., Pew Research Ctr.'s Internet \& Am. Life Project, How Teachers Are Using Technology at Home And in Their Classrooms 35 (Feb. 28, 2013), available at http://www.pewinternet.org/files/old-media/Files/Reports/2013/PIP_Teachers andTechnologywithmethodology_PDF.pdf [hereinafter PURCELL ET AL., TEACHERS USING TECHNOLOGY]. Ninety-six percent of teachers surveyed and/or their students use computers in the classroom or in completing assignments, while 73 percent use a cell phone or smartphone, 67 percent use a digital camera, and 55 percent use a digital video recorder. Id. This report by the Pew Research Center's Internet \& American Life Project is the second installment of a study based on a 2012 survey of 2,462 middle and high school teachers in the U.S., Puerto Rico, and the U.S. Virgin Islands. Id. at 7, 11. See infra notes 395 and 465 for findings from the first and third installments. Though the teachers surveyed for this report are "leading edge teachers" who may not be typical of all middle and high school teachers across the U.S., see PURCELl ET AL., TEAChERs Using TeChNOlOGY, supra, at 8-9 (quotation marks omitted), their ICT usage indicates a growing trend of ICT use in the classroom. Given that students are spending much of their educational lives using ICTs, it is understandable why they would want to use them while in law school and why legal educators might be concerned about the difficulties inherent in separating them from their devices.

${ }^{389}$ See McCreary, supra note 384, at 997 (noting "the reality that it is impossible to prevent Internet access by students" and describing student successes in circumventing attempts to prevent access).

390 See Matthew Bodie, The Future of the Casebook: An Argument for an Open-Source Approach, 57 J. LEGAL EDUC. 10, 11 (2007) ("[P]rofessors have begun to create and assign their own electronic casebooks for student use."). 
professors may be more inclined than their predecessors to permit laptops in the classroom. ${ }^{391}$ Adding this professorial inclination to student demands, difficulties preventing in-class ICT use, and the rise of electronic course materials, inclass ICT use seems a foregone conclusion.

If legal educators are faced with the knowledge that electronic devices will be part of the classroom landscape whether they like it or not, they will likely adopt the refrain of "If you can't beat 'em, join 'em." Even those who formerly banned laptops will follow their ICT-enthusiast colleagues' lead in finding ways to incorporate ICTs into classroom activities. Laptop note taking, clicker questions, ${ }^{392}$ and real-time Internet research will be just a jumping off point for the ways that creative legal educators will try to use electronic devices as a significant learning tool, and not merely a distraction. ${ }^{393}$

\section{Legal Writing, or Just Writing?}

Educators at all levels have been bemoaning in recent years students' lack of writing ability. ${ }^{394}$ Digital technology, especially the Internet $^{395}$ and tex-

391 This is by no means a foregone conclusion. According to my own definition, I am a member of the Digital Generation. And yet, although I went to law school at a time when laptops were commonplace, I ban laptops in my classroom.

392 See Nancy G. Maxwell, From Facebook to Folsom Prison Blues: How Banning Laptops in the Classroom Made Me a Better Law School Teacher, Rich. J.L. \& TeCH., Nov. 2007, at 1, 10-11, 32-33 (discussing use of "individual handheld wireless transmitters similar to remote controls," or "clickers," by law professors).

393 Given their vast experience with ICTs, the Digital Generation are uniquely positioned to identify viable solutions to the challenges posed by permitting laptops and other ICTs in class. Legal educators might be well advised to enlist their Digital Generation students in the effort to find methods of using ICTs in the classroom that maximize their pedagogical benefits and minimize their detriments.

394 See Amanda Lenhart et al., Pew Research Ctr.'s Internet \& Am. Life Project, Writing, TECHNOLOGY AND TEENS 1 (2008), available at http://www.pewinternet.org /files/old-media/Files/Reports/2008/PIP_Writing_Report_FINAL3.pdf.pdf ("Research in K12 schools, colleges and universities has prompted concern among advocates, educators and policy makers that many young Americans do not possess strong writing skills.").

395 The Internet is blamed for encouraging sloppy, cut-and-paste work. See, e.g., KRISTEN Purcell et Al., Pew Research Ctr.'s Internet \& Am. Life Project, How Teens Do ReSEARCh IN THE Digital World 27 (2012), available at http://www.pewinternet.org /files/old-media/Files/Reports/2012/PIP_TeacherSurveyReportWithMethodology110112.pdf [hereinafter Purcell et AL., TeEns Do Research] (discussing the first installment of a Pew report on the impact of technology on education). The Internet is also credited with undermining students' ability to determine the credibility of the information they find. See id. at 26; Taslitz, supra note 244, at 111-12. Studies of elementary school and secondary school children and college students have found that young people have difficulty assessing the credibility of what they find on the Internet. Taslitz, supra note 244, at 111-12; see PURCELL ET AL., TEENS Do RESEARCH, supra, at 26. The more young people use the Internet, the more credible they believe the information they find there to be. Taslitz, supra note 244, at 112; see Purcell et AL., TeEns Do Research, supra, at 26. 
ting ${ }^{396}$ has taken a fair amount of the blame for this. But law is largely a profession of writing - ranging from formal writing, such as contracts and pleadings, to informal writing, such as emails to colleagues and clients. Proficient legal writing requires the ability to interpret, to analyze, to synthesize, and to convey ideas clearly and precisely. Law schools cannot afford for their graduates to be inept writers.

Even the rise of digital technology is unlikely to change the importance of writing to the practice of law. With this in mind, law schools will probably devote greater resources to legal writing courses in the coming years. These courses are likely to have an expanded scope, with more emphasis on proper electronic communication, such as how to write a formal email to a client summarizing a conference call with opposing counsel. Legal writing instructors may also need to fill in gaps in their students' writing education by, for example, teaching students who have long since communicated predominantly through text messages how to draft a letter. ${ }^{397}$

But the greatest change in law school writing courses will probably be one of attitude and expectation. Legal writing instructors may expect students to have less of a foundation of writing skills than is expected today. They will likely come to view teaching basic writing skills as a major part of their job. In short, law school writing courses may become less courses on legal writing, and more courses on simply writing.

\section{Make Room for Meditation}

As noted above, legal educators are starting to incorporate meditation instruction and practice into their courses. ${ }^{398}$ This trend is likely to continue as the Digital Generation take over legal education. The driving forces will be at least threefold: One motivating factor will be the growing problem of law student and attorney stress and depression and the destructive behaviors that tend to go hand-in-hand, such as alcoholism and suicide. ${ }^{399}$ Because of meditation's

396 See, e.g., M.A. Drouin, College Students' Text Messaging, Use of Textese and Literacy Skills, 27 J. COMPUTER Assisted LEARNING 67, 68 (2011) (noting assertions that language used in texting is having a detrimental effect on people's use of standard English).

397 This need has already been recognized by the legal professionals who developed Core Grammar for Lawyers, "an online, self-directed learning tool designed to help law students, pre-law students, paralegal professionals, and practicing attorneys acquire the grammar and punctuation skills that are prerequisites to successful legal writing." See generally CORE GRAMMAR FOR LAWYERS, http://Www.coregrammarforlawyers.com/ (last visited Mar. 8, 2015).

398 See supra text accompanying notes 370-74.

399 See, e.g., Todd David Peterson \& Elizabeth Waters Peterson, Stemming the Tide of Law Student Depression: What Law Schools Need to Learn from the Science of Positive Psychology, 9 Yale J. Health Pol'y L. \& Ethics 357, 358-59 (2009) (observing that law students suffer from elevated levels of depression, stress, and anxiety and report significantly higher levels of alcohol and drug use than their non-law student peers); Martin E.P. Seligman et al., Why Lawyers Are Unhappy, 23 CARDOzo L. REV. 33, 37 (2001) (discussing that lawyers are at greater risk for depression, heart disease, alcoholism, and illegal drug use than the general 
known stress-relieving benefits, meditation will likely be incorporated more broadly into classes such as legal professionalism and other classes concerned with attorney wellbeing. Another motivating factor will be the perceived decline in students' attentional capacity concomitant with their use of ICTs. Out of concern that students are plagued with "popcorn brain, ${ }^{400}$ legal educators will likely teach meditation practices in an attempt to increase students' powers of focus and concentration - just like some, such as Professor Baker, are already doing. A final motivating factor will be the perceived ability of meditation to complement and enhance skills within certain disciplines, such as negotiation. $^{401}$

That said, predicting that even a majority of law professors will be inclined to teach meditation in their classes goes too far. Meditation instruction is not a natural fit within every law school course, and not every law professor will necessarily recognize its value to legal education. Like dispute resolution, ${ }^{402}$ meditation may at first be the province of only a few pioneers before it is ultimately accepted into the regular law school curriculum. But even if its incorporation into the curriculum is gradual, meditation will likely become part of mainstream legal education in the future because of the many potential benefits it has for legal professionals.

\section{Cutting Back on the Case Method?}

Today, one widely used method of legal instruction is the so-called "case method" developed by Christopher Columbus Langdell, a teaching method that involves "student examination of judicial decisions coupled with Socratic style

population and suffer from major depressive disorder at a 3.6 times higher rate than employed persons do generally); Rosa Flores \& Rose Marie Arce, Why Are Lawyers Killing Themselves?, CNN (Jan. 20, 2014, 2:42 PM), http://www.cnn.com/2014/01/19/us /lawyer-suicides/ (stating that lawyers rank fourth in suicide deaths by profession, according to data provided to CNN by the Centers for Disease Control and Prevention).

400 See Elizabeth Cohen, Does Life Online Give You 'Popcorn Brain'?, CNN (Jun. 23, 2011, 7:03 AM), http://www.cnn.com/2011/HEALTH/06/23/tech.popcorn.brain.ep/index.html (describing "a brain so accustomed to the constant stimulation of electronic multitasking that [the person is] unfit for life offline, where things pop at a much slower pace").

401 See Riskin, Saltman Lecture, supra note 352, at 292-93 (describing how negotiators may improve their ability to utilize Roger Fisher and Daniel Shapiro's core concerns framework by improving their awareness skills through mindfulness).

402 See Frank E.A. Sander, Alternative Dispute Resolution in the Law School Curriculum: Opportunities and Obstacles, 34 J. LeGAL EDUC. 229, 230-32 (1984) (describing early efforts to incorporate dispute resolution into the law school curriculum). In 1983, only fortythree of the ABA-accredited law schools nationwide (25 percent) offered dispute resolution courses. Ellen Conlin et Al., A.B.A. Standing Comm. on Dispute Resolution, Directory of Law School Dispute Resolution Courses and Programs 2 (Anne Clare ed., 1986). By 1986, the number had grown to 111 out of 175 accredited schools (63 percent). Id. By the year 2000, 182 out of 183 accredited law schools (99.5 percent) offered 830 dispute resolution courses and programs in total. Kimberlee K. Kovach, Foreword to A.B.A. Section of Dispute Resolution, Directory of Law School Dispute Resolution Courses AND PROGRAMS (Jack C. Hanna et al. eds., 2000). 
analysis." ${ }^{403}$ Langdell first introduced this teaching method to legal education in 1870, when he became dean of Harvard Law School. ${ }^{404}$ Langdell's case method has been the subject of a great deal of criticism, from scholars, ${ }^{405}$ educational reform groups, ${ }^{406}$ and students ${ }^{407}$ alike, though it lives on as the primary method of legal instruction. ${ }^{408}$ But as the Digital Generation become both the students and the professors, this method will probably lose its primacy.

Existing law professors are already starting to embrace alternative teaching methods and instructional tools, many of which involve technology. ${ }^{409}$ These include PowerPoint slides, in-class Internet access, ${ }^{410}$ videos, ${ }^{411}$ class podcasts and blogs, web-based course management systems and interactive course web pages, ${ }^{412}$ clickers, ${ }^{413}$ data projectors, ${ }^{414}$ computerized tutorials and lessons, ${ }^{415}$

403 Russell L. Weaver, Langdell's Legacy: Living with the Case Method, 36 VILL. L. REV. 517,518 (1991).

${ }^{404} I d$. at 518, 520. But see id. at 520-21 (noting that there is some disagreement regarding whether the method originated with Langdell and whether the idea to use it was his alone).

405 E.g., Edward Rubin, What's Wrong with Langdell's Method, and What to Do About It, 60 VAND. L. REV. 609, 612 (2007) (arguing that legal educators using the case method "are trapped inside a pedagogic fossil, marvelously preserved from a vanished era by the adamantine rock of a licensed monopoly").

406 See A.B.A. Section of Legal Educ. \& Admissions to the Bar, Legal Education And Professional DeVelopment-An Educational CONTINUUm: RePORT OF THE TASK ForCE on Law Schools and the Profession: Narrowing the Gap 236 (1992) (criticizing the method's too frequent emphasis on "qualities that have little to do with justice, fairness, and morality in daily practice"); Roy STUCKeY ET AL., Best PRACTICES FOR LEGAL EDUCATION: A ViSION AND A ROAD MAP 99 (2007), available at http://www.cleaweb.org/Resources /Documents/best_practices-full.pdf (noting that the case method is overused in law school and it "has significant defects as an instructional tool. Its impact on individual students is sporadic, it emphasizes certain steps of the cognitive process while ignoring others, and it does not provide a feedback mechanism to address and correct skills deficiencies."); William M. Sullivan et al., Summary: Educating Lawyers: Preparation for the PROFESSION OF LAW 6 (2007) (identifying "lack of attention to practice and inadequate concern with professional responsibility" as "unintended consequences" of legal education's reliance upon the case method).

407 See Weaver, supra note 403, at 518-19 (noting student complaints that the case method is inefficient, poorly used, and a tool of intimidation and harassment).

408 See John Burwell Garvey \& Anne F. Zinkin, Making Law Students Client-Ready: A New Model in Legal Education, 1 Duke F.L. \& Soc. Change 101, 102 (2009) ("[T] he teaching method of studying cases combined with Socratic questioning ... is still the primary method of teaching law in the United States.").

409 Paul L. Caron \& Rafael Gely, Taking Back the Law School Classroom: Using Technology to Foster Active Student Learning, 54 J. LEGAL EDUC. 551, 551 (2004) ("Law schools ... have witnessed an explosive growth in the use of technology in the classroom. Many law teachers now deploy a wide array of technological bells and whistles ....").

$410 I d$. at 556.

411 See Dwight Golann, Using Video to Teach Negotiation and Mediation, DisP. Resol. MAG., Winter 2007, at 8, 8-9 (describing various purposes for which video can be used in ADR instruction).

412 Camille Broussard, Teaching with Technology: Is the Pedagogical Fulcrum Shifting?, 53 N.Y.L. ScH. L. REV. 903, 906-07 (2008-09). The Blackboard Learning System and The West Education Network (TWEN) are two of these course management systems. Id.

413 See Caron \& Gely, supra note 409, at 560-61; Maxwell, supra note 392, at 10-11. 
online simulations ${ }^{416}$ and flipped classrooms, ${ }^{417}$ among others. As the Digital Generation become law students, this trend toward technology in the classroom and away from reliance on the case method is likely to continue ${ }^{418}$ - not only because many legal educators already think the case method is suboptimal and are finding these technology-based methods to be effective, but also because they have read that the Digital Generation will not tolerate traditional teaching methods. ${ }^{419}$ Seeking to teach in a way that their Digital Generation students can learn, ${ }^{420}$ and guided by statements of best practices for legal education that advocate the use of technology, ${ }^{421}$ these educators will probably utilize the case method less often as they more frequently incorporate technology into the classroom.

The movement away from the case method as the primary form of law school instruction will surely continue as the Digital Generation take over the teaching profession. These Digital Generation professors will probably feel

414 Craig T. Smith, Teaching Synthesis in High-Tech Classrooms: Using Sophisticated Visual Tools Alongside Socratic Dialogue to Help Guide Students Through the Labyrinth, 9 Persp.: Teaching Legal Res. \& Writing 110, 110-11 (2001).

415 The Center for Computer-Assisted Legal Instruction (CALI), a non-profit consortium of law libraries, law schools, and other related organizations, distributes over nine hundred interactive legal tutorials and lessons for use in law schools. See About CALI, CALI: The CEnTER for COMPUTER-Assisted Legal InStRuction, http://www.cali.org/content /about-cali (last visited Mar. 9, 2015).

416 See Ira Steven Nathenson, Best Practices for the Law of the Horse: Teaching Cyberlaw and Illuminating Law Through Online Simulations, 28 SANTA Clara COMPUTER \& HigH TECH. L.J. 657, 693-707 (2012) (describing use of "Cybersimulations" as an instructional method in a cyberlaw course and describing specific examples).

417 See generally William R. Slomanson, Blended Learning: A Flipped Classroom Experiment, 64 J. LEGAL Educ. 93 (2014) (describing one law professor's experience flipping his civil procedure course). The so-called "flipped" classroom is one in which the traditional lecture and homework aspects of a class are reversed: Students view short video lectures outside of class and class time is used for discussion, exercises, or projects. EDUCAUSE Learning Initiative, 7 Things You Should Know About ... Flipped Classrooms (2012), available at http://net.educause.edu/ir/library/pdf/ELI7081.pdf.

418 See StUCKeY ET AL., supra note 406, at 117 ("If technology is not the future of legal education, it is at least part of the future. Proven and experimental uses of technology will continue to grow, and some components of legal education will be transformed by it.") (footnote omitted).

419 See, e.g., Horstman, supra note 82, at 58-59 (noting that digital natives do not learn like traditional students from one-way lectures); SMALL \& VORGAN, supra note 81 , at 25 (finding that digital natives have shorter attention spans, especially for traditional forms of learning); Prensky, supra note 166, at 3 (questioning whether digital natives cannot pay attention in class or simply choose not to because they feel it is not worth their attention).

${ }^{420}$ See Stephen M. Johnson, Teaching for Tomorrow: Utilizing Technology to Implement the Reforms of MacCrate, Carnegie, and Best Practices, 92 NeB. L. REV. 46, 54-55 (2013) (describing the Digital Generation's learning styles and noting that "it would seem to be beneficial to incorporate technology more fully into law school pedagogy to fit those students' learning styles, rather than requiring students to try to modify their learning styles to fit the mold of traditional law school pedagogy").

421 See StUCKey et AL., supra note 406, at 117-19 (describing the use of technology to enhance learning as part of best practices for legal education). 
comfortable with technology-based teaching methods because of the prevalence of technology throughout their educational careers. It is foreseeable that Digital Generation professors will gravitate toward the instructional methods they experienced as law students, just as many of their predecessors have replicated their own law school experiences by using the case method. ${ }^{422}$ And since Digital Generation professors will likely have less reason to view case method instruction as part of the law school right of passage, ${ }^{423}$ they will probably be more open-minded about technology-based alternatives.

This is not to suggest that legal education is an either/or proposition, that legal educators will either use the case method or will integrate technology into the classroom. Though the case method may well lose its primacy in legal instruction in the coming years, it is unlikely to disappear from legal education entirely. As a threshold matter, most of the research regarding the Digital Generation's learning styles has examined students at the undergraduate level and below, rather than law students. ${ }^{424}$ Thus, the case method's compatibility with Digital Generation law students remains somewhat of an open question. Future research might indicate that certain aspects of the case method make it an effective instructional tool for Digital Generation students, whether in respect to their preference for interactive instruction, ${ }^{425}$ or their attentional resources, ${ }^{426}$ or otherwise.

422 As Professor Rogelio Lasso remarks, "[1]aw school professors receive little or no instruction on how to teach. The only model for teaching law school was provided by their law professors. As a result, most law professors teach in much the same way they were taught ...." Rogelio Lasso, From the Paper Chase to the Digital Chase: Technology and the Challenge of Teaching 21st Century Law Students, 43 Santa Clara L. REV. 1, 13 (2002) (footnote omitted).

${ }^{423}$ See Peggy Cooper Davis \& Elizabeth Ehrenfest Steinglass, A Dialogue About Socratic Teaching, 23 N.Y.U. REV. L. \& Soc. Change 249, 279 (1997) (suggesting that some professors value Socratic dialogue as part of law school tradition that students have come to expect).

424 See Johnson, supra note 420, at 56.

425 To the extent that the interaction between the professor and the student engaged in Socratic dialogue makes the case method more engaging than pure lecture, the case method might be an effective way to teach the Digital Generation. See Stephen R. Alton, Roll Over Langdell, Tell Llewellyn the News: A Brief History of American Legal Education, 35 OKLA. CiTY U. L. REV. 339, 351-52 (2010) (referring to the case method as "intellectually stimulating"). However, scholars disagree about whether the case method truly promotes active learning, or whether it is "primarily a vicarious form of instruction, where the 'thinking' that goes on between the teacher and the one student involved in the dialog[ue] 'rubs off on all the students in the class.' "Caron \& Gely, supra note 409, at 555 (quoting Michael Hunter Schwartz, Teaching Law by Design: How Learning Theory and Instructional Design Can Inform and Reform Law Teaching, 38 SAN Diego L. ReV 347, 351 (2001)).

${ }^{426}$ Some professors believe that calling on students without warning makes them more alert in class and causes them to pay better attention to class proceedings. See, e.g., Davis \& Steinglass, supra note 423, at 278. This makes sense from an attentional resources perspective: If students sit in class without fear of being called upon, they will likely experience a dip in tonic alertness as they grow bored with the lecture. They might choose to ignore the lecture and to allocate their top-down attentional resources to something more diverting, such as a Sudoku puzzle. But if students know they could face Socratic questioning at any 
Moreover, despite the criticisms of the case method, many practicing lawyers - and not only litigators - still learn legal rules by reading cases. ${ }^{427}$ A case method of instruction focused on teaching common law rules may not provide all the instruction needed to go from law student to practicing lawyer, ${ }^{428}$ but a legal education that does not instruct law students how to read a case and to glean the rules from it is, arguably, an inadequate legal education. The case method may not be the best - and is not the only - way to teach students how to read a case, but it is a long-established one. And so, while the case method may undergo future modifications, ${ }^{429}$ and will likely have to share the stage with technology-based teaching methods more and more in the coming years, it is likely to survive and to remain part of legal education. ${ }^{430}$

\section{B. Changes in Client Relations}

Just as legal education is certain to adapt to digital technology and the Digital Generation who love it, practicing lawyers are sure to experience changes in their relations with clients in the coming decades. This Section sets forth three predictions for how legal practice will adapt to changes prompted by the widespread use of ICTs, namely (1) a movement toward alternative billing arrangements, (2) increased attorney-client communication via text messages, and (3) shorter, more frequently interrupted meetings.

time, their tonic alertness levels will instead probably increase during class. Moreover, upon hearing the sound of the professor calling their names, they will likely experience a sharp increase in phasic alertness. This sound will also engage their bottom-up attentional mechanisms, likely causing them to allocate their top-down attentional resources to the class proceedings. In this way, use of the case method could produce discernible attentional benefits. However, other aspects of the case method experience might undermine the attentional benefits it provides. Some students report that fear of humiliation by the professor makes it hard for them to concentrate. See id. This, too, makes sense from an attentional resources perspective: If being called on in class is stressful for students, then knowing they could be called on at any time will probably heighten their ANS arousal. As their attentional resources are allocated to detecting the stressor (i.e., the sound of their names being called), unrelated information (i.e., class proceedings) will probably be blocked out, thereby negating the case method's attentional benefits.

${ }^{427}$ In my years of practicing as a transactional lawyer, there were many times that I researched case law in order to be able to answer a question posed by a client or a supervising attorney.

428 See Rubin, supra note 405, at 651-53 (arguing that the first-year curriculum should include an introduction to regulatory and transactional law in addition to common law).

${ }^{429}$ See id. at 654-55 (proposing a revised first-year law school curriculum, including several variations to the case method's current form). The case method has already undergone significant changes from the original form Langdell introduced to legal education. See Alton, supra note 425, at 352 (noting that Langdell "would hardly recognize much of what goes on in our classrooms").

430 See Johnson, supra note 420, at 53 ("Technology will not replace the traditional law school classroom ...."). 


\section{Bye-bye, Billable Hour}

The economic downturn in the late 2000s caused many in the news media and the legal industry to expect that corporate clients would push for alternative billing arrangements to reduce their legal costs, and that law firms would quickly agree in order to stem the declining demand for legal services. ${ }^{431}$ These speculations in turn sparked a great deal of talk about the billable hour's impending death. ${ }^{432}$ Though many law firms have in fact devoted substantial time and effort to creating alternatives to the billable hour, at least one recent report suggests the use of alternative fee arrangements may be declining, rather than increasing. ${ }^{433}$ It appears that the billable hour is still viable and is still a major part of legal billing practices. ${ }^{434}$ This may change in the future - not because of another recession, but because of the Digital Generation's love of trying to do multiple things at once.

As noted above, the Digital Generation love to multitask and they do so frequently. ${ }^{435}$ Given this, it seems unlikely that they will foreswear multitasking when they become practicing attorneys. But multitasking at work-texting Client $\mathrm{X}$ and taking calls from Client $\mathrm{Y}$ while trying to draft a shareholders' agreement for Client Z - will make it even harder for Digital Generation lawyers to keep accurate track of billable time and to make sure that their billed hours account for every shift of attention between tasks and all the associated time costs. Digital Generation clients (likely heavy multitaskers themselves)

431 Has the News of the Death of the Billable Hour Been Greatly Exaggerated?, A.B.A. Section of Litigation: A.B.A. Annual Meeting 1 (Aug. 8-12, 2013), available at http://www.americanbar.org/content/dam/aba/administrative/litigation/materials/aba-annual2013/written_materials/1_1_has_the_news.authcheckdam.pdf [hereinafter Death of the Billable Hour].

432 See id. at $1-2$.

433 Id. at 2 (citing a survey by Fulbright \& Jaworski L.L.P. of 275 in-house attorneys in the U.S., which found that 51 percent used some type of alternative billing arrangement, as compared to 61 percent the prior year). If alternative fee arrangement use is truly declining, it may be partly because lawyers are not convinced that the arrangements are profitable. Two recent surveys of practicing lawyers regarding alternative fee arrangement profitability found that fewer than 25 percent of those surveyed believe alternative fee arrangements are more profitable than hourly billing arrangements. Victor Li, How Profitable Are Alternative Fee Arrangements, in Practice?, ABA JouRnAL, http://www.abajournal.com/lawscribbler/article /how_profitable_are_alternative_fee_arrangements_in_practice (Oct. 1, 2014, 10:38 AM $\mathrm{CDT}$ ). Others have a more optimistic view of alternative billing arrangements' viability. See Death of the Billable Hour, supra note 431, at 2 (citing a report indicating that the use of alternative fee arrangements is rising and is expected to increase in popularity in the coming years). Regarding alternative fee arrangements, president of BTI Consulting Group Michael Rynowecer has this to say: "[Alternative fee arrangements] are here, partners are making money off of them, and they're likely to stay. . . Clients like alternative fees. That's not going away." Li, supra (quoting Michael Rynowecer).

${ }^{434}$ Death of the Billable Hour, supra note 431, at 1, 7. Hence the title of this ABA Annual Meeting program, a clear reference to Mark Twain's famous cable from London that said, "The reports of my death are greatly exaggerated." MARK TwaIn, THE WIT AND WisDOM OF Mark Twain: A Book of QuOTATIONS 46 (Paul Negri ed., 1999).

435 See supra note 178 and accompanying text. 
will presumably recognize their generation's tendency to multitask, and might surmise that their lawyers are frequently multitasking while billing by the hour. This may provide additional motivation for the clients to demand an alternative billing arrangement to ensure that they are getting the benefit of all the work they are paying for. It may also give the lawyers a reason to want an alternative fee arrangement, as they might find they are doing little bits and pieces of work for various clients and not getting paid for all of it when they charge in sixminute increments. Assuming the arrangements adequately capture the value of the work being performed, this change could be advantageous for both attorneys and clients.

\section{Why Talk When We Can Text?}

Lawyers practicing today communicate extensively with clients via email; by some accounts, they are more likely to have regular interaction with clients through email than by phone or in person. ${ }^{436}$ This development is in some ways problematic, both from a perspective of security and confidentiality ${ }^{437}$ as well as with regards to the effectiveness of email communication as compared to telephone or in-person communication. ${ }^{438}$ These problems will likely be magnified with Digital Generation lawyers and their clients.

As discussed above, the Digital Generation's younger members use email only infrequently, if at all. ${ }^{439}$ They currently prefer texting to any other form of communication with people in their lives. ${ }^{440}$ It is foreseeable that Digital Generation clients will bring their texting habits - or whatever replaces texting in the coming years - to their communications with their attorneys. And, likewise, their attorneys will text them back. The existing concerns for security and confidentiality with email communication will be exacerbated, as the security pro-

436 See 4 Am. Bar Ass'n, 2013 Legal Technology Survey Report, Web AND Communication Technology 62 (Joshua Poje ed., 2013). This 2013 survey of 823 ABA lawyer members in private practice found that, of the lawyers surveyed, 92.4 percent communicate with clients via email "regularly," while 91.5 percent regularly communicate via telephone or voicemail, and 52 percent regularly communicate face-to-face (plus or minus a 3.5 percent margin of error). $I d$. at ii, 62 .

437 For example, of the lawyers surveyed by the ABA, 58.2 percent report sending confidential or privileged communications or documents to clients via email one or more times per day, and an additional 19.7 percent report doing so between one and four times per week. Id. at 58 . Yet in terms of the safety precautions taken when sending these documents, 76.3 percent relied on the confidentiality statement in the message body, only 31.8 percent used encryption, and only 12.2 percent password protected the documents. Id. at 59 .

438 See, e.g., Noam Ebner et al., You've Got Agreement: Negoti@ting via Email, 31 Hamline J. Pub. L. \& Pol'y 427, 434-43 (2010) (noting that email negotiation is likely to involve increased contentiousness, diminished interparty cooperation, reduction in integrative outcomes, diminished interparty trust, and increased tendency toward sinister attribution as compared to face-to-face negotiation).

439 See supra note 176 and accompanying text.

440 See supra note 176 and accompanying text. 
tocols will surely lag behind the technologies, ${ }^{441}$ and the professional guidelines for ethical communication practices will likely struggle to keep pace with the dizzying array of available communication methodologies. ${ }^{442}$

Even if the legal profession develops effective security and confidentiality protocols for communication via new technologies, the use of text messaging and other rapid communication technology in legal practice is troubling from a client counseling perspective. Quite simply, the practice of law does not neatly fit into 160 characters. ${ }^{43}$ Trying to communicate clearly via email is hard enough - doing it via text only increases the risk of miscommunication. No amount of emoticons can replace the nuances of speech. No degree of chat shorthand $^{444}$ can make a flurry of texts a suitable substitute for considered counsel delivered through a medium that permits explanation and elaboration. The very nature of texting - its rapidity, the instantaneousness expected in responding - is part of what makes texting inimical to the provision of sound legal advice. Attorneys would be well advised to pause, reflect, and consider the implications of their responses before firing them off. While texting may not prevent them from doing so, it certainly encourages them not to. Surely the legal profession will adapt to growing use of text messages and other forms of instant messaging, as it has adapted to the rise of email over the last few decades. And yet, much as the use of email in legal practice has proved problemat-

441 See Roland L. Trope \& Sarah Jane Hughes, Red Skies in the Morning-Professional Ethics at the Dawn of Cloud Computing, 38 WM. Mitchell L. REv. 111, 124-25 (2011) ("[T]he external threats have evolved much faster than the safeguards against them, due to the rapid evolution of communications technology.").

${ }^{442}$ For a contrary viewpoint, see $i d$. at 136 ("It is our belief that the development and adoption of new communications technologies will seldom require significant changes to the long-standing professional ethical rules, however surprising, rapid, and disruptive the technologies prove to be upon their emergence.").

443 Standard text messages are restricted to 160 characters. See Mark Milian, Texting Pioneer Was a Man of Letters, L.A. TIMES, May 11, 2009, at B1 (explaining the history of the 160-character maximum).

444 The NetLingo website provides a list of hundreds of acronyms and shorthand commonly used in text messaging and various forms of instant messaging and Internet chat. Using the terms on this list, an attorney might write to her client, with respect to a settlement offer she believes to be illusory, IAC, IBIWISI. Her client may understand this to mean In any case, I'll believe it when I see it, thereby expressing her doubts and a "wait and see" attitude. Then again, he could also construe it as If anyone cares, I'll believe it when I see it and think she is annoyed and feels unappreciated. Or, alternatively, it could mean I am confused; I'll believe it when I see it, which would suggest either that the offer is unclear or that she is overwhelmed by the situation. In turn, the client's response TTT could be understood by the attorney to mean Thought that, too, indicating he agrees with his lawyer's assessment of the offer's illusory nature, or To the top, perhaps suggesting he wants her to push for a bigger settlement figure, or, more cryptically, That's the ticket. See NetLingo List of Chat Acronyms \& Text Shorthand, NeTLingo, http://www.netlingo.com/acronyms.php (last visited Mar. 9, 2015). To be fair, nothing would prevent either the attorney or the client from using full words for clarity. Yet this somewhat facetious example demonstrates some of the challenges of relying upon a medium that was never intended to be used for the nuanced communication demands of legal practice. 
ic, the rising importance of text messaging is certain to create its own challenges.

\section{Are We Done Yet?}

The practice of law in its current form features many occasions that demand hours-long interactions - for instance, presenting a case in court, meeting with clients and opposing counsel to hammer out the terms of a new joint venture, and preparing clients for depositions. Practicing lawyers can probably recall any number of times in their experience when the talks were intense, the breaks were few, and the food was ordered in, if eaten at all.

Let us assume that the Digital Generation adopt as children the suggestion of taking a technology break every fifteen minutes in order to improve their concentration. Starting in elementary school and continuing all the way through law school, their teachers have encouraged it in an attempt to get them to focus. This is the way they sit through every class and the way all their studying gets done. It is a predictable consequence of forming this habit that the Digital Generation will continue to take frequent technology breaks when they enter legal practice. Digital Generation clients will likely do the same in their careers. Consequently, it seems likely that day-long, sustained meetings with breaks only to use the restroom will be passé, and that shorter interactions with more interruptions will be the norm.

This predicted development is not inherently bad. Two benefits are readily apparent: First, concentrated periods of interaction with frequent breaks may lead to greater efficiency in the time between breaks. Second, if technology breaks become a social norm and everyone takes a break at the same time, this reduces the number of occasions in which either attorney or client (or both) is staring down at his lap while trying to check messages surreptitiously on the phone underneath the table. Two drawbacks are just as apparent: First, taking frequent breaks interrupts the flow of a meeting and risks cutting off discussion that might otherwise result in hatching an idea or a reaching a deal. Second, lawyers and clients who habitually rely upon breaks may struggle to engage for longer than fifteen minutes at a time even in situations that demand it, such as a lengthy examination of a witness on the stand or an appellate argument before a tribunal.

\section{Changes in Court}

If law schools and client relations must adapt to the world ICTs are creating, surely courts will not be immune. This Section sets forth three predictions for how courtrooms and litigation will change in the future based on the influences of ICTs and the Digital Generation, including the following: (1) widespread use of ICTs in courthouses and courtrooms; (2) reliance on ICTs for presentations to judges and juries; and (3) potential changes to the length of court filings. 


\section{ICTs Permitted - and Problematic}

ICT use is already prevalent in courtrooms today. A 2013 survey of attorneys conducted by the ABA regarding technology use in the legal profession found that 47.9 percent of respondents who practice in a courtroom report using their laptops in the courtroom for various tasks, while 77.4 percent report using their smartphones and 34 percent report using a tablet. ${ }^{445}$ They use their devices particularly for accessing the Internet, checking for new email, sending email, conducting online research, and calendaring. ${ }^{446}$ Generally speaking, these figures reflect an increase in ICT usage by courtroom attorneys over the last few years. $^{447}$

It is foreseeable that the percentage of attorneys utilizing ICTs in the courtroom - for these purposes and others - will continue to increase because courts will increasingly permit ICTs to be brought into and used in the courthouse. These changes will not happen overnight, but will instead likely take a decade or more to be fully implemented. In fact, some courts, such as the criminal courts in Cook County, Illinois, ${ }^{448}$ will probably go in the opposite direction initially and will institute ICT bans before ultimately permitting ICTs in the courtroom. The initial hesitance is understandable in light of significant concerns about ICTs in the courtroom, but it seems likely that courts will ultimately accept ICTs in recognition of their ubiquity in daily life and our growing reliance upon them.

The concerns raised about ICTs in the courtroom generally fall in two major categories: security problems and potential impacts on court proceedings. ${ }^{449}$ Security concerns stem largely from ICTs' camera functions. Many ICTs are capable of taking both still pictures and videos, and there have been instances

4453 Am. Bar Ass'n, 2013 Legal Technology Survey Report, Litigation And Courtroom Technology iii, 19-23 (Joshua Poje ed., 2013) [hereinafter Am. BAR Ass'N, TEChNOLOGY III]. These results are based on a survey of 822 ABA lawyer members in private practice, with a plus or minus 3.4 percent margin of error. $I d$. at iii.

${ }^{446} I d$. at 20, 22. Thirty and one-tenth percent of lawyers who practice in a courtroom report accessing the Internet in court, while 29.1 percent check for new email, 28.2 percent send email, and 26.5 percent conduct online research. $I d$. at 20 . Seventy-one and nine-tenths percent percent report using a smartphone for checking email, while 67.2 percent use one to send email, 53.5 percent use the phone for calendaring, and 46.7 percent use it to access the Internet. Id. at 22. Similarly, 27.4 percent check for new email on a tablet, 26.9 percent use a tablet to send email, 23.7 percent access the Internet on a tablet, and 21.1 percent use a tablet for calendaring. Id. at 24.

447 Id. at $\mathrm{x}$-xi.

448 See Press Release, State of Ill. Circuit Court of Cook Cnty., Electronic Communications/Internet Devices Ban Goes into Effect April 15 at 26th and California (Apr. 11, 2013), available at http://www.cookcountycourt.org/MEDIA/ViewPressRelease/tabid/338/ArticleId /2199/Electronic-communications-Internet-devices-ban-goes-into-effect-April-15-at-26th-and -California.aspx.

449 See Nora Sydow, “Can You Hear Me Now?” Issues and Policy Considerations for Cell Phones and Other Electronic Devices in the Courts, CT. MANAGER, Summer 2010, at 45, 45 (2010). 
of witness and juror intimidation when someone in a courtroom has taken a picture of jurors or witnesses, including some who are undercover agents. ${ }^{450}$ In addition, guns, Tasers, and stun guns can be modified to masquerade as cell phones; these weapons-come-cell-phones present an obvious security risk in court. $^{451}$ The second major concern with ICTs in the courtroom regards the extent to which ICT use "could adversely impact court proceedings-and ultimately, the fair and effective administration of justice." of this has to do with jurors. There is reason to worry about jurors' use of ICTs to discuss ongoing jury trials, whether by posting on social media or otherwise, and about the possibility that jurors will use ICTs to conduct their own trialrelated research. ${ }^{453}$ Another substantial part has to do with journalists. Journalists' use of ICTs to provide real-time reports of trial proceedings through Twitter or blogging or other forms of real-time communication may have a negative impact on justice in the courtroom. ${ }^{454}$ Finally, there is some concern that audible disruptions from cell phone ringers (even when set to "vibrate") and typing on keyboards may undermine the solemnity of court proceedings. ${ }^{455}$ In light of all these concerns, a policy prohibiting ICTs from being brought into the courthouse is understandable.

Such a policy is also likely to be short-lived. In all likelihood, the pendulum will swing definitively back to the side of permitting ICT use in the courtroom in the coming years-both in recognition of the importance of ICTs in our daily lives and business practices, ${ }^{456}$ and because prohibiting ICT use is

${ }^{450}$ Id. at 46. For instance, in February 2010, Judge Nancy Russo of Ohio's Cuyahoga County Common Pleas Court declared a mistrial after jurors noticed that two spectators in the courtroom were videotaping the jury and the prosecutors with their cell phones. Christopher J. Davey et al., Conference of Court Pub. Info. Officers, New Media AND the Courts: The CurRent Status AND A LoOK AT THE Future 43 (2010), available at http://ccpio.org/wp-content/uploads/2012/06/2010-ccpio-report.pdf. Judge Russo cited the spectators for "intimidating and frightening the jurors." $I d$.

451 Sydow, supra note 449 , at 46.

${ }^{452}$ Id.

453 See id. In one instance of juror misuse of ICTs, a juror in a child kidnapping and sexual assault case in Lancastershire, England was dismissed from the jury after she posted details of the case on her Facebook page and indicated an intent to poll her online friends for advice in deciding the case. DAVEY ET AL., supra note 450, at 24. In another, a Maryland appeals court overturned a first-degree murder conviction because a juror consulted Wikipedia one night after deliberations to look up the definition of "lividity." Id. (quotation marks omitted).

${ }^{454}$ Sydow, supra note 449, at 46; see also DAVEY ET AL., supra note 450, at 38 ("Headlines from across the nation reflect the difficulties microblogging attorneys, jurors, journalists and judges have created for courts. When abused or improperly managed, the technology has the potential to taint witnesses, disseminate inappropriate or potentially threatening photos, produce appellate issues, or provide an inappropriate communication thread for jurors, parties and observers.").

455 Sydow, supra note 449 , at 47.

456 See id. ("[M]obile devices are increasingly essential to our personal and professional lives, and mobile communication technologies are being incorporated into a wide variety of business processes. ... Mobile devices are essential to many attorneys' practice. ... For court patrons, coming to court is often an extremely time-consuming and unpleasant experi- 
costly, time-consuming, and ultimately impractical. ${ }^{457}$ Courts also have an interest in being "transparent and open to the citizens they serve." technology in the courtroom can serve this end, despite the many courtroom management issues it creates. ${ }^{459}$ Permitting ICTs in the courtroom will require a significant investment in developing appropriate policies to manage the competing interests at stake, ${ }^{460}$ and there will certainly be growing painspotentially severe ones. Yet in the end, permitting ICT use in the courtroom is inevitable.

\section{A Multimedia Extravaganza}

Laptops have uses in the courtroom beyond accessing the Internet and checking email. According to the ABA courtroom technology survey, 23.5 percent of attorneys who practice in a courtroom currently deliver presentations using their laptops. ${ }^{461}$ In addition, close to half use a projection screen, more than a third use a digital projector, more than a quarter use a DVD player, and over 12 percent use a television. ${ }^{462}$ A significant percentage of attorneys present evidence using their laptops, evidence cameras, and digital cameras, among other digital technologies. ${ }^{463} \mathrm{~A}$ day in court is becoming a multimedia extravaganza.

This trend is likely to accelerate when the Digital Generation comprise the majority of practicing attorneys, for at least two distinct reasons. The first is that Digital Generation lawyers will want to incorporate ICTs into their courtroom presentations. The Digital Generation love technology; two of the hallmarks of their generation are their enthusiasm for digital media and their ability to use digital technology to create content. ${ }^{464}$ From the time they were in grade school, they have been incorporating various media into their projects and presentations. ${ }^{465}$ If the Digital Generation have grown comfortable presenting

ence. Allowing court patrons the use of mobile devices inside the court complex would allow them to conduct other business while they wait.").

457 See id. (noting the likely delays that would be caused by a policy that prohibits bringing ICTs into the court facilities). As Sydow writes, "[b]anning [ICTs] from the courts is growing increasingly difficult and impractical." Id.

458 DAVEY ET AL., supra note 450, at 44.

459 See id.

460 See id. at 88-89 (setting forth recommendations for next steps in studying the potential benefits and risks of new technology in the courtroom).

461 AM. BAR Ass'N, TeChNOLOGY III, supra note 445, at 20.

462 Id. at 38 (finding that 43.3 percent use a projection screen, 35.8 percent use a digital projector, 27.9 percent use a DVD player, and 12.5 percent use a television).

${ }^{463} I d$. at 39 (finding that 38.5 percent present evidence using a laptop, 14.8 percent use an evidence camera, 7 percent use a digital still camera, and 5 percent use a digital video camera).

464 Rosen, REwIRED, supra note 110, at 26.

465 See LenharT ET AL., supra note 394, at 11 (69 percent of teens reported creating audio, video, PowerPoint, or multimedia presentations for school within the prior year); see also Kristen Purcell et al., Pew Research Ctr.'s Internet \& Am. Life Project, The Impact 
their information with a multimedia backdrop, it seems likely that they will turn to this method of presentation in the courtroom as well.

The second is that Digital Generation lawyers will need to turn to multimedia presentations in the courtroom in order to capture the audience's attention-regardless of whether that audience is a Digital Generation judge or a Digital Generation jury. Researchers have noted that the Digital Generation seem to learn differently than their predecessor generations; they tend to have shorter attention spans for traditional forms of learning, particularly one-way lectures. ${ }^{466}$ They are used to getting information quickly, and prefer that the information come in the form of graphics, rather than text. ${ }^{467}$ Even conventional television can seem boring to the Digital Generation - a conservative estimate of one-third of them use other media (especially the Internet) while they are "watching" television. ${ }^{468}$ The generation's lifelong immersion in fast-paced media, with rapid scene changes and dazzling colors, shapes, and forms, has been credited with this shift. ${ }^{469}$ As Dr. Dimitri Christakis, a pediatrician at the University of Washington School of Medicine, describes it, "[i]f a child's brain gets habituated to that pace and to the extreme alertness needed to keep responding and winning [as when playing video games], the child ultimately may find the realities of the world underwhelming, understimulating." 470

To ensure that a Digital Generation judge or a jury is paying attention to her case, a Digital Generation attorney essentially will be forced to incorporate a variety of media into her presentation. ${ }^{471}$ This raises questions with significant implications: What impact will this reliance on multimedia presentations have on legal outcomes? If the judge's or the jury's ability to pay attention to

of Digital Tools on Student Writing and How Writing Is Taught in Schools 11 (2013), available at http://www.pewinternet.org/files/old-media/Files/Reports/2013 /PIP_NWP\%20Writing\%20and\%20Tech.pdf [hereinafter PURCELl ET AL., How WRITING Is TAUGHT] (third installment of Pew report on the impact of technology on education). Seventy-seven percent of teachers reported assigning a multimedia project at some point during the academic year, including 84 percent of the English teachers and 82 percent of the history/social science teachers surveyed. $I d$. at $14,16$.

466 See sources cited supra note 419.

467 Prensky, supra note 166, at 3.

468 See Small \& Vorgan, supra note 81, at 25 (estimating one-third of Digital Generation children are multitasking while watching TV). The Kaiser Family Foundation report estimates as many as 68 percent of the Digital Generation are multitasking while watching television. See supra note 178.

469 See, e.g., RoSEN, REWIRED, supra note 110, at 85 (noting that children "are used to a fast, shallow pace of information presentation and get bored when trying to absorb information at the rates that were normal for their parents"); SMALL \& VORGAN, supra note 81, at 26 (stating that neural circuitry and some parts of the brain that normally adapt to more traditional learning styles are becoming less developed, such that classroom learning and lecture/notetaking seems boring).

470 Rosen, IDISORDER, supra note 111, at 113 (quoting Dr. Dimitri Christakis).

471 As Rosen writes, "the key is that we can no longer assume that students can be forced to unitask without a loss of attention." RosEN, REWIRED, supra note 110, at 86 . The same is very likely true when those students grow up and become factfinders in the courtroom. 
information depends upon its delivery in a technologically enhanced, engrossing fashion, might an attorney's failure to incorporate digital media in making his case result in a miscarriage of justice?

\section{Briefer Briefs?}

The Digital Generation write frequently. ${ }^{472}$ Most teens write something for school on almost a daily basis. ${ }^{473}$ In addition, the Digital Generation engage in many forms of informal "writing," such as texting, tweeting, blogging, and microblogging on social network sites, using ICTs. ${ }^{474}$ Though frequent, the Digital Generation's writing tends to be short. In a recent survey, 82 percent of teens reported that their typical school writing assignments are between one paragraph and one page in length. ${ }^{475}$ Although there seems to be agreement among business leaders, ${ }^{476}$ educators, ${ }^{477}$ parents, ${ }^{478}$ and young people ${ }^{479}$ that writing well is very important for one's future success, there is some question whether writing at length is similarly crucial. Even teachers who continue to believe that formal writing assignments are critically important have raised doubts about the value of longer textual expression, such as term papers, in today's digital environment. ${ }^{480}$

With this backdrop in mind, it seems relevant to question what impact the trend toward shorter writings may have on legal writing in the future. Will thirty-page court filings remain the norm, ${ }^{481}$ or will briefs become briefer? Though it is tempting to extrapolate from research reporting a trend in favor of shorter writing in school that legal writing will soon follow suit, this prediction presumes too much. The fact that email is becoming the most common form of

472 See LENHART ET AL., supra note 394, at i (“Teenagers' lives are filled with writing. All teens write for school, and 93 percent of teens say they write for their own pleasure. ... Parents believe that their children write more as teens than they did at that age.").

${ }^{473} I d$. at iii. Of teens who were surveyed, 50 percent reported that their school work requires daily writing, while 35 percent say they write several times a week, and the remaining 15 percent write less often. $I d$. at iv.

474 Purcell ET AL., How Writing Is TAUght, supra note 465, at 18; see also Lenhart ET AL., supra note 394, at ii (finding that 85 percent of teens ages twelve to seventeen at least occasionally engage in some form of personal electronic communication).

475 LENHART ET AL., supra note 394, at iv.

476 See Nat'l COMm'n on Writing, Writing: A Ticket to Work ... Or a Ticket OUt: A SURVEY OF BUSINESS LEADERS 5-10, 15-16 (2004), available at http://www.collegeboard.com/prod_downloads/writingcom/writing-ticket-to-work.pdf (describing a 2004 survey of sixty-four members of the Business Roundtable that found that writing is an important skill for salaried employees and a significant consideration in both hiring and promotion).

477 See, e.g., Purcell et Al., How Writing Is TAUGHT, supra note 465, at 19-20.

478 See, e.g., LENHART ET AL., supra note 394, at 37.

479 See, e.g., id. at 42.

480 Purcell ET AL., How Writing Is TAUGHT, supra note 465, at 21, 23.

481 E.g., FED. R. APP. P. 28.1(e)(1) (requiring appellant's principal brief not to exceed thirty pages). 
business writing ${ }^{482}$ does not imply that there is not a time and place for other, lengthier forms of writing, or that shorter writing forms are an acceptable substitute for longer forms in all situations. Moreover, in many cases it is harder to be precise in short writings; condensing a complex legal argument into a shorter span of pages may actually involve greater, not less, effort. This is one instance in which the Digital Generation will likely adapt to norms of the legal profession, rather than the other way around.

\section{CONCLUSION}

Each of the foregoing predictions of the influence of ICTs and the Digital Generation on the legal profession is exactly that - a prediction. In many ways, predicting the ways that technology will shape the legal profession in the coming decades is like forecasting what features our flying cars will have twenty years from now. It is inherently speculative. Predictions about technology tend also to be a bit overly optimistic or overly fearful, depending upon whether the predictor is the first on his block to adopt the newest gadget or the last to part ways with his typewriter.

While we cannot be certain what the future will hold for the legal profession, we can be sure that ICTs (in some form or another) will be a part of it. Even if we could rid the world of ICTs for attention's sake, most of us would opt not to-no more than we would abandon our cars or microwaves or ballpoint pens or any other invention once thought to be indicative of society's general decay ${ }^{483}$ that is now a well-accepted part of everyday life. It is unrealistic to think that we can return to a pre-ICT existence. Our lives are simply different now. Plus, the Digital Generation have never known any other way of life. So instead of worrying whether ICTs are "good" or "bad" for the practice of law as if we could get rid of them, we should accept that they are inevitable. To this end, legal professionals - both current and future - should pursue the suggestions that accept ICTs as a fact of life and that aim to help them adapt to technology, rather than encourage them to run from it.

482 See NAT'L COMM'N ON WRITING, supra note 476, at 11.

483 See Allan Collins \& Richard Halverson, Rethinking Education in the Age of Technology: The Digital Revolution and Schooling in America 31 (2009) (observing that, in 1950, ballpoint pens were decried as "the ruin of education in our country") (quotation marks omitted). 